EMERSON GALVES MORETTO

\title{
ELABORAÇÃO DE PRÓTESES AURICULARES INDIVIDUALIZADAS POR MEIO DE MANUFATURA APOIADA POR COMPUTADOR
}

Dissertação apresentada à Escola Politécnica da Universidade de São Paulo para obtenção do Título de Mestre em Ciências. 


\section{ELABORAÇÃO DE PRÓTESES AURICULARES INDIVIDUALIZADAS POR MEIO DE MANUFATURA APOIADA POR COMPUTADOR}

Dissertação apresentada à Escola Politécnica da Universidade de São Paulo para obtenção do Título de Mestre em Ciências.

Área de Concentração:

Sistemas Eletrônicos

Orientador:

Marcelo Knörich Zuffo 
FICHA CATALOGRÁFICA

Moretto, Emerson Galves

Elaboração de Próteses Auriculares Individualizadas por Meio de Manufatura Apoiada por Computador / E. Galves Moretto. São Paulo, 2016.

$110 \mathrm{p}$.

Dissertação (Mestrado) - Escola Politécnica da Universidade de São Paulo. Departamento de Sistemas Eletrônicos (PSI).

1. Processamento digital de imagens. 2. Computação gráfica. 3. Manufatura apoiada por computador. 4. Próteses e implantes. I. Universidade de São Paulo. Escola Politécnica. Departamento de Sistemas Eletrônicos (PSI). II. t. 


\section{AGRADECIMENTOS}

Agradeço primeiramente à minha noiva, uma pessoa fantástica que admiro todo dia. Seu amor à medicina, seu zelo e sua dedicação na forma que cuida de seus pacientes foram grandes inspirações para dedicar todo meu esforço neste trabalho.

Agradeço imensamente à Profa. Dra. Neide Pena Coto pelo apoio incondicional desde o primeiro dia deste trabalho. É a grande idealizadora desta pesquisa e sua conclusão só foi possível a ela.

Agradeço ao Prof. Dr. Reinaldo Dias por aceitar, incentivar e dar atenção ao projeto. Seu reconhecimento nacional e internacional na área de próteses bucomaxilofaciais é o reflexo de suas contribuições para a sociedade.

Agradeço meu orientador Prof. Dr. Marcelo K. Zuffo pelo apoio, pela confiança, pela amizade e pela total liberdade cedida para a investigação científica. A ciência deve ser sem paredes, sem limitações, sem viés. Obrigado professor.

Agradeço ao Laboratório de Fenômenos de Superfície (LFS) da Engenharia Mecânica, ao Laboratório de Sistemas Integráveis (LSI) da Engenharia Elétrica, ao Departamento de Engenharia de Produção (PRO), todos da Escola Politécnica, ao Departamento de Cirurgia, Prótese e Traumatologia Maxilo Faciais da Faculdade de Odontologia e ao Departamento de Química Fundamental Instituto de Química, todos da Universidade de São Paulo pelo apoio técnico, didático e grande incentivo ao projeto. 


\section{RESUMO}

Próteses auriculares tem o objetivo de proporcionar uma maior confiança a pacientes com perdas parciais ou totais da orelha. A aparência realista de uma prótese é fator fundamental para a recuperação psicossocial dos pacientes, pois auxilia na dissimulação da perda. O procedimento convencional de elaboração de próteses auriculares envolve o trabalho de um especialista que utiliza processos manuais para recriar a forma singular de uma orelha. Este é um processo lento, complexo e naturalmente pode ocasionar imperfeições. Este estudo apresenta um procedimento que, a partir de exames de imagem, utiliza técnicas computacionais de reconstrução, espelhamento e inversão de modelos tridimensionais para manufatura aditiva (impressão 3D) de moldes. Os resultados mostram que a prótese elaborada utilizando o processo exibe alto grau de realismo, apresentando 97,8\% de similaridade dimensional comparada com a orelha sã do paciente.

Palavras-chaves: Próteses auriculares. Reabilitação facial. Impressão 3D. Manufatura aditiva. Processamento de imagens. Computação gráfica. CAM. 


\begin{abstract}
Auricular prostheses are intended to provide confidence to patients with partial or total loss of the ear. The realistic appearance of a prosthesis is a key factor for the psychosocial recovery helping in dissimulation of loss. The standard procedure of auricular prosthesis design involves the work of an expert using manual processes to recreate the complex shape of the ear. This slow and complex process can easily lead to imperfections. This study presents a procedure that starting from an image exam uses computational techniques of reconstruction, mirroring and inversion of three-dimensional models for additive manufacturing (3D printing) of molds. The results show that the designed prosthesis using the process has a high level of realism, with $97.8 \%$ of similarity compared to the healthy ear of the patient.
\end{abstract}

Keywords: Auricular prosthesis. Facial rehabilitation. 3D printing. Additive manufacturing. Image processing. Computer graphics. CAM. 


\section{LISTA DE ILUSTRAÇÕES}

1 Processo convencional de confecção de próteses. . . . . . . . . . . 17

2 Etapas do método proposto por Subburaj et al. (2007). . . . . . 24

3 Modelo fabricado em 3D e prótese obtida por Karatas et al. (2011). 26

4 Estudo apresentado por Watson e Hatamleh (2014) onde utiliza-se de um espectrômetro. . . . . . . . . . . . . . . . 26

5 Modelo de uma camada tomográfica em relação a sua representação tridimensional. .................... . . . 32

6 Processo Reconstrução Tridimensional. . . . . . . . . . . . . . . . 34

7 Processo de geração de material de suporte. . . . . . . . . . . 35

8 Processo de Fabricação Sinterização Seletiva a Laser. . . . . . . . 38

9 Processo de Fabricação por Filamento Fundido. . . . . . . . . . . 40

10 Subtração da região contralateral. . . . . . . . . . . . . . . . . 43

11 Etapas do processo proposto para fabricação de moldes individualizados. . . . . . . . . . . . . . . . . . . . . 44 44

12 Aplicação da filtragem por Difusão Anisotrópica. . . . . . . . . . 48

13 Filtragem por Crescimento de Regiões Probabilístico. . . . . . . . 52

14 Contorno Ativo "Snake". . . . . . . . . . . . . . . . . . . 53

15 Representação da energia externa. . . . . . . . . . . . . . . . 56

16 Vetor gradiente em destaque. . . . . . . . . . . . . . . . 59

17 Fluxo do Vetor Gradiente em etapas. . . . . . . . . . . . . . . . . 61 
18 Ampliação dos vetores gradiente sobre uma região de borda. . . . 61

19 Convergência do GVF. . . . . . . . . . . . . . . . . . . . . . 63

20 Convergência em imagem real. . . . . . . . . . . . . . . . . . 64

21 Segmentação do conjunto de imagens DICOM por contorno ativo "Snake" com GVF ................... 65

22 As 15 possibilidades de intersecção da célula, desconsiderando rotação reflexões simétricas. . . . . . . . . . . . . . . 66

23 Modelo tridimensional com destaque para a superfície formada por uma malha de triângulos . . . . . . . . . . . . . . . 67

24 Modelo tridimensional com destaque para os relevos na superfície causados pela distância entre camadas . . . . . . . . . . . . 68

25 Comportamento do Laplaciano discreto uniforme em um polígono $P 69$

26 Representação do comportamento do operador Laplaciano em malha tridimensional . . . . . . . . . . . . . . . . . . . 69

27 Aplicação da suavização por Laplace dependente de escala. . . . . 71

28 Desníveis inerentes ao processo de Manufatura Aditiva por camadas 74

29 Disposição do ambiente para suavização superficial, composto por um dessecador hermético disposto sobre uma mesa aquecedora . . 77

30 Moldes fabricados para os casos clínicos. . . . . . . . . . . . . 80

31 Molde para prótese facil do caso clínico RL . . . . . . . . . . . . . 81

32 Interface do usuário para elaboração do molde . . . . . . . . . . . 82

33 Interface do usuário para parametrização e segmentação da região de interesse ....................... 83 
34 Aplicação do filtro de Crescimento de Regiões Probabilístico em três imagens de tomografia . . . . . . . . . . . . . . . . 84

35 Suavização superficial do modelo 3D . . . . . . . . . . . . . . 86

36 Destaque para as regiões pontiagudas resultantes do método laplaciano discreto . . . . . . . . . . . . . . . . . 86

37 Sobreposição dos modelos suavizados pelos dois métodos (em azul) com o modelo original (em vermelho). . . . . . . . . . 87

38 Destaque para os desníveis causados pelo processo de fabricação $\mathrm{FFF} \ldots \ldots \ldots \ldots \ldots \ldots$

39 Foto ampliação durante o processo de suavização superficial, polímero apresenta aspecto cristalino pela absorção de solvente. . . .

40 Ampliação de 32 vezes sobre detalhe da superfície obtida. . . . . . 89

41 Vista lateral da projeção tridimensional do perfil de rugosidade antes do tratamento de superfície . . . . . . . . . . . . . . . 90

42 Vista lateral da projeção tridimensional do perfil de rugosidade obtido .......................... . . 90

43 Vista superior da projeção tridimensional do perfil de rugosidade

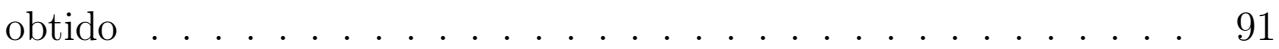

44 Parâmetros ISO 25178-2 obtidos sobre os moldes. . . . . . . . . . 92

45 Silicone pigmentado injetado no molde . . . . . . . . . . . . . . 93

46 Prótese obtida para o caso clínico ARF . . . . . . . . . . . . . . . . 94

47 Prótese obtida para o caso clínico ARF . . . . . . . . . . . . . . . 94

48 Prótese obtida para o caso clínico KSS . . . . . . . . . . . . . 95 
49 Prótese obtida para o caso clínico RL . . . . . . . . . . . . . . 96

50 Comparação métrica entre a prótese obtida e a reconstrução volumétrica, primeiro ponto. . . . . . . . . . . . . . 97

51 Comparação métrica entre a prótese obtida e a reconstrução volumétrica, segundo ponto. . . . . . . . . . . . . . . . . . . . . 98 


\section{LISTA DE TABELAS}

1 Tabela de Unidades Hounsfield (HU) para algumas substâncias e tecidos do corpo. . . . . . . . . . . . . . . . . 31

2 Resultado da classificação por Crescimento de Regiões: pixels são classificados conforme valores de seus vizinhos. . . . . . . . . . . . 49

3 Tabela de conhecimento para classificador bayesiano. . . . . . . . 51

4 Tabela comparativa entre estratégias de Manufatura Aditiva. . . . 72

5 Classificação de solventes conforme sua toxicologia. . . . . . . . . 76

6 Correlação de características entre o presente trabalho e seus correlatos. . . . . . . . . . . . . . . . . 81

$7 \quad$ Valores da Distância Hausdorff entre as técnicas de suavização . 85

$8 \quad$ Valores de rugosidade de amostras de pele. . . . . . . . . . . . . . 91

9 Medidas e diferenças dos padrões morfológicos auriculares entre a orelha saudável do paciente e a prótese obtida . . . . . . . . . . 95 


\section{LISTA DE ABREVIATURAS E SIGLAS}

$\begin{array}{ll}\text { USP } & \text { Universidade de São Paulo } \\ \text { CAD } & \text { Computer-Aided Design } \\ \text { CAM } & \text { Computer-Aided Manufacturing } \\ \text { DICOM } & \text { Digital Imaging and Communications in Medicine } \\ \text { AM } & \text { Additive Manufacturing } \\ \text { FDM } & \text { Fused Deposition Modeling } \\ \text { SLS } & \text { Selective Laser Sintering } \\ \text { SLA } & \text { Stereolithography } \\ \text { FFF } & \text { Fused Filament Fabrication } \\ \text { LOM } & \text { Laminated Object Manufacturing } \\ \text { FOB } & \text { Free On Board } \\ \text { FDA } & \text { Food and Drug Administration } \\ & \\ \text { Foridonitrila Butadieno Estireno }\end{array}$




\section{SUMÁRIO}

1 Introdução 14

1.1 Relevância . . . . . . . . . . . . . . . . . . . 16

1.1.1 Análise do Comitê de Ética em Pesquisa . . . . . . . . . . 19

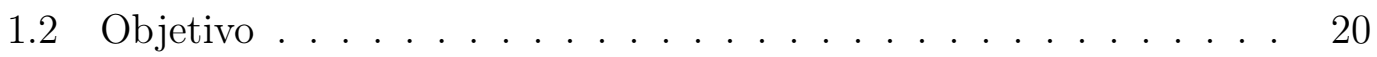

1.3 Organização . . . . . . . . . . . . . . . . . 20

2 Revisão de Literatura $\quad 22$

2.1 Trabalhos Correlatos . . . . . . . . . . . . . . . . 22

2.2 Segmentação de Imagens . . . . . . . . . . . . . . . . . . . . . . 27

3 Conceitos Fundamentais 30

3.1 Imagens Médicas de Tomografia Computadorizada . . . . . . . . . 30

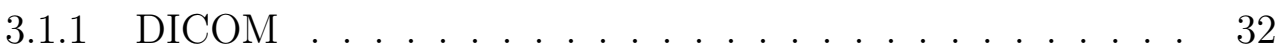

3.2 Reconstrução Tridimensional . . . . . . . . . . . . . . . . . . 33

3.3 Manufatura Aditiva . . . . . . . . . . . . . . . . . . . . . 34

3.3.1 Estereolitografia . . . . . . . . . . . . . 36

3.3.2 Manufatura de Objetos Laminados . . . . . . . . . . 36

3.3 .3 Sinterização Seletiva a Laser . . . . . . . . . . . . . . . . 37

3.3.4 Jato de Tinta $3 \mathrm{D} \ldots \ldots \ldots$. . . . . . . . . . . . . . . 38

3.3.5 Fabricação por Filamento Fundido (FFF) . . . . . . . . . . 39 
4.1 Processamento de Imagens . . . . . . . . . . . . . . . . . . . . 45

4.1.1 Filtragem .................... 45

4.1.1.1 Difusão Anisotrópica . . . . . . . . . . . . 45

4.1.2 Crescimento de Regiões Probabilístico . . . . . . . . . . 48

4.2 Segmentação de Imagens . . . . . . . . . . . . . . . . . . . . . 52

4.2.1 Método de Contornos Ativos "Snake" . . . . . . . . . . . 52

4.2.1.1 Energia Interna . . . . . . . . . . . . . 54

4.2.1.2 Energia Externa . . . . . . . . . . 55

4.2.1.3 Energia Total . . . . . . . . . . . 56

4.2.1.4 Problemas do Contorno Ativo . . . . . . . . . . 57

4.2.2 Fluxo do Vetor Gradiente . . . . . . . . . . . . . . 58

4.2 .3 Implementação . . . . . . . . . . . . . . . . . . . 61

4.2.3.1 Convergência . . . . . . . . . . . 63

4.3 Reconstrucao Tridimensional . . . . . . . . . . . . . . 65

4.3.1 Reconstrução Tridimensional de Superfícies . . . . . . . . . 65

4.3.2 Suavização de Malhas Tridimensionais por Laplace . . . . 66

4.4 Fabricação do Molde . . . . . . . . . . . . . . . . . . . . . . 72

4.4 Material ...................... 72

4.4.2 Processo de Tratamento de Superfície . . . . . . . . . . . 74 
5.1 Software . . . . . . . . . . . . . . . . . 81

5.2 Publicação . . . . . . . . . . . . . . . . . . . 83

5.3 Filtragem por Crescimento de Regiões Probabilístico . . . . . . . 83

5.4 Suavização de Malhas Tridimensionais . . . . . . . . . . . . 84

5.5 Análise Física . . . . . . . . . . . . . . . . . . . . . . . . 87

5.5.1 Análise de Perfil Superficial . . . . . . . . . . . . . 88

5.6 Elaboração da Prótese Auricular . . . . . . . . . . . . . . . . . . . 92

5.7 Questionário . . . . . . . . . . . . . . . 97

6 Conclusões 101

$\begin{array}{ll}\text { Referências } & 103\end{array}$

Apêndice A - Parecer do Comitê de Ética em Pesquisa $\quad 107$

$\begin{array}{ll}\text { Apêndice B - Questionário para especialistas } & 108\end{array}$ 


\section{INTRODUÇÃO}

O uso de técnicas de Processamento de Imagens e Computação Gráfica em imagens médicas tem sido um tema crescente de pesquisas há alguns anos. Mais recentemente, essas técnicas vem oferecendo melhorias significativas à clínica médica, como no auxílio ao diagnóstico, na segmentação automática de regiões de interesse, na visualização tridimensional de um exame, dentre outros.

O sucesso da aplicação de um algoritmo de Processamento de Imagem é fundamentalmente associado a qualidade da imagem na qual é aplicado (BANKMAN, 2008). Imagens de exames médicos provenientes de tomógrafos computadorizados atuais possuem representação espacial com resolução submilimétrica, o que possibilita seu uso para aplicações onde a precisão é necessária, como para a representação morfológica de estruturas e segmentação de regiões de interesse.

Em paralelo as técnicas e algoritmos computacionais, nos últimos anos foi possível observar uma evolução tecnológica e maior acessibilidade à equipamentos de Manufatura Aditiva, ou também comumente conhecida como Impressão 3D. Essa tecnologia que surgiu em 1981 no Instituto Municipal de Pesquisa de Nagoya, possibilita a fabricação de objetos tridimensionais em diversos tipos de materiais, como polímeros e até mais recentemente culturas de células (MURPHY; ATALA, 2014).

A associação de técnicas computacionais de Processamento de Imagens e Computação Gráfica juntamente com a capacidade de materialização da Ma- 
nufatura Aditiva nos permite explorar novas possibilidades na área da Saúde. O reflexo das possibilidades desse arcabouço é observado em pesquisas recentes que apresentam métodos inéditos de auxílio à clínica médica, como sua aplicação em planejamento cirúrgico, em que a região de interesse é fabricada em escala real permitindo uma análise mais efetiva pela equipe cirúrgica antes do procedimento (RENGIER et al., 2010). Outra possibilidade é a confecção de próteses e implantes individualizados impressos em 3D. Dada a característica física singular de cada pessoa, uma prótese individualizada e realista pode trazer uma maior confiança para o paciente, auxiliando sua recuperação psicossocial, pois colabora para a dissimulação da perda (TANNER; MOBLEY, 2006; CARVALHO et al., 2013).

A prótese bucomaxilofacial é uma especialidade da Odontologia que se dedica à reabilitação de perdas faciais, intra e extra orais. As próteses confeccionadas nesta área da Odontologia tem o objetivo da proteção, prevenção, reabilitação funcional e estética de regiões ausentes ou defeituosas, como sequelas cirúrgicas, de traumas ou em razão de malformações congênitas. Particularmente nesta modalidade de próteses, a qualidade estética, sob os aspectos geométricos e de detalhamento superficial, é fator importante para a reabilitação, pois propicia a dissimulação da perda e por consequência uma maior confiança ao paciente, aumento da autoestima e devolução menos traumática ao convívio da vida em sociedade (WATSON; HATAMLEH, 2014; CARVALHO et al., 2013).

A reabilitação protética extra oral é responsável por reparar áreas da face como a região ocular, oculopalpebral (perda do olho e anexos, pálpebras e sobrancelhas), nasal e auricular. As próteses auriculares são as que exigem maiores cuidados por parte do profissional pois a orelha é um órgão par e sua geometria detalhada torna sua confecção mais complexa. A aparência natural é fundamental para reabilitação psicossocial do paciente e sua reinserção na sociedade. Como 
toda a reabilitação protética facial, as próteses auriculares são confeccionadas envolvendo processos manuais, modelos e fotografias. Esses processos aliados a singularidade geométrica principalmente do pavilhão auricular tornam a elaboração de uma prótese um desafio para o protesiólogo bucomaxilofacial.

Nesse contexto, a associação da recente evolução tecnológica em Manufatura Aditiva com técnicas avançadas de Processamento de Imagens e Computação Gráfica se apresenta como um meio promissor para a exploração de novas práticas clínicas, objetivando menor custo (RAVURI et al., 2014), menor tempo de confecção e menor necessidade de consultas, minimizando o tempo do paciente no ambulatório (LIACOURAS et al., 2011; CARVALHO et al., 2013; WATSON; HATAMLEH, 2014) e uma melhor qualidade no tratamento ao paciente (WATSON; HATAMLEH, 2014). Esta associação aplicada ao desenvolvimento de próteses maxilofaciais pode trazer benefícios à reabilitação protética, reduzindo o tempo de elaboração e principalmente para o paciente, em que se busca uma prótese mais realista possível.

\subsection{Relevância}

O procedimento convencional de confecção de próteses bucomaxilofaciais, de acordo com Carvalho et al. (2013), no Ambulatório de Prótese Bucomaxilofacial da Faculdade de Odontologia da Universidade de São Paulo, se inicia na moldagem da região sã e da região comprometida, conforme ilustrado na figura 1 item a, utilizando alginato (hidrocolóide irreversível), gaze e gesso comum. Com o auxilio de gesso tipo pedra obtém-se os modelos de interesse. Sobre o modelo da região comprometida esculpe-se manualmente em cera ou modelina o formato da prótese espelhada a partir de observação visual, prova-se no paciente e procedese os ajustes necessários. Com a ceroplastia ou modelagem da prótese pronta é realizada sua muflagem, conforme apresentado no item b da figura 1 . Com o 
uso de silicone médico Factor II (Factor II Inc., Arizona, EUA), por exemplo, em ambulatório e na presença do paciente é realizado a pigmentação da prótese com auxilio de pigmentos minerais buscando a coloração natural da região da pele contralateral. Na sequência, o silicone é levado a mufla, prensado e aguardado o tempo de vulcanização do silicone (procedimento que leva aproximadamente 5 horas). Após da desmuflagem, há um processo de caracterização da prótese para que as cores básicas da pele podem ser realçadas com pintura externa para se assemelhar com o lado contralateral e a pele circunvizinha. O tempo total clínico e de laboratório necessário para criar uma prótese leva entre 14 a 24 horas de trabalho, de acordo com a Academia Americana de Prótese Bucomaxilofacial (WIENS et al., 1994).

Figura 1: Processo convencional de confecção de próteses.

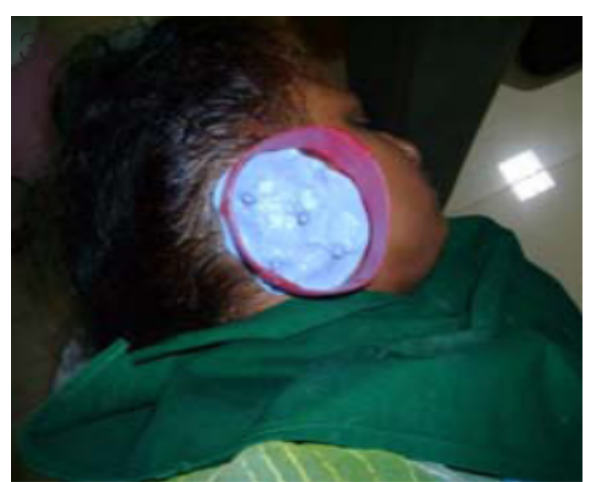

a)

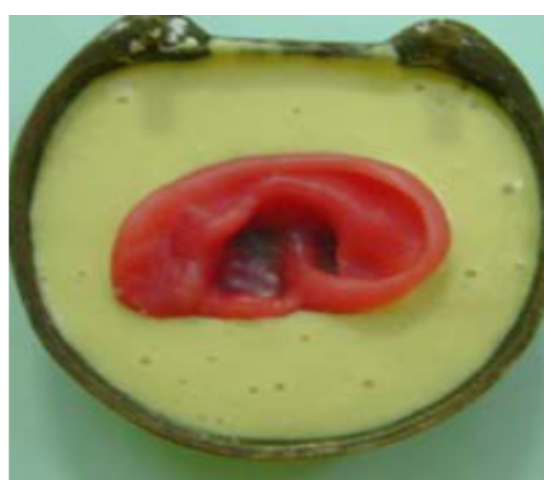

b)

a) Moldagem da orelha sã.

b) Muflagem sobre modelo obtido.

Fonte: Subburaj et al. (2007).

Consequentemente ao processo de confecção da prótese é preciso realizar adaptações finais com a presença do paciente e essas consultas são repetidas até que se obtenha um resultado adequado sob o ponto de vista do especialista e do paciente.

De acordo com o estudo de Tanner e Mobley (2006), do Departamento de Prótese Bucomaxilofacial da Universidade de Utah, o custo total de uma prótese 
auricular é de aproximadamente $\mathrm{U} \$ 2.000,00$, envolvendo o custo com materiais, consultas presenciais e o tempo necessário dos especialistas para a elaboração. Uma prótese convencional possui uma duração aproximada de 2 a 3 anos, podendo variar de acordo com os cuidados do usuário.

Recentemente, técnicas computacionais e de Manufatura Aditiva têm sido exploradas em conjunto para produzir próteses com o objetivo de reduzir algumas desvantagens dos métodos convencionais, como apresentado por Karatas et al. (2011), Watson e Hatamleh (2014) e Ravuri et al. (2014). A combinação de tecnologias de software e hardware com o foco no auxílio a fabricação se dá o nome de Computer-Aided Manufacturing (Manufatura Apoiada por Computador - CAM).

A fabricação por meio de impressão 3D auxiliada por técnicas computacionais oferece o potencial de simplificar o procedimento e diminuir a quantidade de trabalho exigida em laboratório (KARATAS et al., 2011). Além disso, impressoras 3D atuais oferecem resolução em torno de 100 micrômetros, o que permite reproduzir até mesmo pequenos detalhes do objeto a ser materializado.

Dada a singularidade geométrica de cada caso clínico, há a necessidade de se obter previamente a anatomia específica de cada paciente para a elaboração de uma prótese individualizada. A partir de um exame de imagem de Tomografia Computadorizada axial do crânio, o ouvido externo da parte contralateral saudável do paciente pode ser segmentado e espelhado por algoritmos de Processamento de Imagens. A partir das imagens segmentadas é possível realizar a reconstrução tridimensional da região da orelha por meio de técnicas de Computação Gráfica. Dessa maneira, a região inversa, ou seja, um molde, pode ser gerado para a elaboração da prótese e fabricado por meio de impressão 3D.

De acordo com trabalhos realizados nesta área (KARATAS et al., 2011; RAVURI et al., 2014; WATSON; HATAMLEH, 2014; SUBBURAJ et al., 2007), 
as vantagens e possibilidades do uso de CAM na elaboração de próteses são: (1) possibilidade de se obter uma prótese mais realista, pois o modelo utilizado é proveniente do lado contralateral, (2) menor tempo para produção da prótese, (3) eliminação da deformação do tecido durante a moldagem no primeiro processo, pois não seria mais necessário a moldagem através de contato direto no paciente, (4) menor quantidade de consultas presenciais do paciente, pois diminui a necessidade de consultas periódicas para avaliação da prótese, (5) possibilidade de armazenar os arquivos dos moldes de forma digital, permitindo que as reproduções futuras das próteses sejam mais simples e rápidas, principalmente considerando o aspecto da duração aproximada de 3 anos das próteses.

Dessa forma, o emprego da Manufatura Apoiada por Computador à produção de próteses maxilofaciais se apresenta como um meio interdisciplinar com possibilidade de proporcionar vantagens frente aos métodos convencionais e com o foco de oferecer ao paciente uma maior confiança no seu processo de reabilitação.

\subsubsection{Análise do Comitê de Ética em Pesquisa}

Dada a característica investigativa e experimental envolvendo um procedimento clínico de elaboração de próteses, o presente trabalho foi submetido como projeto para análise e aprovação do Comitê de Ética em Pesquisa da Faculdade de Odontologia da Universidade de São Paulo.

Sob o número de parecer 864.391 datado de 10 de Novembro de 2014 (anexo A) foram obtidas as seguintes recomendações, integralmente reproduzidas abaixo:

"Apenas como sugestão, para caracterizar pesquisa, seria interessante adotar alguns indicadores a serem avaliados (ex: características anatômicas peculiares, adaptação, conforto, etc). Sugere-se a obtenção de Carta de Autorização do paciente caso haja possibilidade de 
quebra de sigilo na divulgação do caso."

Seguindo as sugestões apresentadas pelo Comitê foram obtidas Cartas de Autorização dos pacientes e/ou responsáveis envolvidos. O capítulo 5 Resultados deste trabalho faz uma abordagem sobre as características anatômicas peculiares. Os aspectos adaptação e conforto não estão contidos nesse estudo e deverão ser objetos de pesquisa na continuação do mesmo.

Ainda sobre o parecer, a seção de Conclusões ou Pendências e Lista de Inadequações também está reproduzida integralmente abaixo:

"É um trabalho necessário, já que mostrará a reprodução 3D como auxiliar da reconstrução auricular, o que pode ser empregado para outras reconstruções da anatomia humana."

\subsection{Objetivo}

O objetivo deste trabalho é oferecer uma nova técnica de elaboração de próteses auriculares com grande semelhança física se comparada a orelha sã, e em menor tempo se comparado ao método convencional, através de técnicas de Processamento Digital de Imagens, Computação Gráfica e Manufatura Aditiva.

Por consequência, espera-se auxiliar os profissionais envolvidos a obter uma melhor reabilitação psicológica e social de seus pacientes devido ao uso de uma prótese individualizada mais realista.

\subsection{Organização}

O capítulo 2 Revisão de Literatura, apresenta as principais contribuições originais neste tema, com o detalhamento das diferentes técnicas empregadas assim como seus resultados obtidos. 
O capítulo 3 Conceitos Fundamentais faz uma breve introdução a assuntos essenciais para a compreensão das técnicas envolvidas.

O capítulo 4 Materiais e Métodos detalha o método proposto e as suas seções trazem a fundamentação das técnicas utilizadas de Processamento Digital de Imagens, Computação Gráfica, Manufatura Aditiva, material utilizado e o processo químico de suavização de superfície empregado.

O capítulo 5 apresenta os resultados obtidos com análises técnicas sobre os casos clínicos aplicados e um parecer de especialistas da área.

Por fim, o capítulo 6 faz uma análise conclusiva sobre o método proposto apontando suas características, vantagens, desvantagens e aspectos estáveis do procedimento. 


\section{REVISÃO DE LITERATURA}

A busca por métodos que possibilitem a construção de próteses mais realistas e em menor tempo envolve diferentes disciplinas e diversas frentes de pesquisas. A revisão de literatura das contribuições na área contempla trabalhos correlatos utilizando técnicas de Manufatura Aditiva e Manufatura Apoiada por Computador voltados à elaboração de próteses auriculares. Também foi contemplado nessa revisão métodos de Processamento de Imagens para segmentação de tecidos moles a partir de imagens médicas.

\subsection{Trabalhos Correlatos}

O primeiro trabalho observado nesta área foi de Coward, Watson e Wilkinson (1999), que utilizou-se de imagens de Ressonância Magnética para reconstruir um modelo tridimensional do paciente. A partir desse modelo, a região auricular saudável é segmentada manualmente através de uma ferramenta de Computer-Aided Design (Desenho assistido por computador - CAD), espelhada e posicionada virtualmente sobre o lado contralateral, sobrepondo a região malformada. Uma vez posicionada, é realizada a materialização da região sobreposta utilizando Manufatura Aditiva. Sobre o modelo materializado é feito um molde utilizando cera e deste molde é obtida a prótese através da injeção de silicone.

Em seu trabalho, Jiao et al. (2004) utilizou-se de uma técnica similar a Coward, Watson e Wilkinson (1999), diferindo da imagem utilizada, no caso 
Tomografia Computadorizada e da aplicação de uma operação booleana entre o modelo saudável e defeituoso, permitindo que seja materializada apenas a região que precisa ser reconstruída, aproveitando partes restantes do pavilhão auricular malformado. Com o objeto materializado, um procedimento similar também é realizado, extraindo o molde a partir da peça fabricada e deste molde é obtida a prótese de silicone.

Mardini, Ercoli e Graser (2005) e Ciocca e Scotti (2004) utilizaram de scanners 3D para a captura da superfície da orelha saudável, resultando em um modelo tridimensional que depois de impresso é também utilizado para criação de um molde de cera. O estudo apresentado por Ciocca e Scotti (2004) também faz uma abordagem sobre os aspectos de otimização de tempo e viabilidade do procedimento.

Em um segundo trabalho de Ciocca et al. (2007), ainda utilizando scanner 3D, o modelo tridimensional é construído e posicionado virtualmente sobre o lado comprometido. De forma a preservar as dimensões e a perspectiva do modelo tridimensional foram utilizados marcadores fiduciais fixados no rosto do paciente. Esses marcadores servem como referências espaciais e as distâncias precisam ser medidas previamente e utilizadas como parâmetro para o correto dimensionamento e posicionamento do modelo tridimensional. Com o modelo virtual posicionado, um molde é extraído da parte inversa e então é fabricado. O molde é utilizado com preenchimento de silicone e após a cura e desmoldagem é obtida a prótese.

Como apontado nos estudos que utilizam-se de scanners 3D é necessário um trabalho de modelagem tridimensional para correções de perspectiva, dimensões e de regiões de oclusão. A característica geométrica do pavilhão auricular torna o processo de correção mais complexo e por consequência possui a desvantagem de exigir expertise em modelagem 3D com ferramentas de CAD e CAM (CIOCCA 
et al., 2007).

O método proposto por Subburaj et al. (2007) segue essencialmente os mesmos passos apresentados nos métodos anteriores (COWARD; WATSON; WILKINSON, 1999; JIAO et al., 2004; MARDINI; ERCOLI; GRASER, 2005). Entretanto, os ajustes manuais de posicionamento do modelo tridimensional são feitos através de um dispositivo háptico, o qual permite ao usuário uma interação em 3 dimensões. Depois de posicionado, o modelo é impresso e é utilizado para a criação de um molde de cera. O molde de cera por sua vez é utilizado para a moldagem da prótese de silicone. A figura 2 apresenta o resultado obtido por Subburaj et al. (2007).

Figura 2: Etapas do método proposto por Subburaj et al. (2007).

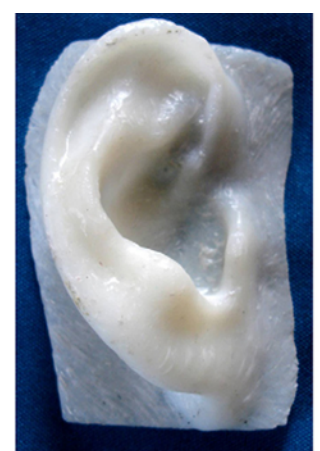

a)

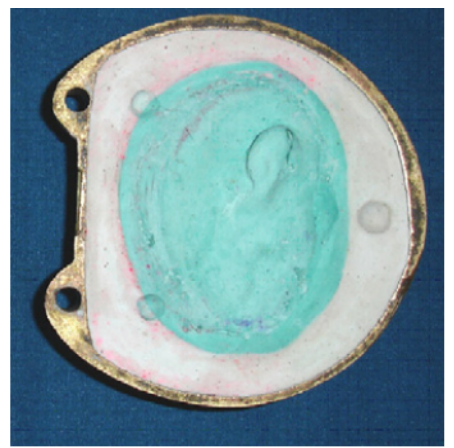

b)

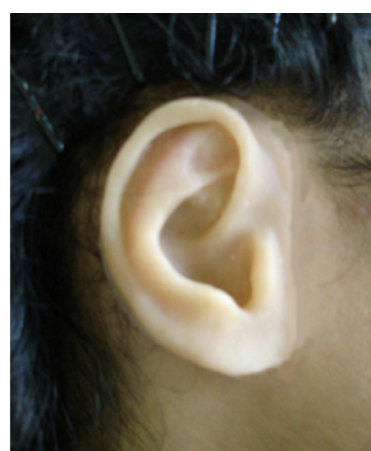

c)

a) Modelo estereolitográfico fabricado.

b) Molde de cera extraído a partir do modelo.

c) Prótese obtida.

Fonte: Subburaj et al. (2007).

Já Turgut et al. (2009) difere da técnica de Coward, Watson e Wilkinson (1999) no método utilizado para Manufatura Aditiva, ao invés de Fabricação por Filamento Fundido ou Fused Filament Fabrication (FFF) é utilizada a Sinterização Seletiva por Laser ou Selective Laser Sintering (SLS). O procedimento apresentado foi aplicado em 10 pacientes, todos bem sucedidos. A desvantagem do método é o alto custo necessário para aquisição do equipamento de SLS e o su- 
primento utilizado. Por outro lado, os processos de fabricação por SLS geralmente são mais rápidos e possuem maior resolução se comparado ao FFF.

Mais recentemente, Liacouras et al. (2011) utilizou-se de uma técnica de fotografia tridimensional composta por 5 câmeras sincronizadas para a obtenção do modelo da orelha saudável. O modelo resultante é segmentado manualmente através do uso de softwares de CAD e um molde virtual é obtido a partir do inverso da seleção de uma região. O autor também detalha os equipamentos utilizados em seu trabalho, que ao todo custaram cerca de U\$200.000,00 (duzentos mil dólares).

Os trabalhos apresentados por Karatas et al. (2011) e Karayazgan-Saracoglu, Gunay e Atay (2009) são bastante similares ao de Coward, Watson e Wilkinson (1999), porém utilizam de imagens de Tomografia Computadorizada para obter o modelo da orelha saudável, que então é materializada. A figura 3 apresenta a prótese auricular obtida por Karatas et al. (2011). Os procedimentos posteriores seguem conforme o método convencional, com o molde obtido a partir do pavilhão auricular materializado.

O procedimento apresentado por Watson e Hatamleh (2014) inicia-se de modo convencional, extraindo do paciente um molde com material hidrocolóide irreversível. Através de injeção de silicone no molde, um modelo físico da orelha saudável é criado e sobre esse modelo é realizado uma digitalização 3D através de um scanner. O modelo virtual é espelhado através de ferramentas CAD e impresso. As próximas etapas seguem o procedimento convencional de elaboração de próteses. Neste caso, a Manufatura Apoiada por Computador é utilizada apenas para o espelhamento do modelo. O estudo foi aplicado em 2 pacientes e foi utilizado um espectrômetro para a discretização exata da cor da pele do paciente e, através de software (Spectromatch Pro, Hampton, Reino Unido), foi calculada a composição da pigmentação a ser utilizada na caracterização da prótese. A figura 4 apresenta 
Figura 3: Modelo fabricado em 3D e prótese obtida por Karatas et al. (2011).

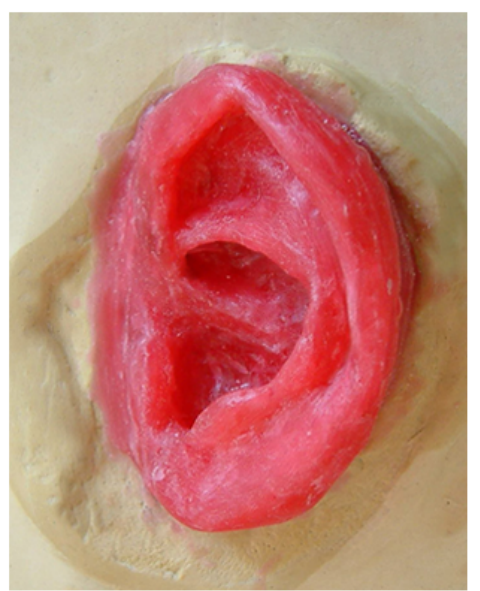

a)

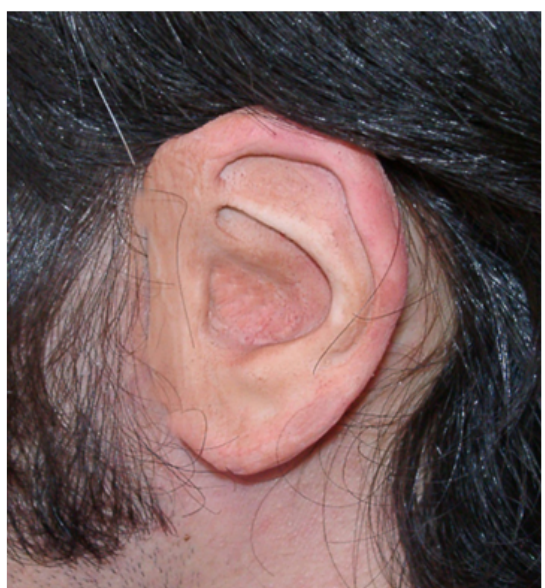

b)

a) Modelo Estereolitográfico.

b) Prótese obtida.

Fonte: Karatas et al. (2011).

o modelo com material hidrocolóide, o uso do espectrômetro e a prótese auricular obtida.

Figura 4: Estudo apresentado por Watson e Hatamleh (2014) onde utiliza-se de um espectrômetro.

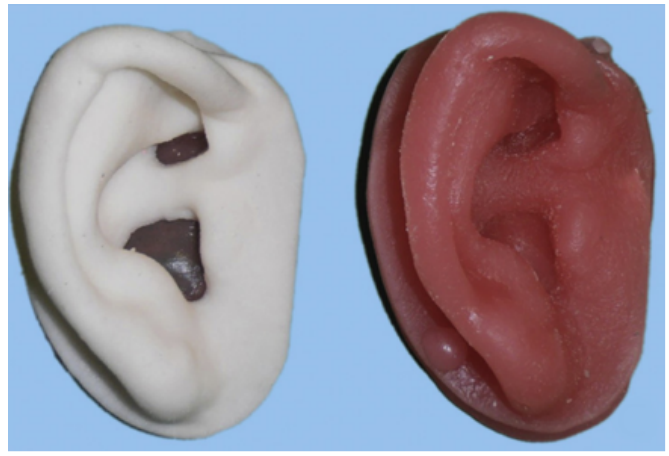

a)

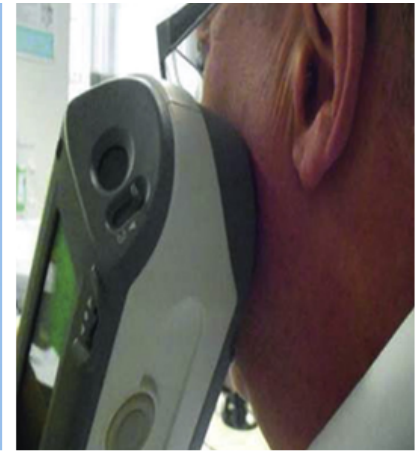

b)

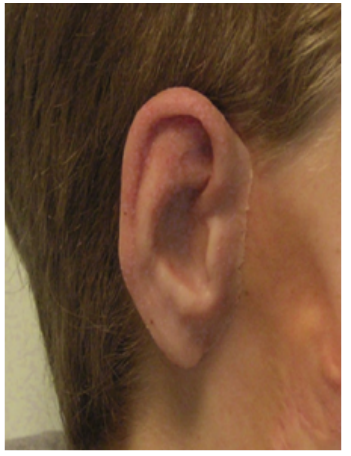

c)

a) Modelo estereolitográfico obtido por scanner 3D.

b) Uso de espectrômetro para caracterização da cor da pele.

c) Prótese obtida.

Fonte: Watson e Hatamleh (2014).

Fundamentalmente, grande parte dos estudos na área não utilizam-se de Pro- 
cessamento de Imagens para uma segmentação automática ou semiautomática da região de interesse. Em todos os trabalhos revisados foi observado uma demanda por ferramentas de modelagem CAD para segmentação manual da região da orelha, correções de oclusões e perspectivas. Outro aspecto observado na maior parte dos trabalhos, com exceção de Liacouras et al. (2011), foi a materialização direta do pavilhão auricular espelhado, sendo necessário a continuidade do uso dos meios convencionais para a criação do molde para a elaboração da prótese.

\subsection{Segmentação de Imagens}

A Segmentação de Imagens, definida como o processo de separação de regiões de interesse em uma imagem através de uma ou mais características, é parte essencial e amplamente utilizada em inúmeras técnicas de Processamento de Imagem (GONZALEZ; WOODS, 2006). Em imagens médicas é utilizada para diversos fins, como na extração de estruturas anatômicas, análise de dinâmica de fluxo, medida de volume de órgãos e tecidos, localização de patologias, dentre outros.

De modo geral, os métodos de segmentação podem ser classificados em 4 grupos: filtragem local, contornos ativos, crescimento e agrupamento de regiões e otimização de funções de energia global.

O método de segmentação de imagens por contorno ativo "Snake" proposto por Kass, Witkin e Terzopoulos (1988) permitiu que um novo conjunto de técnicas de segmentação fosse explorado. O método proposto possui determinada flexibilidade matemática e a partir dele originaram-se derivações de seu método (PRINCE, 1997; YEZZI et al., 1997; COHEN, 1991; KICHENASSAMY et al., 1995; CHAN; VESE, 2001).

O modelo de contorno ativo, em sua formulação original proposto por Kass, Witkin e Terzopoulos (1988), faz uso de uma curva deformável que busca cir- 
cundar a região a ser segmentada. A curva se comporta sob ação de energias ou "forças" internas (intrínsecas à geometria da curva) e externas (derivadas das bordas da imagem). A energia interna atua exercendo uma força de contração ao próprio contorno, enquanto que a energia externa atrai o contorno em direção as bordas da imagem.

A curva deformável, ou contorno ativo, busca o equilíbrio ao se posicionar sobre as fronteiras do objeto. Sua fundamentação matemática provem das equações de otimização de Euler-Lagrange sobre as "forças" do contorno e, portanto, não possui uma solução analítica. Dessa forma, a obtenção de uma solução aceitável se dá através de aproximação por métodos numéricos.

A definição da energia externa originalmente proposta é definida pelo inverso da magnitude do gradiente da imagem, $E_{\text {externa }}=\|\nabla I(x, y)\|^{2}$. Esta definição implica na ausência de energia externa em regiões homogêneas da imagem, pois em regiões sem gradiente a força de atração (energia externa) será nula. Pelo mesmo fato, a definição arbitrária inicial do contorno deve ser próxima da região de interesse, caso contrário o contorno poderá não convergir pela ausência de energia externa.

A ocorrência de ruídos na imagem também pode causar a falha na convergência do contorno ativo, pois a energia externa calculada sobre os ruídos causará eventualmente o equilíbrio do contorno sobre o ruído.

Outros métodos derivados do contorno ativo foram propostos na literatura para solucionar esses desafios, dentre eles, o modelo "Balloon" (COHEN, 1991), o método de "Distance Potential Forces" (COHEN; COHEN, 1993) e o Gradient Vector Flow (Fluxo do Vetor Gradiente - GVF) (PRINCE, 1997).

O método de Fluxo de Vetor Gradiente, proposto por Prince (1997), apresenta uma nova energia externa difundida sobre toda a imagem, permitindo que 
o contorno seja influenciado pela energia em qualquer lugar na imagem. Essa difusão é dada por uma equação diferencial parcial e resulta em um campo vetorial de forças com orientação as normais das bordas da imagem.

Além da melhor capacidade de convergência inerente ao posicionamento inicial e uma maior tolerância à ruídos, o GVF oferece uma melhor deformação em direção às concavidades da imagem (PRINCE, 1997). Associando esta funcionalidade a geometria singular do pavilhão auricular, o GVF se apresenta como um método em potencial para segmentação de regiões complexas e portanto será objeto de estudo e aplicação neste trabalho. 


\section{CONCEITOS FUNDAMENTAIS}

Este capítulo provê um detalhamento de áreas de conhecimento utilizadas por este trabalho, compreendendo assim seus conceitos, aplicações e métodos. Muitos desses conceitos são abordados posteriormente no detalhamento do método proposto.

\subsection{Imagens Médicas de Tomografia Computado- rizada}

O princípio fundamental da Tomografia Computadorizada é representar através de um conjunto de imagens a estrutura interna de um determinado corpo ou objeto. A representação da imagem é concedida pela medição da intensidade de radiação que interage com o corpo.

Essencialmente, elétrons são acelerados e colidem com um alvo, essa colisão resulta em calor (maior parte), espalhamento inelástico (variando de acordo com o núcleo do átomo alvo), perda de energia (na forma de radiação eletromagnética), radiação de freamento (princípio de Bremsstrahlung ${ }^{1}$ ) e emissão de radiação característica, esse último o responsável pela formação da imagem.

A projeção do acúmulo da recepção de radiação é fator formador dos pontos da imagem e representa diretamente a interatividade de um determinado tecido

\footnotetext{
${ }^{1}$ Radiação causada pela alteração na trajetória de um elétron ao sofrer interferência ao passar próximo a um núcleo de outro átomo.
} 
do corpo com a radiação. Cada material que compõe um tecido possui um coeficiente de absorção, fazendo com que seja possível distinguir cada tecido de acordo com a intensidade resultante. Para esse coeficiente é dado o nome de Escala de Hounsfield ou Unidades Hounsfield (HU) e é calculado e normalizado em função do coeficiente da água. Dessa forma, tecidos moles do corpo humano possuem entre -300 a -100 HU, enquanto que ossos são próximos a +1000 HU. A tabela 1 apresenta mais alguns exemplos dos possíveis valores.

Tabela 1: Tabela de Unidades Hounsfield (HU) para algumas substâncias e tecidos do corpo.

\begin{tabular}{ll|}
\hline Substância & Unidade Hounsfield (HU) \\
\hline Ar & -1000 \\
Pulmão & -500 \\
Gordura & -100 a -50 \\
Água & 0 \\
Sangue & 30 a 45 \\
Músculo & 10 a 40 \\
Tecidos moles & 100 a 300 \\
Ossos & 700 a 3000 \\
\hline
\end{tabular}

Fonte: Goldman (2007).

Dessa forma, uma imagem médica de Tomografia Computadorizada representa uma projeção no domínio do espaço das características de cada região do corpo, e cada imagem representa uma fatia do corpo. O conjunto dessas fatias formam um exame que contempla uma região axial do corpo. Cada camada é representada computacionalmente por uma imagem $2 \mathrm{D}$ de tamanho variável de acordo com as características do tomógrafo, geralmente de 512 por 512 pontos, ou pixels ${ }^{2}$. Também variante ao tomógrafo, as camadas podem possuir espessura que varia entre $0,3 \mathrm{~mm}$ a $2 \mathrm{~mm}$, e em uma projeção tridimensional por pontos, a espessura é utilizada para a conversão de um pixel para um ponto tridimensional, ou voxel ${ }^{3}$, conforme modelo ilustrado na figura 5 .

\footnotetext{
${ }^{2}$ Pixel é o nome dado a representação computacional de cada ponto de uma imagem

${ }^{3}$ Voxel é o nome dado a representação computacional de cada ponto de uma imagem tridi-
} 
Figura 5: Modelo de uma camada tomográfica em relação a sua representação tridimensional.

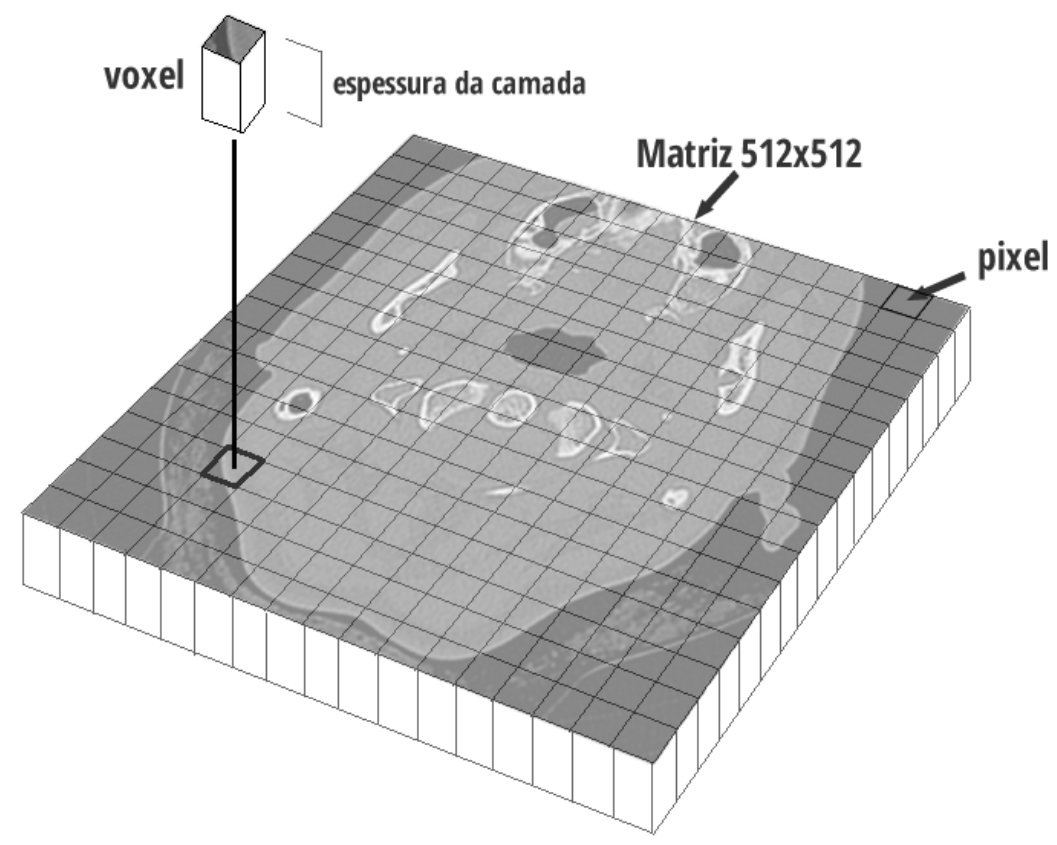

Fonte: Autor.

\subsubsection{DICOM}

Um padrão aberto de imagens médicas foi criado pela National Electrical Manufacturers Association(NEMA) com o objetivo de uniformizar o manuseio, armazenamento, impressão e transmissão desses exames, este padrão, cujo nome é Digital Imaging and Communications in Medicine (DICOM), é amplamente utilizado por fabricantes de equipamentos de aquisição de imagens e desenvolvedores de sistemas clínicos.

Em seu formato, além das imagens em si, diversas outras informações podem ser armazenadas, como a espessura das fatias da tomografia, distância entre fatias, maior e menor escala Housfield obtida, dentre outras. Essas informações são mensional 
essenciais para o estudo analítico das imagens, para a reconstrução tridimensional do exame e para a segmentação de tecidos e/ou regiões de interesse.

\subsection{Reconstrução Tridimensional}

A visualização tridimensional oferece a médicos uma alternativa para interpretação de exames, pois permite uma melhor observação de anatomias complexas, patologias e anomalias em partes do corpo (LORENSEN; CLINE, 1987).

Ao processo de conversão de um conjunto de imagens $2 \mathrm{D}$ obtidas de um tomógrafo ou de uma ressonância magnética para um modelo tridimensional se dá o nome de Reconstrução Tridimensional. Este processo visa gerar superfícies tridimensionais compostas por triângulos a partir de uma aproximação dos contornos pertencentes às camadas transversais nas imagens 2D, conforme ilustrado na 6 , onde uma camada axial (item a) representa uma determinada espessura no modelo tridimensional obtido (item b). Os contornos são determinados de acordo com uma variação brusca de intensidade no valor dos pontos através de alguma técnica de deteç̧ão de bordas.

Neste método, as informações internas do objeto não são consideradas, e portanto, é limitado a reconstrução de objetos morfologicamente bem definidos. A criação de planos a partir dos contornos de cada seç̧ão transversal resulta em uma malha de planos tridimensional que compõe uma superfície sobre todo o objeto, e dessa forma é obtida uma isosurperfície da região de interesse.

A isosuperfície também pode ser facilmente exportada para sistemas de Manufatura Aditiva para sua fabricação no formato STL (Stereolithography). 
Figura 6: Processo Reconstrução Tridimensional.

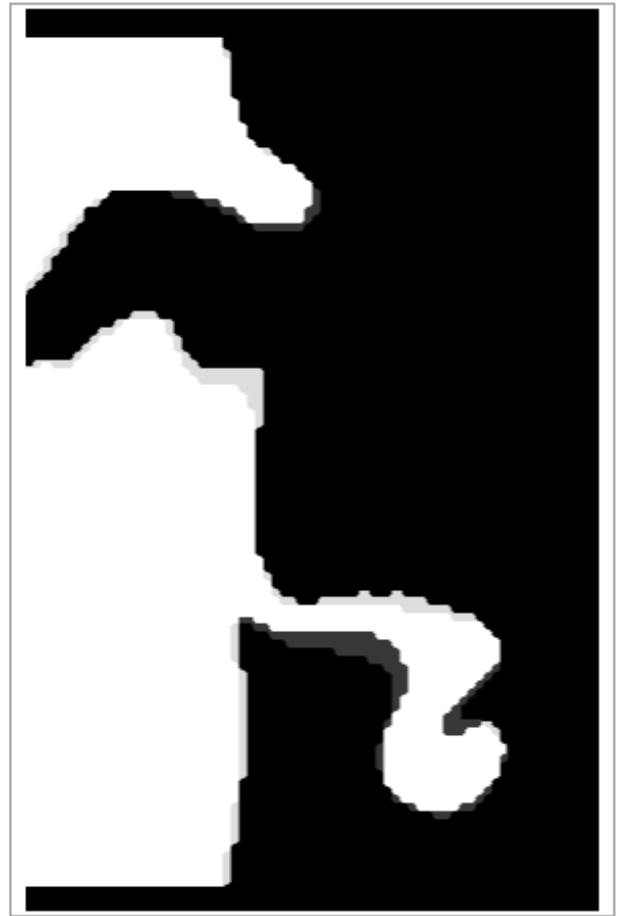

a)

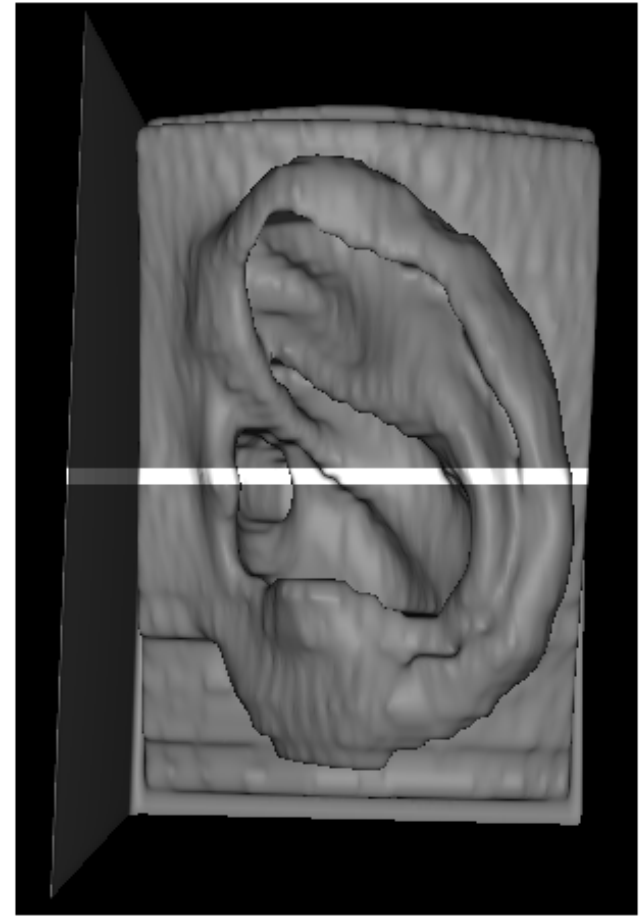

b)

a) Camada de uma tomografia.

b) Superfície tridimensional reconstruída com a camada a) em destaque. Fonte: Autor.

\subsection{Manufatura Aditiva}

A Manufatura Aditiva pode ser definida como um grupo de técnicas utilizadas para fabricar rapidamente um objeto tridimensional com o propósito de auxiliar em sua concepção (PRINZ et al., 1997). É uma tecnologia complementar aos sistemas CAD/CAM e vem sendo utilizada em áreas como na indústria, no aprimoramento de produtos, na medicina com próteses e planejamento cirúrgico, na engenharia biomédica com pesquisas em impressão de tecidos biológicos a partir de células tronco (LANTADA; MORGADO, 2012).

Além de Manufatura Aditiva, a área também é comumente denominada de Rapid Prototyping (Prototipagem Rápida) e 3D Printing (Impressão 3D). 
O processo de fabricação é baseado no paradigma da manufatura por camadas planares, neste método o sólido tridimensional é fatiado em camadas horizontais e fabricado através fusão ou depósito de material camada a camada. O processo de fatiamento é feito por softwares chamados de Planners ou Slicers, que são responsáveis por gerar as trajetórias posicionais de depósito ou fusão a partir de um objeto tridimensional.

Estes softwares também são capazes de utilizar o próprio material de impressão para fornecer substrato para uma camada superior que eventualmente não tenha suporte físico, como por exemplo, em uma cavidade. Essa capacidade geração de um material de suporte pode ser feita de duas formas, suporte complementar - quando há a possibilidade do próprio material de produção ser um suporte natural para a peça, e suporte explícito - quando é preciso fabricar partes que não compõem o objeto para sustentar sua estrutura. Ambas as formas estão ilustradas na figura 7, na qual o item a) ilustra a técnica de suporte complementar e b) o suporte explícito.

Figura 7: Processo de geração de material de suporte.

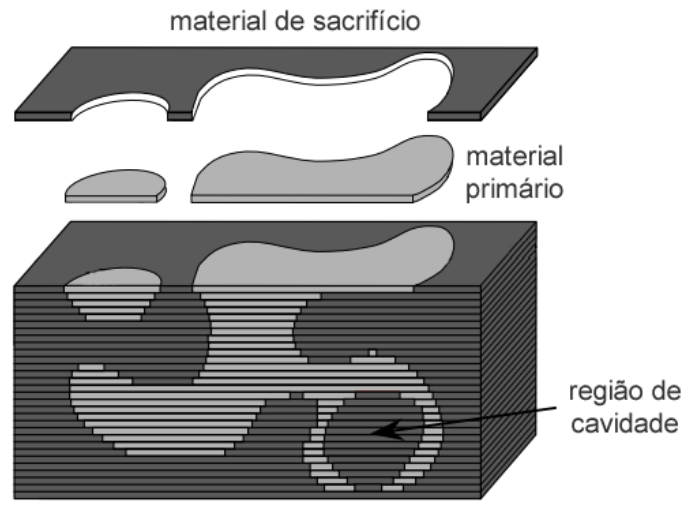

a) Suporte complementar

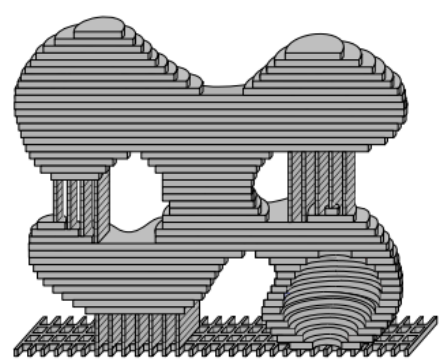

b) Suporte explícito

Fonte: Adaptado de Prinz et al. (1997).

Essa abordagem permite a construção arbitrária de geometrias complexas e requer mínima ou nenhuma intervenção humana em sua operação. Há várias 
técnicas de Manufatura Aditiva que utilizam o processo de depósito ou fusão de material, incluindo estereolitografia, sinterização a laser, laminação, extrusão de termos polímeros, e impressão ink-jet. Uma síntese de cada um desses principais métodos é apresentada na sequência.

\subsubsection{Estereolitografia}

Sistemas de Stereolithography (Estereolitografia - SLA) utilizam como princípio funcional a característica de alguns polímeros cuja as propriedades físicas são alteradas quando expostos a luz, geralmente a luz ultravioleta. A esses polímeros é dado o nome de fotopolímeros e no caso da SLA são utilizados em forma de resinas. A cada camada um padrão de luz é desenhado sobre a resina, solidificando a região exposta.

Suas principais vantagens são a velocidade de fabricação, pois o processo de cura da resina é praticamente instantâneo (HULL, 1984), e uma alta resolução, aproximadamente 25,4 micrômetros (HULL et al., 1993). No entanto, um equipamento de SLA geralmente possui um alto custo se comparado as demais tecnologias.

\subsubsection{Manufatura de Objetos Laminados}

O processo denominado Laminated Object Manufacturing (Manufatura por laminação - LOM) cria objetos através cortes em folhas empilhadas e intercaladas com um adesivo ativado por calor. Na maioria dos casos é utilizado como material folhas de papel e em alguns casos, lâminas de diferentes materiais com o propósito de criar compósitos. A cada camada do objeto, uma folha é empilhada e cortada, e em alguns equipamentos, o papel é previamente impresso com jato de tinta colorido, dando um aspecto visual mais realista à peça.

O objeto resultante dessa modalidade apresenta bastante solidez, estabilidade 
e resistência. Entretanto, dificilmente é possível avaliar aspectos físicos funcionais do objeto e, dependendo do objeto, torna-se difícil a retirada de material de suporte complementar em regiões internas como em cavidades.

\subsubsection{Sinterização Seletiva a Laser}

A técnica Selective Laser Sintering (Sinterização Seletiva a Laser - SLS) utiliza um raio laser de $\mathrm{CO}^{2}$ para sinterizar (calor e fusão) de forma seletiva materiais em pó como náilon com carga de pó de vidro ou fibra de carbono para melhores propriedades físicas. Foi desenvolvida inicialmente pela Universidade do Texas, Austin, EUA, e posteriormente comercializada pela DTM Corp., EUA.

O processo funcional é composto por um braço deslizante que distribui o material sobre uma plataforma a cada camada. O laser é direcionado através de um conjunto ótico móvel e que atinge apenas a região a ser sinterizada. O movimento do laser traça as regiões do objeto, e uma vez que o material tenha sido solidificado, a plataforma da impressão é rebaixada a uma distância que é igual à espessura de uma nova camada. Este processo está ilustrado na figura 8.

Há várias vantagens oferecidas pela SLS, como a não necessidade de material de suporte explícito devido ao fato do objeto sólido ser imerso no pó continuamente, dessa forma o próprio material em pó atua como suporte complementar. A característica da sinterização também oferece uma alta resolução se comparado aos demais métodos ( 10 micrômetros) e permite a utilização de outros tipos de materiais como poliamida, poliestireno e elastômeros. O custo de um equipamento de SLS assim como o custo de produção de um objeto é o maior dentre os demais apresentados. 
Figura 8: Processo de Fabricação Sinterização Seletiva a Laser.

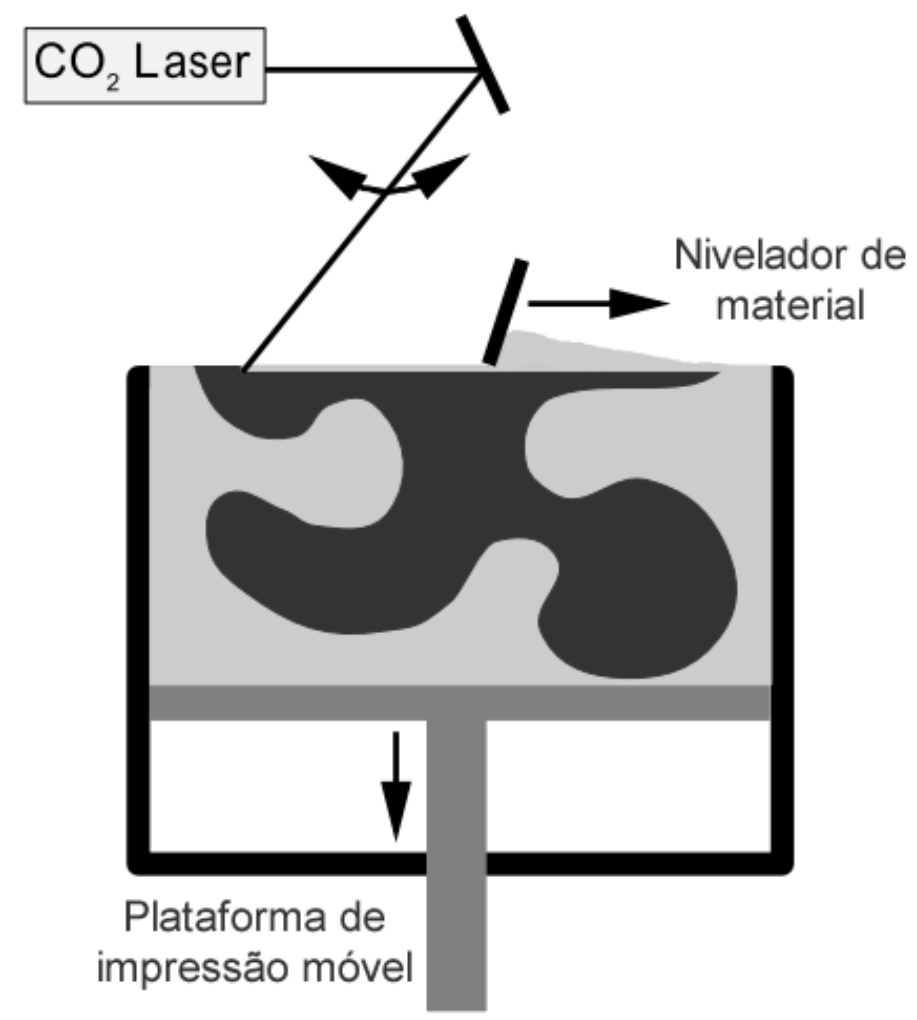

Fonte: Adaptado de Prinz et al. (1997).

\subsubsection{Jato de Tinta 3D}

A estratégia de manufatura 3D Ink-Jet (Jato de Tinta 3D) desenvolvida em 1993 pelo MIT, funciona de forma similar a SLS divergindo do modo utilizado para solidificação o material em forma de pó. Enquanto na SLS é utilizado laser, esta estratégia utiliza-se de um líquido com características de adesivas e/ou catalisadoras. Na maioria dos equipamentos, um braço deslizante distribui o material em pó a cada camada. O líquido atua solidificando as regiões e pode possuir aditivos capazes de adicionar cor e flexibilidade ao objeto produzido.

De forma geral, é possível utilizar diversos tipos de material nesse processo, desde giz (primeiro material utilizado) até compostos cerâmicos. Os aspectos fí- 
sicos do objeto fabricado são diretamente ligados ao tipo de material utilizado e necessita de um processo para remoção de material de suporte complementar, geralmente realizado através de um procedimento químico ou manualmente através de jato de água.

Os equipamentos mais básicos oferecem impressão monocromática em resolução de 28 micrômetros e possui um custo menor se comparado a SLS.

\subsubsection{Fabricação por Filamento Fundido (FFF)}

O processo de Fused Filament Fabrication (Fabricação por filamento fundido FFF) também denominado de Fused Deposition Modeling (Modelagem por depósito de material fundido - FDM) - termo registrado pela Stratasys Inc., Minnesota, EUA - utiliza-se da estratégia de uma contínua deposição de um filamento termo polímero através de bocal aquecido com movimentos nos 3 eixos.

A este processo de deposição é dado o nome de extrusão, e está ilustrado na figura 9 .

Os termos polímeros são utilizados em estado sólido e dispostos em filamentos (geralmente entre $1,75 \mathrm{~mm}$ ou $3 \mathrm{~mm}$ de diâmetro) e se tornam mais viscosos de acordo com sua temperatura de fusão. Entre as opções de termos polímeros há derivações de cores, opacidade, resistência e flexibilidade.

Nesta modalidade se faz necessária a criação de suporte explícito (vide figura 7) para apoio de estruturas "flutuantes", pois durante o processo de fabricação o material é depositado em sua temperatura de fusão, o que o torna mais viscoso, e na ausência de um suporte explícito, o material tende a não permanecer em posição pela ação da força da gravidade.

Os equipamentos de fabricação por FFF possuem geralmente um custo mais acessível se comparado as demais modalidades e por não dependerem de com- 
Figura 9: Processo de Fabricação por Filamento Fundido.
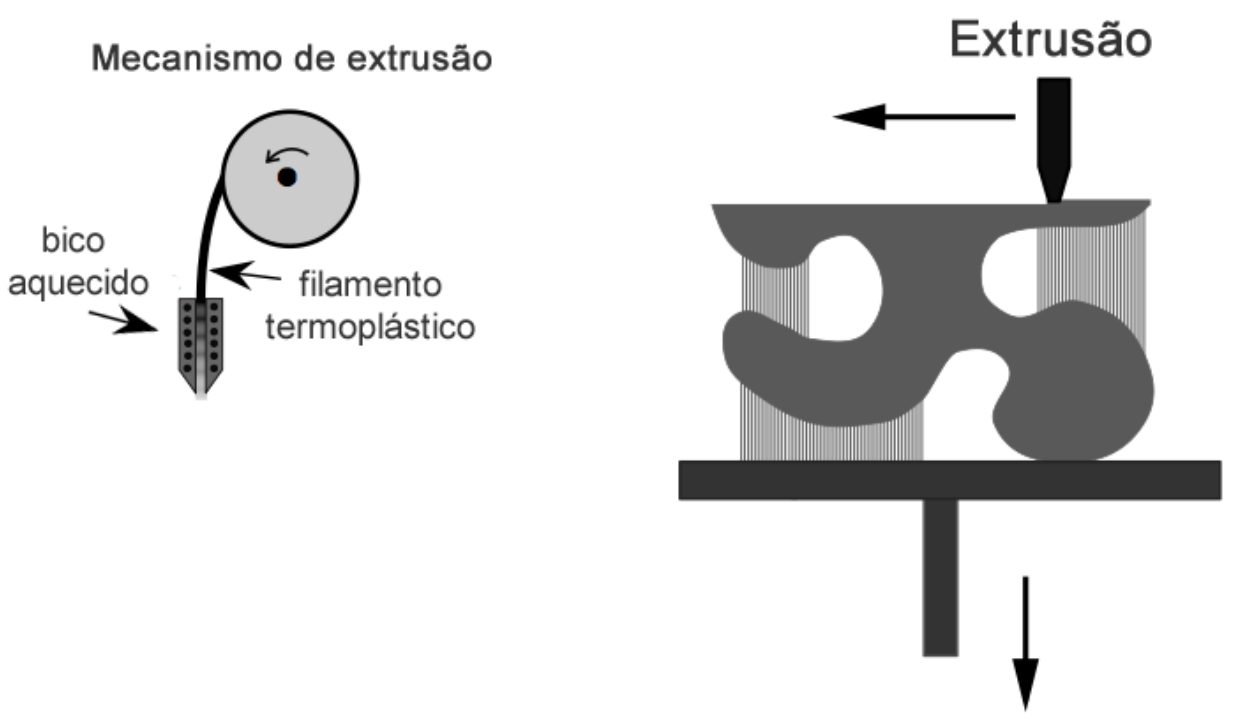

Plataforma de impressão móvel

Fonte: Adaptado de Prinz et al. (1997).

ponentes mais complexos em sua composição, como por exemplo laser, torna-se possível a sua construção mesmo em ambientes não industriais. Dada a simplicidade em sua composição, diversas iniciativas de hardware aberto surgiram nos últimos anos, como o projeto RepRap ${ }^{4}$ que contempla a documentação aberta e gratuita para a construção de mais de 50 modelos de impressoras 3D.

Mesmo os modelos de entrada podem oferecer alta resolução se comparado as demais modalidades, como por exemplo o modelo 3D Cloner ST, Microbras, Brasil, possui 50 micrômetros de resolução nos 3 eixos.

\footnotetext{
${ }^{4}$ http://reprap.org/
} 


\section{MATERIAIS E MÉTODOS}

O presente trabalho explora um conjunto de técnicas computacionais e de fabricação aplicados à manufatura de moldes para a elaboração de próteses auriculares individualizadas. A aplicação de técnicas computacionais a este procedimento caracteriza-se como uma Manufatura Apoiada por Computador (CAM). O processo convencional de elaboração de próteses auriculares, como descrito no capítulo 1, envolve um processo manual e naturalmente pode resultar em imperfeições.

Um novo procedimento para a elaboração de próteses auriculares individualizadas é apresentado pelo presente trabalho, os procedimentos clínicos posteriores, como a caracterização da prótese e sua fixação não são escopo desta pesquisa e continuam sendo etapas consequentes. A compatibilidade do procedimento proposto contempla quaisquer pacientes que tenham algum dano ou má formação em um ou ambos pavilhões auriculares. Em pacientes que tiverem um dos lados saudável deverá ser utilizado o processo de espelhamento do lado contralateral saudável. Já os pacientes que não possuem formação auricular em ambos os lados podem utilizar-se de imagens e/ou moldes de outros pacientes.

O molde, definido como um objeto físico com as geometrias inversas de um pavilhão auricular, permite ao protesiólogo a elaboração de uma próstese auricular através da injeção de silicone. Após a cura do silicone e desmoldagem a prótese é obtida. 
O processo de concepção de um molde envolve várias etapas e é iniciado pela obtenção das imagens médicas do paciente da região de interesse, no caso, uma tomografia computadorizada contemplando o pavilhão auricular saudável. As imagens obtidas da tomografia em formato DICOM são pré-processadas com o objetivo de redução de ruídos provenientes do processo de obtenção e remoção de regiões indesejadas.

A partir do conjunto de imagens pré-processadas é feita uma segmentação automática da região da orelha saudável com interação por parte do usuário. O usuário é responsável por selecionar a região e ajustar parâmetros para a correta segmentação. Os parâmetros são utilizados por algoritmos de Processamento Digital de Imagens que fazem a extração da região de interesse e o espelhamento axial em todas as imagens da tomografia.

No processo de espelhamento da região do pavilhão auricular é também realizada uma subtração da região contralateral através de sobreposição, e dessa forma, caso o paciente possua alguma estrutura remanescente, seja por má formação congênita, ou seja, decorrente de trauma com perda parcial, a nova prótese compreenderá essa diferença estrutural, conforme ilustrado pelo exemplo na figura 10.

Com as imagens segmentadas, uma Reconstrução Tridimensional é realizada a partir da região inversa da segmentada, ou seja, a região que compreenderá o molde. O resultado é uma superfície tridimensional composta por uma malha de triângulos que representa o molde a ser produzido. Um algoritmo de suavização de malhas tridimensionais é aplicado com o objetivo de remover imperfeições causadas principalmente pela distância entre as camadas das imagens de tomografia.

O objeto tridimensional então é convertido para o formato padrão de Manufatura Aditiva, o STL (Stereolithography). Este arquivo contém o detalhamento posicional de cada um dos triângulos que formam o objeto e é amplamente utili- 
Figura 10: Subtração da região contralateral.

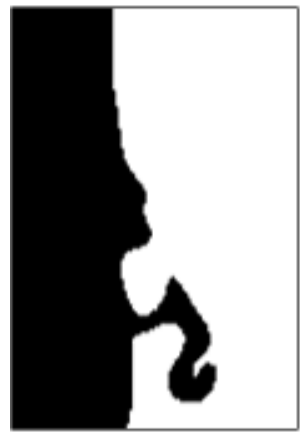

a)

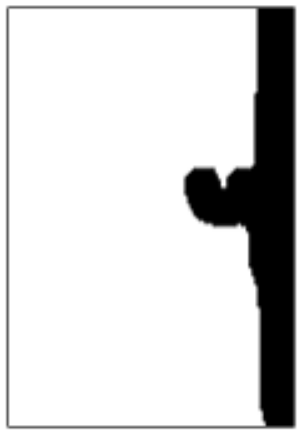

b)

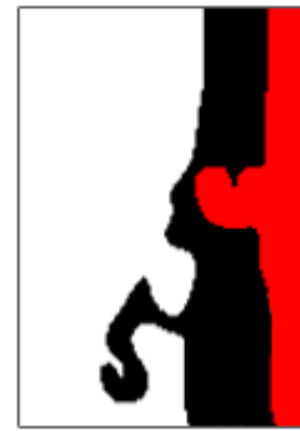

c)

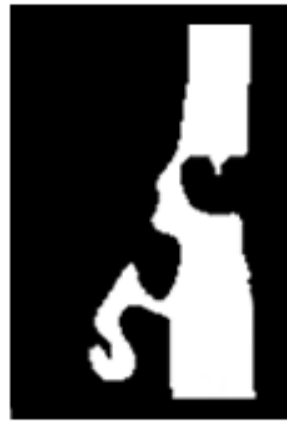

d)
a) Região sã.
b) Região contralateral com uma má formação congênita.
c) Subtração por sobreposição.
d) Resultado do processo.
Fonte: Autor.

zado em quase todas as estratégias de manufatura.

Os processos supracitados são realizados de forma automática por um software de código aberto desenvolvido pelo presente trabalho que recebe como entrada as imagens de tomografia e tem como saída um arquivo STL.

Com o arquivo STL, a fabricação do molde é feita pelo processo de Fabricação por Filamento Fundido (FFF) utilizando um termoplástico com características não tóxicas. O objeto físico obtido é então submetido a um processo químico de Suavização de Superfície com solvente não tóxico de forma a eliminar a rugosidade proveniente do processo de fabricação.

Ao final do tratamento superficial, o molde obtido possui aspecto superficial homogêneo e está apto para a elaboração da prótese através da injeção de silicone pigmentado pelo protesiólogo.

Uma visão geral do processo apresentado por este trabalho está ilustrada pela figura 11. As seções deste capítulo detalham cada uma das etapas. 
Figura 11: Etapas do processo proposto para fabricação de moldes individualizados.

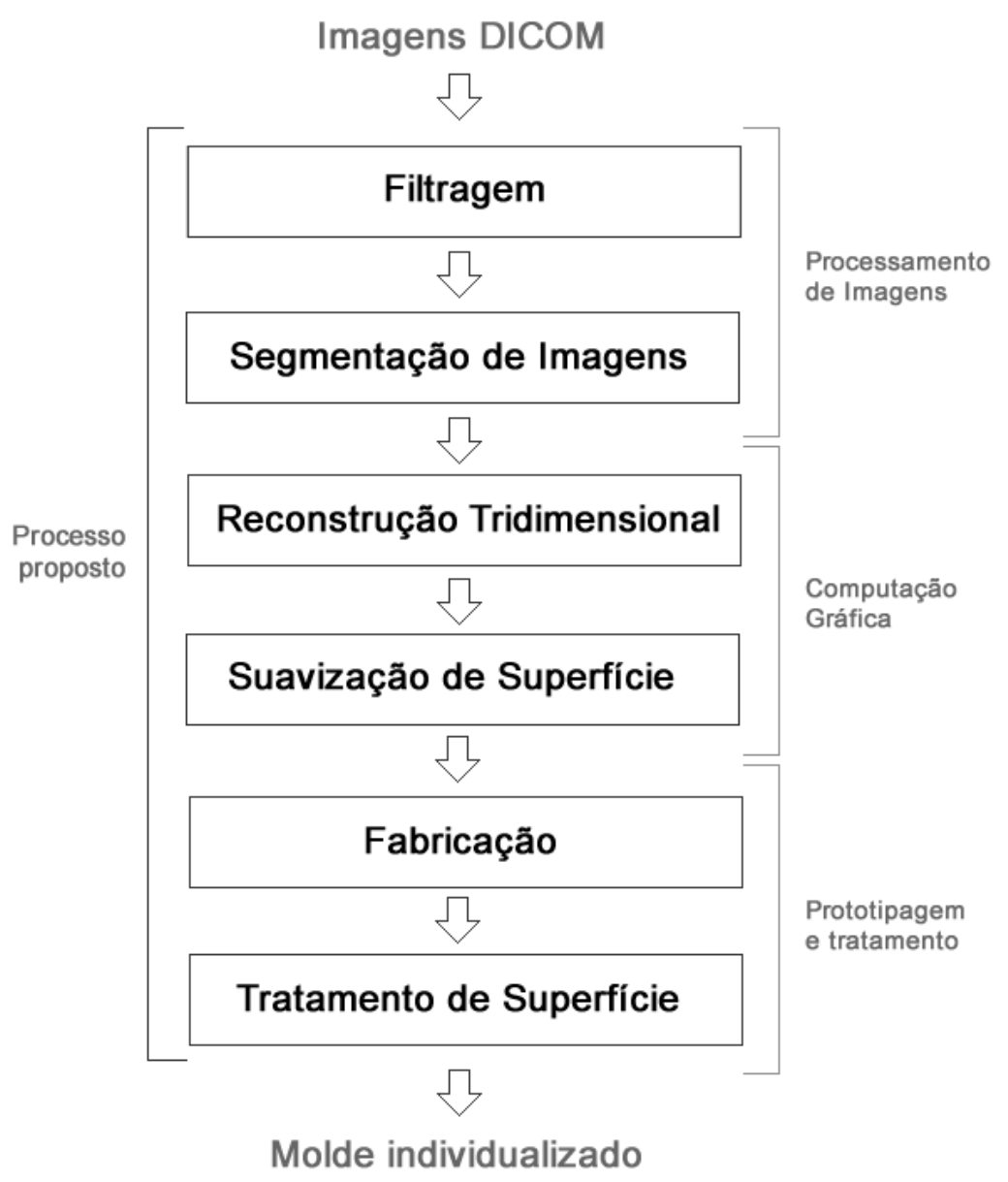

Fonte: Autor.

As técnicas desenvolvidas e utilizadas neste trabalho foram implementadas em linguagem de programação Java, a qual é amplamente utilizada na área, permite independência de Sistema Operacional e é uma ferramenta de código aberto. Todas as ferramentas e códigos-fontes utilizados de terceiros são de código aberto e livre de custo de licenças. 


\subsection{Processamento de Imagens}

Esta seção apresenta as primeiras etapas do processo as quais visam remover ruídos das imagens de tomografia, suprimir regiões não pertencentes ao pavilhão auricular e posteriormente a segmentar e espelhar a estrutura completa da orelha.

\subsubsection{Filtragem}

Imagens médicas são comumente afetadas por ruídos devido a interferências e outros fenômenos inerentes ao processo de aquisição (BANKMAN, 2008). Esses ruídos podem causar falhas indevidas nos processos posteriores, como a segmentação errônea de uma determinada região. As imagens de tomografia computadorizada, utilizadas por este trabalho, apresentam ruídos causados principalmente por difração da colisão entre átomos e radiação de freamento (princípio de Bremsstrahlung). Ambos fenômenos geram pontos indevidos e deixam as imagens com aspecto de granulosidade.

Técnicas de filtragem digital de imagens permitem que regiões de interesse sejam destacadas e demais regiões sejam atenuadas e/ou removidas. Duas técnicas de filtragem são aplicadas com o objetivo de reduzir ruídos (Difusão Anisotrópica) e remoção de regiões indevidas (Crescimento de Região Probabilístico).

\subsubsection{Difusão Anisotrópica}

A segmentação do pavilhão auricular é realizada através da detecção de suas bordas na imagem, conforme detalhado na seção 4.2. Para uma detecção acurada é preciso que as bordas da imagem estejam bem definidas e que os ruídos sejam suprimidos ou minimizados. Os filtros mais simples, como o filtro Passa-Baixa e o filtro Gaussiano, suavizam a imagem uniformemente, atenuando os ruídos de alta frequência por toda a imagem, inclusive sobre as bordas. Neste caso, as bordas 
perdem nitidez e sua detecção se torna mais complexa.

A filtragem por Difusão Anisotrópica proposta por Perona e Malik (1990) possui um comportamento característico, suaviza regiões homogêneas na imagem e mantém o contraste em regiões de bordas. Por este comportamento, o filtro é amplamente utilizado em imagens médicas (RAUT; RUIKAR, 2013) e também é utilizado por este trabalho.

O modelo de Difusão Anisotrópica utiliza da representação de imagem em Espaço de Escala. O Espaço de Escala é uma forma de representação de imagens no qual uma imagem é decomposta em $n$ subamostragens com nitidez gradual. No caso de Espaço de Escala Linear, uma imagem $I$ é descrita em múltiplas escalas derivadas de uma convolução gaussiana de desvio padrão $\sigma$ fixo. Cada escala apresenta um grau de detalhe, a imagem $I$ na escala $\sigma=0$ é a própria imagem enquanto que a imagem $I_{(n+1)}$ apresenta menor nitidez.

Dessa forma, a imagem original $I_{0}$ é decomposta em uma família de imagens derivadas da convolução da imagem original com uma convolução gaussiana $G$, com variância no tempo $t$, conforme equação 4.1 .

$$
I(t)=I_{t} * G(t)
$$

O tempo $t$ é o parâmetro de escala, incrementos em $t$ resultam em representações com menor nitidez.

A representação de Espaço de Escala Linear resulta em imagens cada vez mais borradas uniformemente conforme a escala for aumentando, inclusive sobre as bordas. A convolução gaussiana aplicada difunde linearmente as informações da imagem em todas as direções e por isso é tida como uma Difusão Isotrópica.

Diferentemente do Espaço Escala Linear, Perona e Malik (1990) propuseram 
um Espaço Escala Não-Linear composto por uma função de controle $c$ que inibe a difusão em regiões de bordas. A Difusão Anisotrópica é realizada através da equação diferencial parcial 4.2 .

$$
\frac{\partial I}{\partial t}=c(|\nabla I|) \cdot \nabla I
$$

onde, I a matriz da imagem e $c$ o coeficiente de variação local. Assim, a variação da imagem em função do tempo $(t)$, é dada pelo coeficiente de difusão multiplicado pelo gradiente da imagem. Este coeficiente é o fator responsável pela "detecção" de uma região de bordas e pode ser representado de duas formas, nas equações 4.3 e 4.3 .

$$
c(x)=\frac{1}{1+(x / k)^{2}}
$$

ou,

$$
c(x)=\exp \left[-(x / k)^{2}\right]
$$

onde, $k$ é o fator de magnitude da borda, e deve ser definido de acordo com as características dos contornos da imagem. Não há uma justificativa fundamentada da escolha entre os 2 métodos, assim como para o fator de magnitude de borda. Perona e Malik (1990) apresentam exemplos arbitrários em ambas escolhas.

A discretização da equação da escala de espaço para temporal é dada pela equação 4.5 .

$$
I_{s}^{t+\Delta t}=I_{s}^{t}+\frac{\Delta t}{\left|\eta_{s}\right|} \sum_{p \in \eta_{s}} c\left(\nabla I_{s, p}^{t}\right) \cdot \nabla I_{s, p}^{t}
$$

onde, $I_{s}^{t}$ é a imagem temporal, $t$ representa o passo do tempo discreto, $\eta_{s}$ representa o conjunto de vizinhos do ponto $s$. É possível observar na equação 4.5 que se o coeficiente de controle de bordas tiver um valor baixo, a própria 
imagem vai prevalecer, e é desta forma que as bordas são mantidas. Por esta característica, a Difusão Anisotrópica é classificada como um filtro adaptativo e utiliza a variância local de ruídos como fator de seu comportamento. A figura 12 apresenta o resultado da aplicação do filtro com $t=20$.

Figura 12: Aplicação da filtragem por Difusão Anisotrópica.

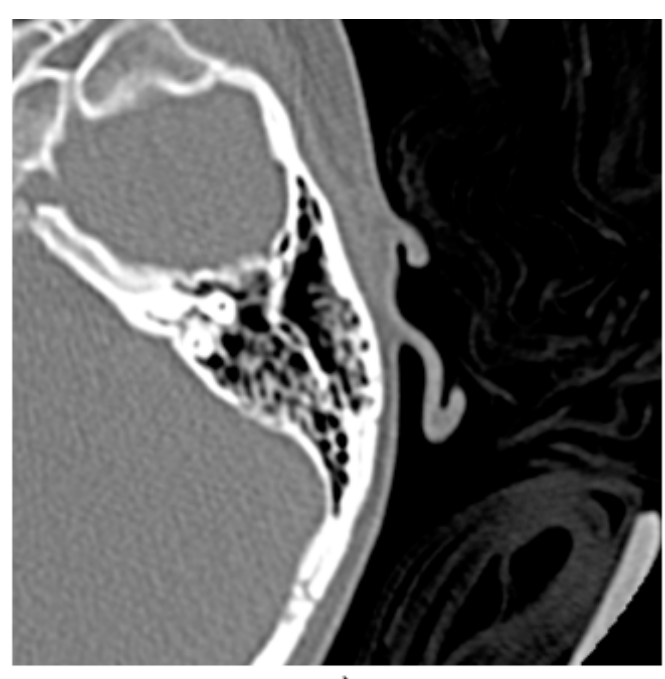

a)

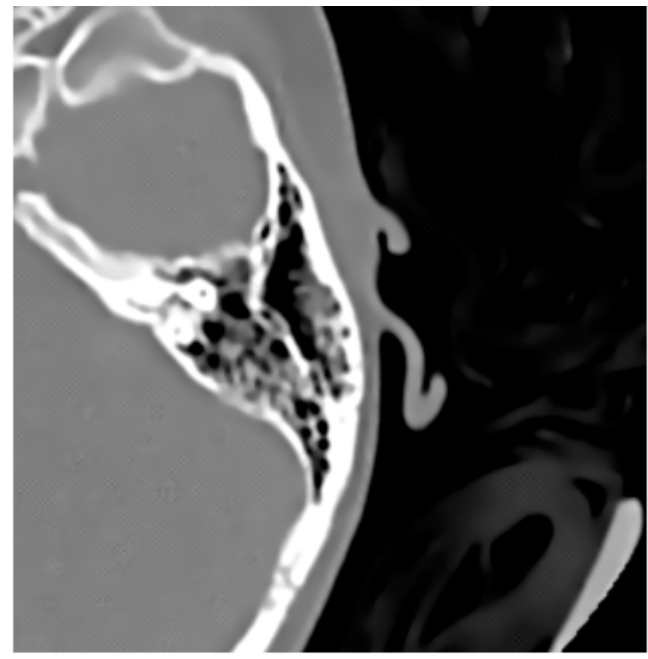

b)

a) Imagem DICOM original.

b) Imagem resultante do filtro.

Fonte: Autor.

É possível observar na imagem 12 (b) que as bordas da imagem são prevalecidas integralmente e regiões ruidosas com aspecto granular são suprimidas praticamente em sua totalidade. O filtro então é o primeiro processo realizado e é aplicado em todas as imagens que compõem a tomografia.

A pseudo código 1 apresenta a implementação do algoritmo de Difusão Anisotrópico de forma incremental e em função da quantidade de iterações.

\subsubsection{Crescimento de Regiões Probabilístico}

A técnica de Crescimento de Regiões leva em consideração a análise da intensidade de um ponto de acordo com seus pontos vizinhos. A técnica parte do 


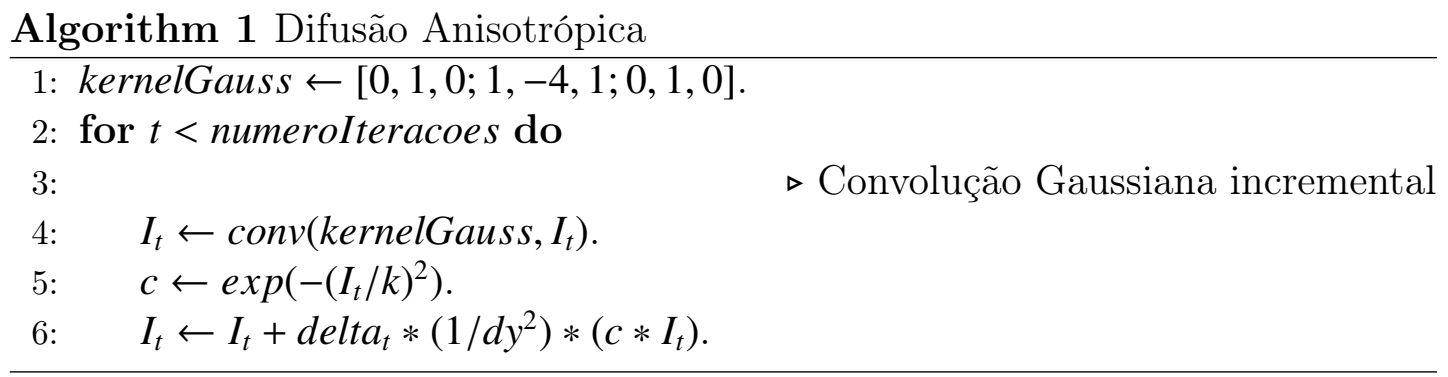

princípio que partes da imagem "similares" e espacialmente interligadas devem pertencer ao mesmo agrupamento. Este processo inicia considerando cada pixel como sendo uma região e é repetido iterativamente, unindo regiões de vizinhança de mesma intensidade até que se atinja um ponto de parada, geralmente baseado em algum critério de dessemelhança. A técnica é aplicada em domínio espacial e pode considerar a vizinhança do pixel de várias formas, sendo a mais comum a vizinhança de pixels norte, sul, leste e oeste.

Os pixels podem ser agrupados pela proximidade de seu valor escalar ou de outras formas, como o desvio padrão. Com valor escalar, todos os pixels são agrupados com valores de intensidade próximos, formando assim uma região de interesse. A proximidade por desvio padrão considera os pixels que possuírem valores dentro de um determinado desvio padrão desejado, formando o segmento de interesse. A tabela 2 representa uma determinada região de uma imagem e ilustra a classificação resultante por Crescimento de Regiões, onde cada região é classificada por uma cor (cinza, amarelo e verde).

Tabela 2: Resultado da classificação por Crescimento de Regiões: pixels são classificados conforme valores de seus vizinhos.

\begin{tabular}{|l|l|l|l|}
\hline 800 & 815 & 819 & 499 \\
\hline 811 & 822 & 799 & 501 \\
\hline 298 & 301 & 456 & 479 \\
\hline 300 & 302 & 488 & 498 \\
\hline
\end{tabular}

Fonte: Autor. 
A característica funcional da técnica de Crescimento de Regiões é a capacidade de classificação de regiões. A imagem resultante de seu processo é composta de regiões espaciais com características em comum. Essa capacidade de classificação pode ser utilizada para outros fins, como na filtragem. Com as regiões em comum definidas, é possível realizar uma análise estatística sobre sua dimensão espacial e reclassificá-la como ruído ou parte de interesse, por exemplo.

O presente trabalho aplica uma técnica de Crescimento de Regiões com um reclassificador espacial probabilístico com o objetivo de eliminar macro ruídos e/ou regiões não pertencentes ao pavilhão auricular.

Inicialmente, os pixels da imagem em formato DICOM são classificados pelo Crescimento de Regiões utilizando a proximidade por desvio padrão $\sigma=70$. O valor de $\sigma$ foi escolhido através de levantamento em trabalhos com análise estatística como em Veldkamp (2011), Boas e Fleischmann (2012), Silva et al. (2012).

Com as regiões agrupadas, o classificador probabilístico é responsável por reclassificar as regiões de acordo com suas dimensões espaciais e valores de intensidade Hounsfield. Esse classificador tem o objetivo de eliminar regiões que não fazem parte do pavilhão auricular e possíveis macro ruídos. A região auricular é toda integrada e não possui partes "soltas". Além disso, demais agrupamentos que não estiverem na classe de tecidos moles (vide tabela 1) podem ser descartados.

Dessa forma, é aplicado um classificador Naive Bayes ${ }^{1}$ que, para cada rótulo de classe, obtêm-se a probabilidade condicional dada suas características independentes: $p\left(K \mid c_{0}, c_{1}, \ldots, c_{n}\right)$ e definida pela equação 4.6 .

$$
p(K \mid c)=\frac{p(K) \cdot p(c \mid K)}{\sum_{\gamma} p(\gamma) \cdot p(c \mid \gamma)}
$$

\footnotetext{
${ }^{1}$ Naive Bayes é um classificador probabilístico baseado no teorema de Bayes com suposições independentes
} 
onde $p$ é a probabilidade condicional, $K$ sua classificação conforme suas características $c_{0}, c_{1}, \ldots, c_{n}$ sendo $c \in-1,1$ e $\gamma$ itera sobre ambas as classes de forma que seja considerada a probabilidade total.

A tabela (3) é utilizada como base de conhecimento para o classificador, a qual foi definida através de mensuração e classificação manual sobre um conjunto de 62 imagens de tomografia da região auricular.

Tabela 3: Tabela de conhecimento para classificador bayesiano.

\begin{tabular}{cccc}
\hline Classe $(K)$ & Área & Escala Hounsfield & Distância entre centroides* \\
\hline Não interesse & $1<\mathrm{x}<5000$ & $-1000<\mathrm{y}<3000$ & indiferente \\
Não interesse & $1<\mathrm{x}<100$ & $200<\mathrm{y}<600$ & $250<\mathrm{d}$ \\
Interesse & $4000<\mathrm{x}$ & $200<\mathrm{y}<600$ & indiferente \\
Interesse & $\mathrm{x}<1500$ & $100<\mathrm{y}<800$ & $\mathrm{~d}<50$ \\
\hline
\end{tabular}

* Considerando a menor distância entre a maior centroide encontrada pertencente à escala Hounsfield de tecidos moles (300 a 600 Hounsfield).

Fonte: Autor.

Aplicando o cálculo de probabilidade condicional da equação 4.6 a partir da tabela de conhecimento 3 sobre as características $c_{n}$ obtidas para cada região encontrada pela técnica de Crescimento de Regiões, é obtida a probabilidade da determinada região pertencer ou não a uma região de interesse. Caso não pertença, a região é substituída por uma região de escala Hounsfield equivalente ao ar (-1000 HU).

Dessa forma, a aplicação do classificador probabilístico atua com um caráter de filtro de macro ruídos na imagem, eliminando regiões que possam ser geradas por artefatos como cabelos e estrutura de apoio do tomógrafo.

A figura 13 apresenta o resultado da filtragem por Crescimento de Regiões Probabilístico, onde o item a) apresenta a imagem de entrada, previamente filtrada por Difusão Anisotrópica, b) a classificação de cada região encontrada em diferentes intensidades e c) as regiões remanescentes após a decisão do classifica- 
dor Naive Bayes.

Figura 13: Filtragem por Crescimento de Regiões Probabilístico.

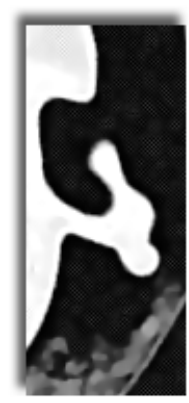

a)

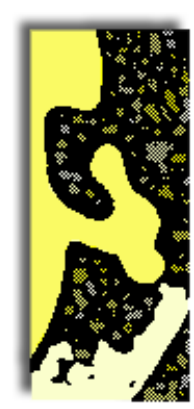

b)

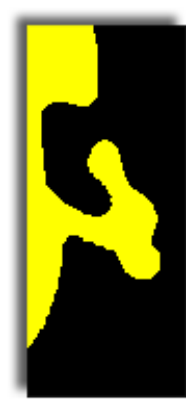

c)

a) Imagem de entrada.

b) Classificação de regiões.

c) Regiões remanescentes após o classificador bayesiano.

Fonte: Autor.

\subsection{Segmentação de Imagens}

\subsubsection{Método de Contornos Ativos "Snake"}

A segmentação por contornos ativos "Snake" (KASS; WITKIN; TERZOPOULOS, 1988) funciona através uma curva matematicamente definida composta por pontos de controle que atuam para formar um contorno deformável que, sob a influência de algumas forças, ajustam interativamente seu formato sobre uma região de interesse da imagem. De forma geral, é uma técnica robusta de segmentação pois seu método envolve cálculos geométricos, físicos e uma determinada capacidade de generalização.

A técnica é caracterizada por um contorno que atua iterativamente para alcançar a região de interesse através de forças pelas quais o contorno é submetido. A figura 14 ilustra seu funcionamento.

O modelo originalmente apresentado propõe a definição de um contorno inicial 
Figura 14: Contorno Ativo "Snake".

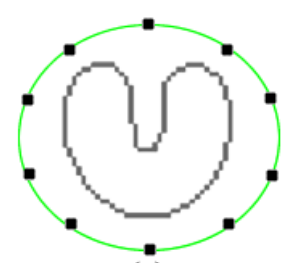

(a)

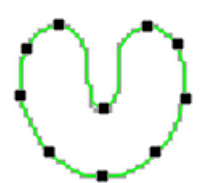

(b)

a) Imagem com contorno em verde arbitrariamente pré-definido.

b) Contorno convergido sobre as bordas da imagem.

Fonte: Autor.

arbitrário. O contorno, definido por $v(s)=[x(s), y(s)]$, é associado com uma energia que define seu comportamento. Esta energia é composta de duas partes, a energia interna e a energia externa.

$$
E_{\text {snake }}=\int_{0}^{1} E_{\text {interna }}(v(s))+E_{\text {externa }}(v(s))
$$

A energia interna $E_{\text {interna }}$, intrínseca à geometria da curva, considera aspectos físicos como a elasticidade e curvatura e representa sua capacidade de se deformar sob a ação da atração entre os pontos de controle do contorno. Essa energia atua como uma força que representa a capacidade do contorno se retrair independente da região de interesse.

A energia externa $E_{\text {externa }}$ é derivada da imagem e determina a força que guia a direção do contorno em relação ao vetor normal de cada um de seus pontos de controle. Ou seja, é a força que atrai o contorno para as bordas da imagem.

Dessa forma, a energia total $E_{\text {snake }}$ é a combinação dessas energias pela qual o contorno ativo busca a minimização de forma iterativa da equação 4.7, buscando seu equilíbrio sobre as bordas da imagem. Dada a característica da minimização de energias da equação 4.7, outras energias podem ser anexadas à equação de forma a oferecer flexibilidade e customização ao comportamento do contorno ativo 
(KASS; WITKIN; TERZOPOULOS, 1988).

\subsubsection{Energia Interna}

A energia interna é obtida a partir do contorno em si e seu objetivo principal é possibilitar uma deformação uniforme. É composta por duas outras energias (elástica e curvatura) e é calculada pelas posições dos pontos vizinhos, a equação 4.8 apresenta sua composição.

$$
E_{\text {interna }}=\alpha(s)\left|\frac{d v}{d s}\right|^{2}+\beta(s)\left|\frac{d^{2} v}{d s^{2}}\right|
$$

O primeiro termo da equação é relacionado a energia de elasticidade e o segundo representa a energia curvatura do contorno. Em ambos os termos há coeficientes ( $\alpha$ e $\beta$ respectivamente) para controle de comportamento do contorno. No primeiro termo, quando uma determinada parte do contorno apresenta uma grande distância entre os pontos, seu valor é alto. No segundo termo, quando alguma região do contorno é flexionada (dobrada), seu valor tende a ser alto. Dessa forma, o ajuste dos coeficientes permite ponderar de forma determinística as duas características do contorno.

$\mathrm{Na}$ representação discreta, a energia elástica é composta por $\mathrm{N}$ pontos $\left(p_{1}, p_{2}, \ldots, p_{n}\right)$ em $\mathbb{R}^{2}$ e pode ser calculada conforme equação 4.9 .

$$
E_{\text {elastica }}=\left\|p_{i}-p_{i-1}\right\|^{2}
$$

Para a energia de curvatura, a representação discreta é dada pela equação 4.10 .

$$
E_{\text {curvatura }}=\left\|p_{i-1}-2 p_{i}+p_{i+1}\right\|^{2}
$$


Como mencionado anteriormente, a solução do contorno objetiva a minimização das energias e, portanto a energia interna fará com que o contorno procure regiões que suavizam e contorne as bordas uniformemente.

\subsubsection{Energia Externa}

A energia externa $E_{\text {externa }}$ é responsável por atrair o contorno para as bordas da imagem e é derivada da própria imagem. É calculada através do inverso da magnitude do gradiente da imagem $I$, como nas equações 4.11 ou 4.12.

$$
E_{\text {externa }}=-|\nabla I(x, y)|^{2}
$$

ou,

$$
E_{\text {externa }}=-\left.\left[G_{\sigma}(x, y) * I(x, y)\right]\right|^{2}
$$

A proposta da segunda equação (4.12) é voltada para aplicação de uma convolução gaussiana de forma a suavizar ruídos que eventualmente poderiam interferir e gerar energia externa em regiões indesejadas. Entretanto, o valor de $\sigma$ utilizado com o propósito de reduzir ruídos pode causar um borramento excessivo na imagem, diminuindo o gradiente das bordas. Assim, como no estudo apresentado por Gil et al. (2006), este trabalho faz o uso de uma filtragem prévia por Difusão Anisotrópica (PERONA; MALIK, 1990) ao invés da convolução gaussiana, a qual possui a característica de manter a nitidez nas regiões de borda e removendo ruídos. Portanto, foi optada pela equação 4.11 do inverso da magnitude do gradiente.

A representação do sinal negativo da energia externa, conforme equações 4.11 e 4.12, é devido a seu cálculo ser derivado do gradiente e dessa forma, regiões com gradiente alto deverão ter energia baixa. A figura 15 ilustra o resultado do cálculo 
da energia externa.

Figura 15: Representação da energia externa.

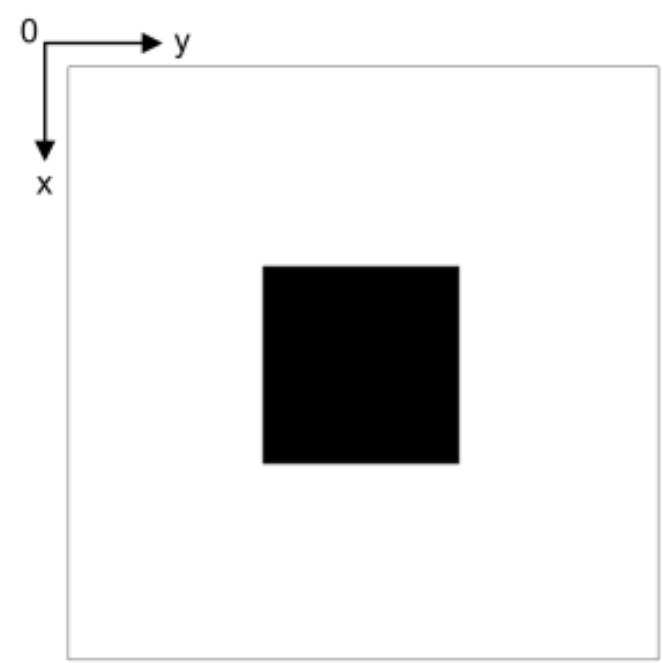

(a)

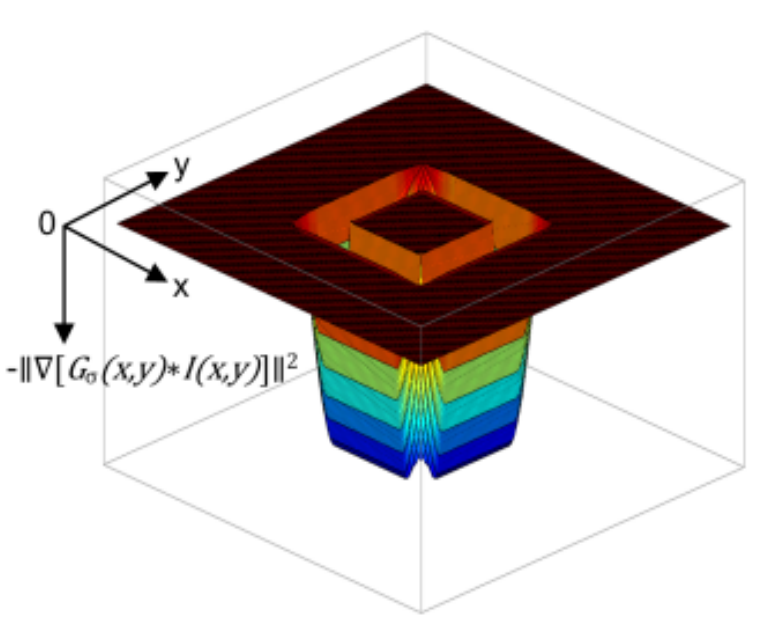

(b)

a) Imagem original.

b) Energia externa derivada da equação 4.12 .

Fonte: Autor.

\subsubsection{Energia Total}

A partir de um contorno inicial arbitrário, a solução é obtida pela minimização iterativa da energia total. A minimização é dada pela descida de gradiente, onde, para cada passo da iteração os pontos de controle buscam a região com menor energia local. A minimização pode ser representada como na equação 4.13.

$$
\min \int_{0}^{1} \alpha E_{\text {elastica }}+\beta E_{\text {curvatura }}+\gamma E_{\text {externa }}
$$

Na representação da equação 4.13, a energia interna é separada em duas partes $\left(E_{\text {elastica }}\right.$ e $\left.E_{\text {curvatura }}\right)$ para permitir a aplicação de coeficientes específicos ( $\alpha$ e $\beta$ respectivamente).

A minimização da soma das energias para cada ponto de controle é feita 
gradualmente. A cada passo da iteração é calculada a energia interna entre cada ponto e seus respectivos cálculos de fluxo em relação a energia externa. Assim, o menor valor encontrado da soma de energias é a nova posição do ponto de controle. Para todas $\eta$ iterações, as novas posições dos pontos são determinadas e o contorno alcança as bordas quando a soma das energias é convergida e se torna estacionária.

A implementação numérica da minimização é dada por:

- Selecionar as $N$ posições iniciais $p_{1}, p_{2}, \ldots, p_{N}$

- Atualizar posições $p_{1}, p_{2}, \ldots, p_{N}$ enquanto não convergir, conforme equação 4.14 .

$$
p_{k} \leftarrow p_{k}-\lambda \frac{\partial}{\partial p_{k}} \sum\left[\alpha\left|p_{i}-p_{i-1}\right|^{2}+\beta\left|p_{i-1}-2 p_{i}+p_{i+1}\right|^{2}-\gamma\left[G_{\sigma}(x, y) * \nabla I\right]^{2}\right]
$$

\subsubsection{Problemas do Contorno Ativo}

A técnica de contorno ativos "Snakes" originalmente proposta por Kass, Witkin e Terzopoulos (1988) apresenta algumas limitações de convergência:

- No caso de regiões homogêneas, onde a variação de intensidade é zero, o contorno deverá se deformar apenas sob as energias internas, pois não haverá energia externa atraindo o contorno em direção às bordas. Isso pode causar erros de convergência principalmente em regiões côncavas, pois o contorno possivelmente poderá se estabilizar antes de atingir a borda;

- A presença de ruídos e/ou artefatos na imagem poderá parar a deformação do contorno antes da região de interesse; 
- Os pontos iniciais do contorno deverão ser inicializados arbitrariamente próximos as bordas da imagem, caso contrário não serão atraídos na direção correta.

\subsubsection{Fluxo do Vetor Gradiente}

O método de Fluxo do Vetor Gradiente (GVF)(PRINCE, 1997) apresenta uma nova formulação para o cálculo de energia externa capaz de minimizar os problemas do método original de inicialização arbitrária, convergência em regiões côncavas e tolerância a ruídos. Isto é feito através da difusão do vetor gradiente por nas duas direções $(x, y)$ e por toda a matriz da energia externa. O GVF difere fundamentalmente na energia externa, onde um cálculo de difusão-reação através de equação diferencial parcial é feito com o objetivo de espalhar a energia por toda a imagem.

A primeira etapa do GVF é a formação do mapa das bordas através da obtenção do gradiente da convolução gaussiana com a imagem, conforme equação 4.15 .

$$
f(x, y)=\left|\nabla\left[G_{\sigma}(x, y) * I(x, y)\right]\right|
$$

onde $\sigma$ é parametrizado conforme grau de necessidade de suavizar ruídos na imagem. Entretanto, uma filtragem por Difusão Anisotrópica mais efetiva é realizada previamente na fase de pré-processamento, conforme detalhado na seção 4.1.1.1. E dessa forma, a convolução gaussiana da equação 4.15 é suprimida, resultando na equação 4.16 .

$$
f(x, y)=|\nabla I(x, y)|
$$


O vetor gradiente $\nabla f$ resultante do mapa de bordas possui vetores em direção às bordas, entretanto está presente somente nas regiões próximas as bordas, como ilustrado na imagem 16. A obtenção do mapa de bordas pode ser feita pelas derivativas horizontais e verticais através de qualquer método de detecção de bordas. Foi utilizado o operador de Sobel para a extração das derivativas por ser amplamente utilizado na área.

Figura 16: Vetor gradiente em destaque.
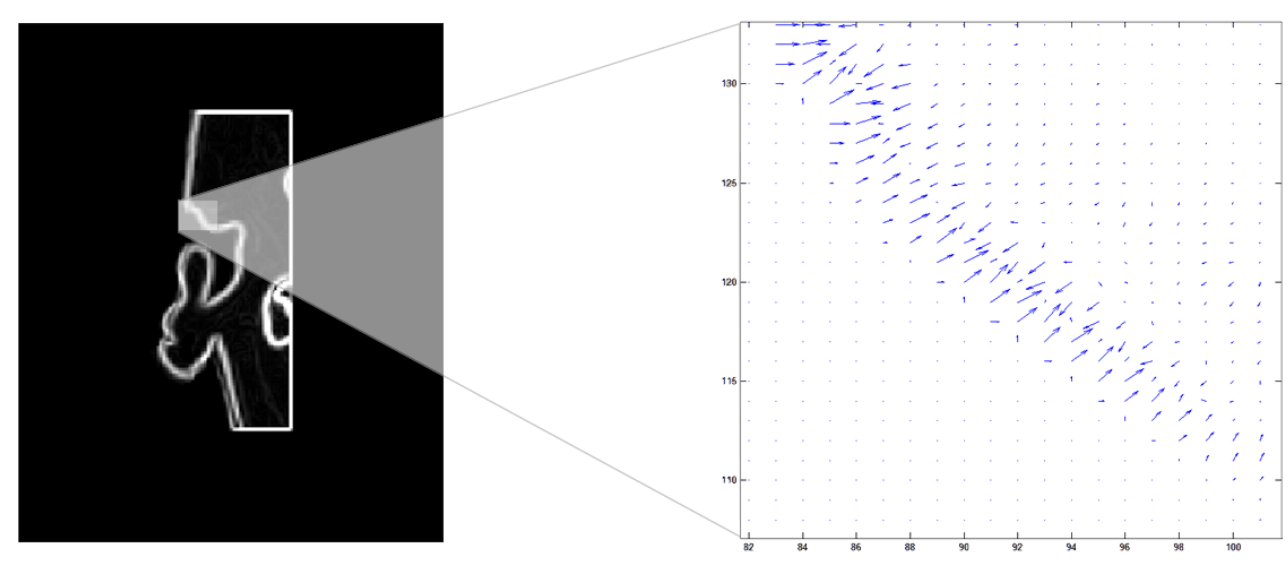

Fonte: Autor.

A difusão deste vetor gradiente por toda a imagem é dada pela função de minimização de energia descrita pela equação 4.17 e resulta no Fluxo do Vetor Gradiente, definido por $g(x, y)=(u(x, y), v(x, y))$.

$$
E=\iint \mu\left(u_{x}^{2}+u_{y}^{2}+v_{x}^{2}+v_{y}^{2}\right)+|\nabla f|^{2}|g-\nabla f|^{2} d x d y
$$

onde, $u$ é a componente vertical e $v$ a componente horizontal do gradiente calculadas pelas derivadas parciais. Quando o termo $|\nabla f|$ possui um valor baixo, ou seja, pouca variação de intensidade, a energia é dominada pelas derivadas parciais do vetor gradiente, difundindo o vetor gradiente uniformemente. Por outro lado, quando o valor de $|\nabla f|$ é alto, o segundo termo da equação prevalece, tornando a energia alta e por consequência não propagando a difusão dos vetores. 
Isto produz o efeito da manutenção do vetor de fluxo $g$ em regiões com alto gradiente e difunde os vetores em regiões homogêneas. O parâmetro $\mu$ controla a relação entre os dois termos da equação e é ajustado proporcionalmente com a quantidade de ruído aditivo presente na imagem (XU; PRINCE, 1998). Como sugerido por Xu e Prince (1998), o valor de $\mu$ utilizado foi 0.2 .

Através de cálculo numérico, a Equação Diferencial Parcial pode ser redefinida com $u$ e $v$ em função das iterações $t$, conforme apresentado em 4.18 e 4.19 .

$$
\begin{aligned}
& u_{t}(x, y, t)=\mu \nabla^{2} u(x, y, t)-\left[u(x, y, t)-f_{x}(x, y)\right] \cdot\left[f_{x}(x, y)^{2}+f_{y}(x, y)^{2}\right] \\
& v_{t}(x, y, t)=\mu \nabla^{2} v(x, y, t)-\left[v(x, y, t)-f_{y}(x, y)\right] \cdot\left[f_{x}(x, y)^{2}+f_{y}(x, y)^{2}\right]
\end{aligned}
$$

onde, $\nabla^{2}$ é divergente do gradiente calculado pelo operador laplaciano e $f_{x}$ e $f_{y}$ são as componentes verticais e horizontais do gradiente respectivamente.

Fundamentalmente, as equações 4.18 e 4.19 podem ser associadas as equações de difusão generalizadas, originalmente utilizadas pela equação da condução de calor, dispostas em função do tempo $t$. A quantidade de iterações $t$ pode ser definida arbitrariamente ou através de uma condição de convergência, que no caso, quando a diferença entre $u_{t}(t)$ e $u_{t}(t-1)$ for igual a zero.

A figura 17 apresenta a evolução do processo de difusão dos vetores em duas etapas $(t=0$ e $t=100)$ e seu resultante em convergência total.

Conforme mencionado anteriormente, a difusão ocorre por toda imagem, inclusive dentro da região a ser segmentada, onde as regiões internas também possuem energia externa alta, conforme ilustrado na figura 18. 
Figura 17: Fluxo do Vetor Gradiente em etapas.

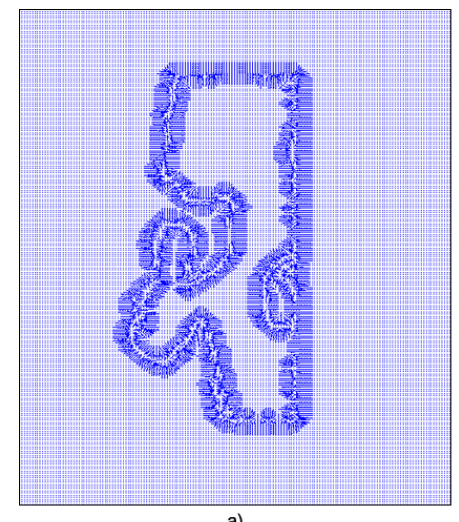

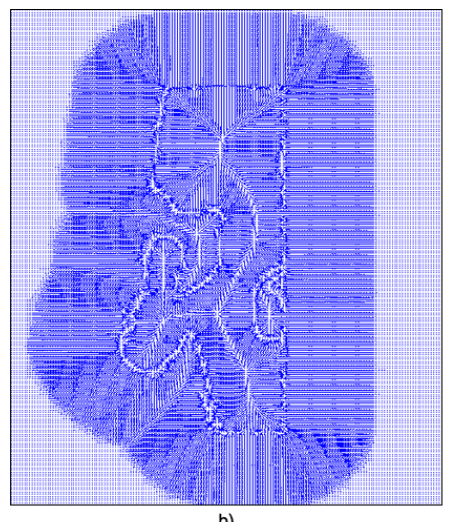

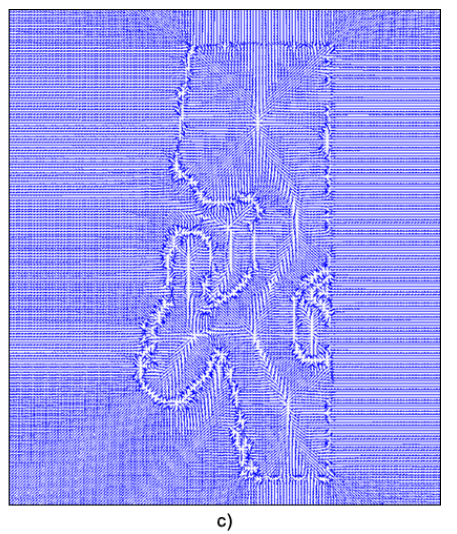

a) Gradiente em $t=0$.

b) Gradiente em $t=100$.

c) Convergência em $t=210$.

Fonte: Autor.

Figura 18: Ampliação dos vetores gradiente sobre uma região de borda.

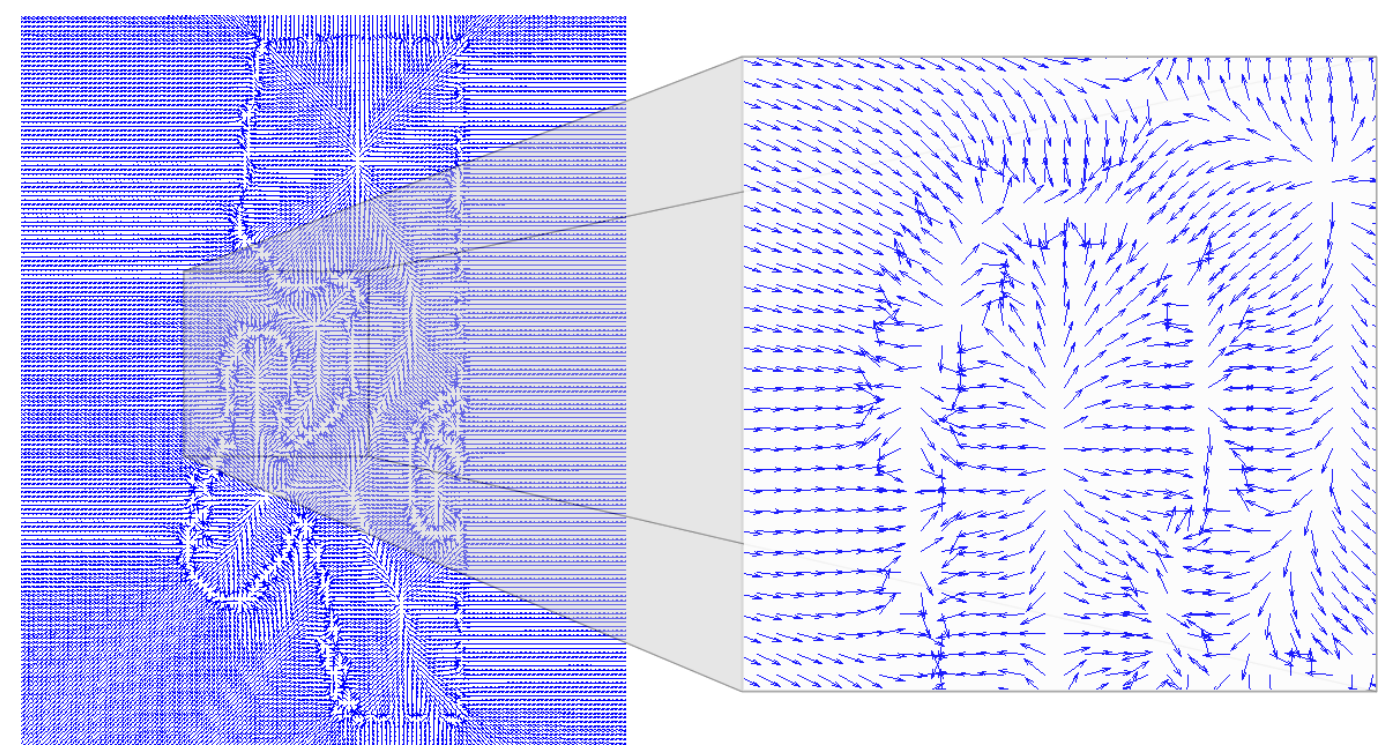

Fonte: Autor.

\subsubsection{Implementação}

O cálculo do campo vetorial é iniciado a partir do mapa das bordas, o qual é gerado pelo operador de gradiente Sobel para derivativas horizontal $F_{x}$ e vertical $F_{y}$, conforme: 


$$
F_{x}=\left[\begin{array}{ccc}
-1 & -2 & -1 \\
0 & 0 & 0 \\
+1 & +2 & +1
\end{array}\right], F_{y}=\left[\begin{array}{ccc}
-1 & 0 & +1 \\
-2 & 0 & +2 \\
-1 & 0 & +1
\end{array}\right]
$$

A partir do mapa das bordas, o operador Laplaciano é aplicado iterativamente e o cálculo da difusão é feito para todos os pontos do mapa, conforme ilustrado na figura 17. A implementação da difusão do vetor de fluxo é ilustrada pelo algoritmo 2 .

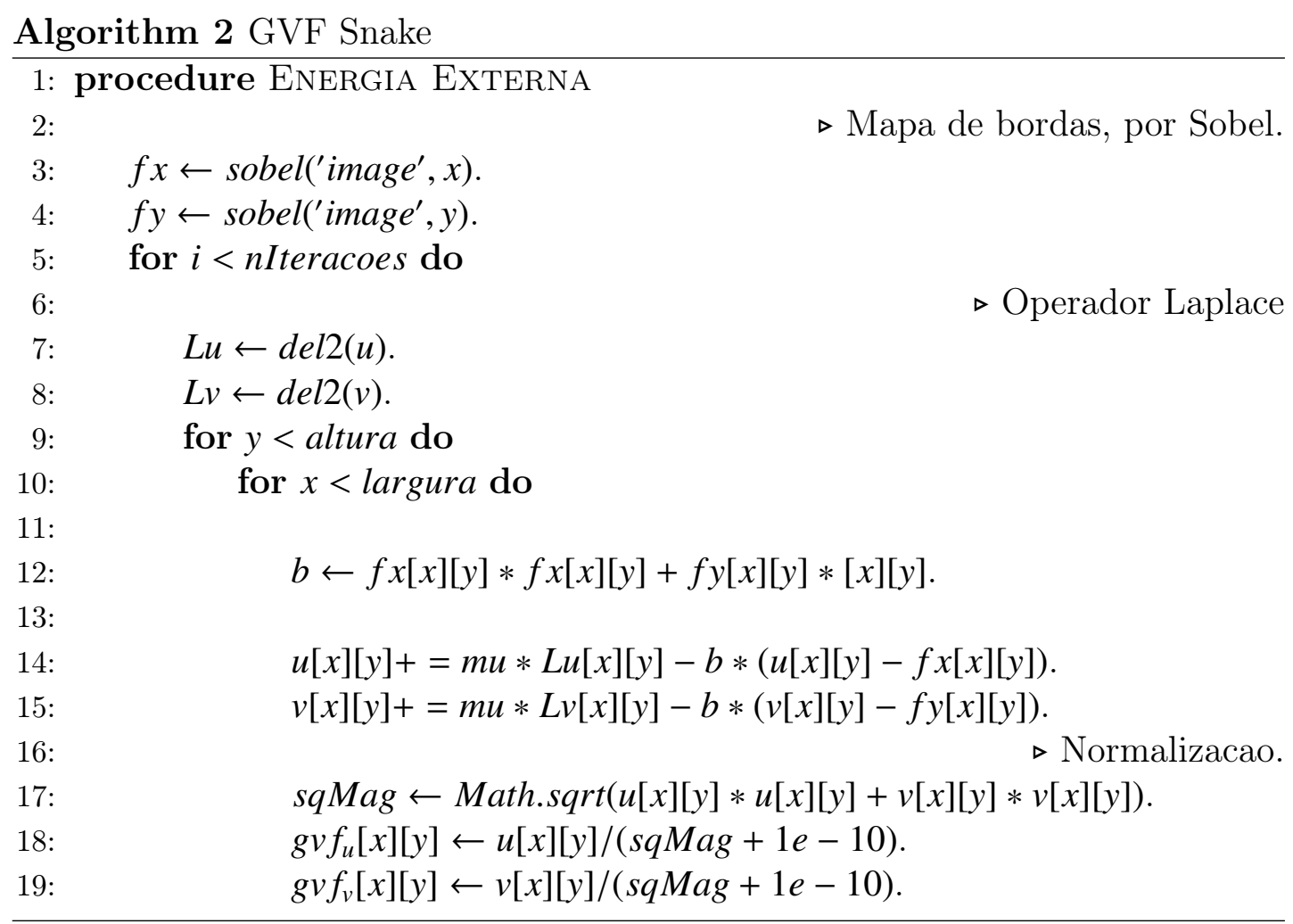

Após o vetor de fluxo gradiente estar propagado por toda a imagem, o contorno inicial é definido automaticamente de forma circular, com centro posicionado no centro da imagem e com diâmetro da largura da imagem, conforme ilustrado na figura 20 a). 


\subsubsection{Convergência}

Com o contorno inicial definido, a função de minimização de energias é executada iterativamente até a convergência. Para cada ponto de controle é calculada a energia total para todas as suas possíveis direções. A figura 19 ilustra este cálculo e a convergência do ponto sobre a borda da imagem. A primeira imagem (a) apresenta o contorno em $s(i)$ e a convergência do contorno sobre as bordas da imagem em $s(i+1)$ é ilustrada em (b). Os pontos em azul na imagem são relacionados a energia total calculada para cada uma das possibilidades de movimento e a intensidade de cada ponto representa a minimização da energia total. Os pontos em verde ilustram os pontos de controle da "Snake" e a sua convergência é dada quando a menor energia total é obtida em sua posição atual.

Figura 19: Convergência do GVF.
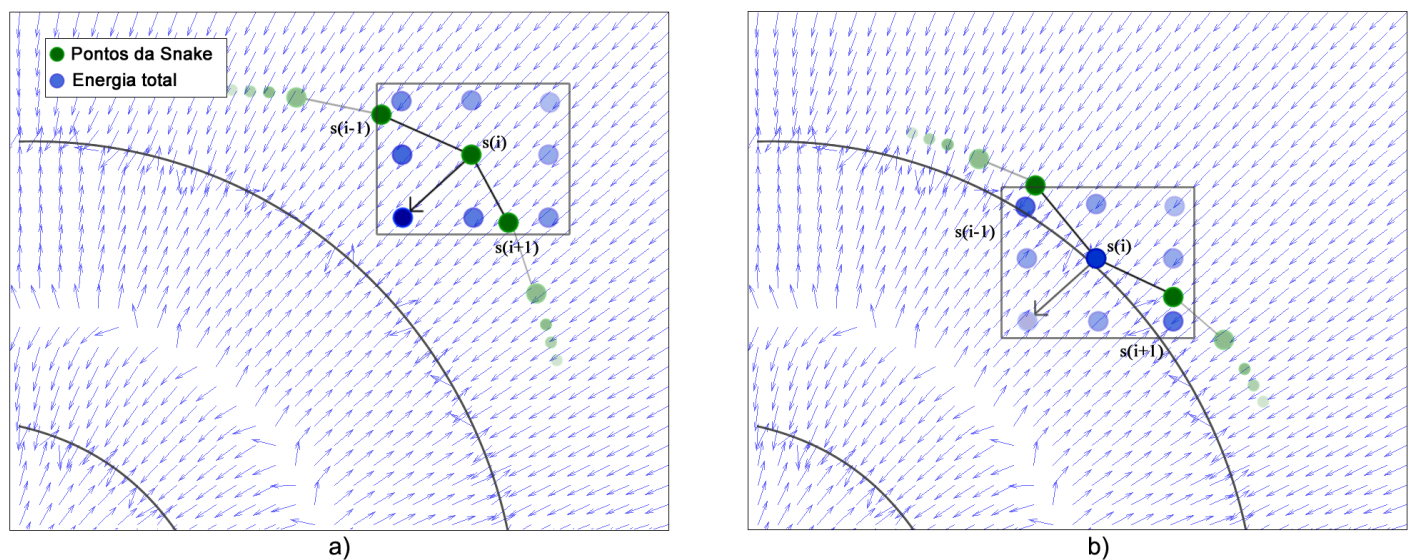

b)

a) Contorno ativo em $s(i)$.

b) Convergência do contorno ativo sobre a borda da imagem.

Fonte: Autor.

Dessa forma, a próxima posição de um determinado ponto de $s(i)$ é a posição onde haverá menor energia total conforme minimização pela descida de gradiente, vide equação 4.13. A minimização é realizada para todos os pontos de controle e a convergência total se dá pela estabilização do contorno e dessa forma é obtida a segmentação da região de interesse, conforme figura 20. 
Figura 20: Convergência em imagem real.

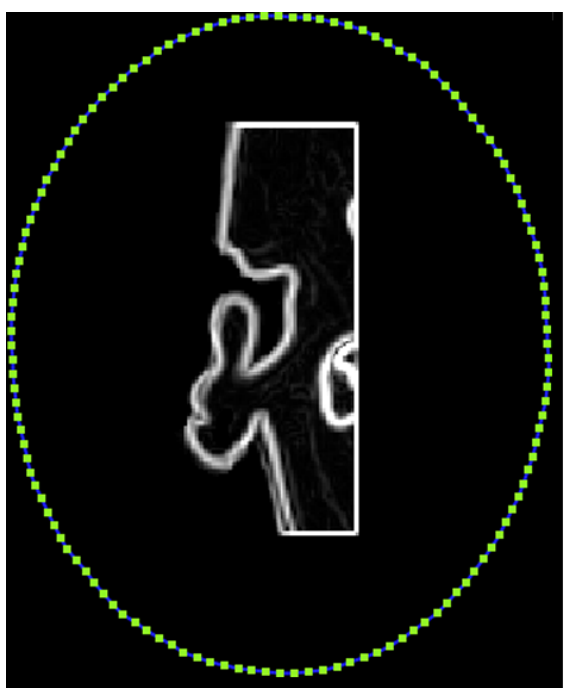

a)

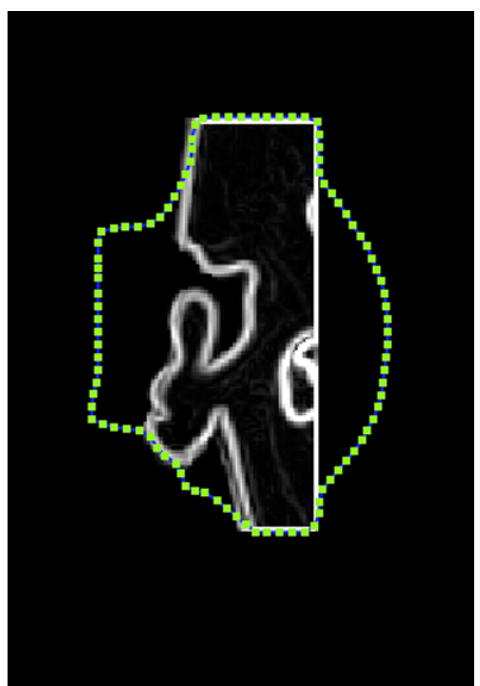

b)

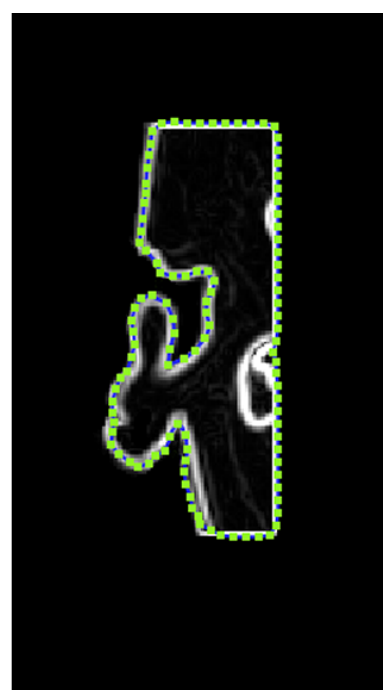

c)

a) Contorno inicial arbitrário.

b) Contorno em $s(30)$.

c) Contorno ativo convergido sobre a região do pavilhão auricular.

Fonte: Autor.

Ao final da minimização de energia o contorno ativo representa geometricamente a região de interesse segmentada. O processo é realizado para todas as demais camadas da imagem DICOM, entretanto, o contorno inicial arbitrário é definido uma única vez e é estabelecido apenas na camada intermediária do conjunto de imagens DICOM. Para as camadas subsequentes, o contorno inicial é definido pelo contorno final da camada antecessora, ou seja, o contorno final obtido na camada acima ou abaixo é aproveitado como uma estimativa inicial mais precisa, reduzindo o tempo computacional e minimizando possíveis erros de segmentação.

O resultado obtido é composto por $n$ imagens bidimensionais com a região do pavilhão auricular segmentada, conforme ilustrado pela figura 21. 
Figura 21: Segmentação do conjunto de imagens DICOM por contorno ativo "Snake" com GVF
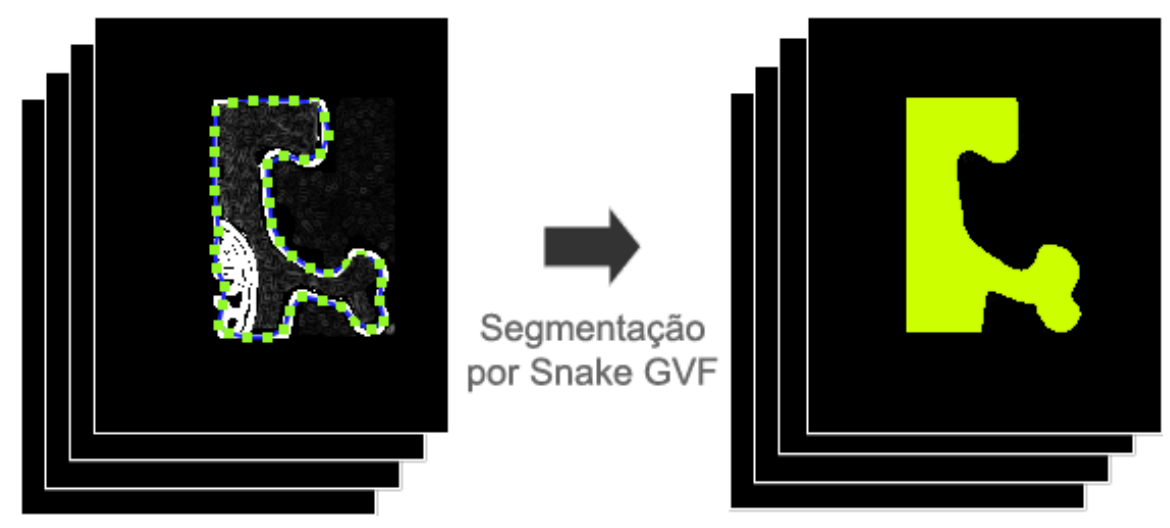

Fonte: Autor.

\subsection{Reconstrucao Tridimensional}

\subsubsection{Reconstrução Tridimensional de Superfícies}

O resultado obtido da etapa de processamento de imagens é um conjunto de imagens binárias bidimensionais representando o pavilhão auricular em camadas axiais. As camadas, ou secções horizontais, são então combinadas entre si e transformadas em uma geometria tridimensional composta por uma malha de triângulos que compreende a superfície do objeto. A esta transformação se dá o nome de Reconstrução Tridimensional de Superfícies.

A reconstrução da geometria tridimensional combina os valores dos pixels entre as camadas de forma a encontrar um triângulo que intercepte os pixels de acordo com sua intensidade. A técnica utilizada por este trabalho para reconstrução de superfície é conhecida como Marching Cubes, proposta por Lorensen e Cline (1987).

A técnica utiliza uma abordagem de divisão e conquista na qual uma célula equivalente a um cubo é alinhada de acordo com 8 pixels do conjunto de imagens, 4 da camada inferior e 4 da camada superior. Para cada posicionamento possível 
em todo o conjunto de imagens são verificadas as intersecções entre cada uma de suas 12 arestas. O valor de cada um dos 8 pixels é comparado e verificado se faz parte da intersecção. Ao todo, são 256 formas possíveis $\left(2^{8}\right)$ da combinação das possibilidades dos 8 pixels intersectarem as arestas.

As intersecções são combinadas de forma a criar um polígono dentro desta célula. Desconsiderando os polígonos repetidos por rotações e reflexões simétricas, restam 15 possibilidades únicas, ilustradas na figura 22 .

Figura 22: As 15 possibilidades de intersecção da célula, desconsiderando rotação reflexões simétricas.
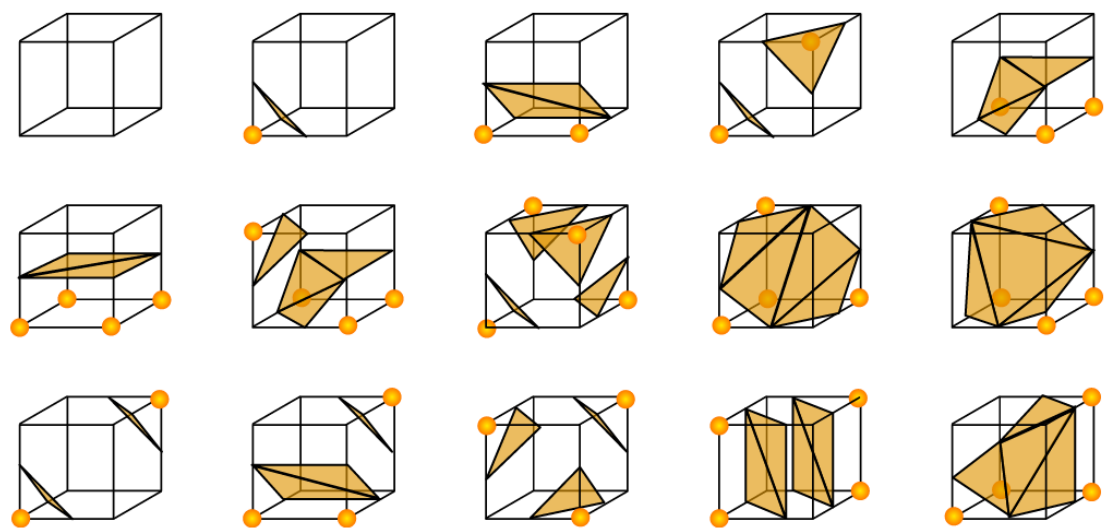

Fonte: Adaptado de Lorensen e Cline (1987).

Finalmente, conforme a classificação, polígonos são gerados para cada uma das posições possíveis da célula no conjunto de imagens. Os polígonos são compostos por triângulos interligados, resultando em uma superfície uniforme, ou uma isosuperfície. A figura 23 ilustra o resultado obtido pelo método Marching Cubes.

\subsubsection{Suavização de Malhas Tridimensionais por Laplace}

Conforme visto na seção 4.3.1, a técnica de reconstrução tridimensional utiliza-se de $n$ imagens bidimensionais para a composição do modelo tridimensional. Essa estratégia resulta em relevos no modelo tridimensional principalmente 
Figura 23: Modelo tridimensional com destaque para a superfície formada por uma malha de triângulos

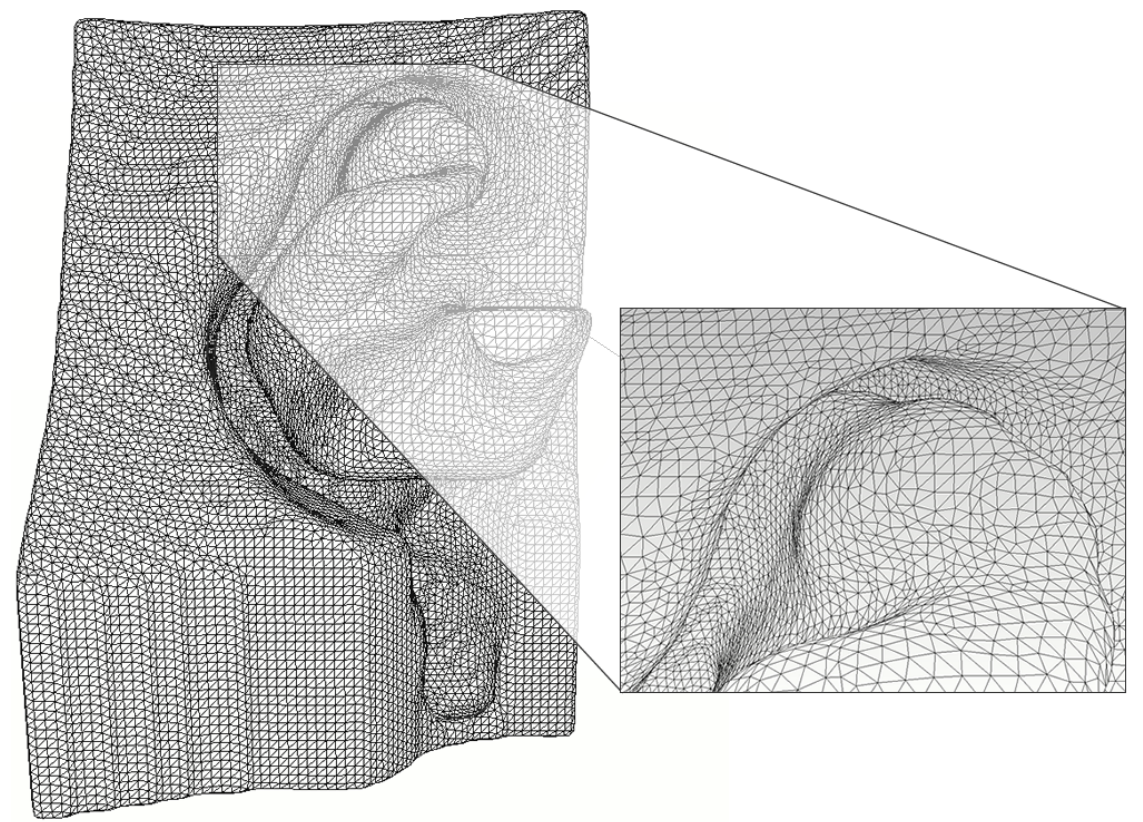

Fonte: Autor.

relacionados à distância entre as imagens 2D e a resolução espacial das imagens. Dessa forma, o modelo 3D do molde gerado pode apresentar artefatos em sua superfície devido à esta distância. Além disso, há também regiões irregulares na superfície da malha de triângulos causadas por ruídos ou falhas pontuais no processo de segmentação. A figura 24 apresenta um modelo tridimensional resultante da reconstrução tridimensional com uma distância de $2 \mathrm{~mm}$ entre camadas.

Um método amplamente utilizado para suavizar malhas tridimensionais é a suavização por Laplaciano discreto. A ideia básica do processo é de que os vértices de uma malha são incrementalmente movimentados na direção de seu operador Laplaciano através de uma difusão. A versão diferencial da difusão da suavização é dada pela equação 4.20.

$$
\frac{\partial M}{\partial t}=\lambda L(M)
$$


Figura 24: Modelo tridimensional com destaque para os relevos na superfície causados pela distância entre camadas

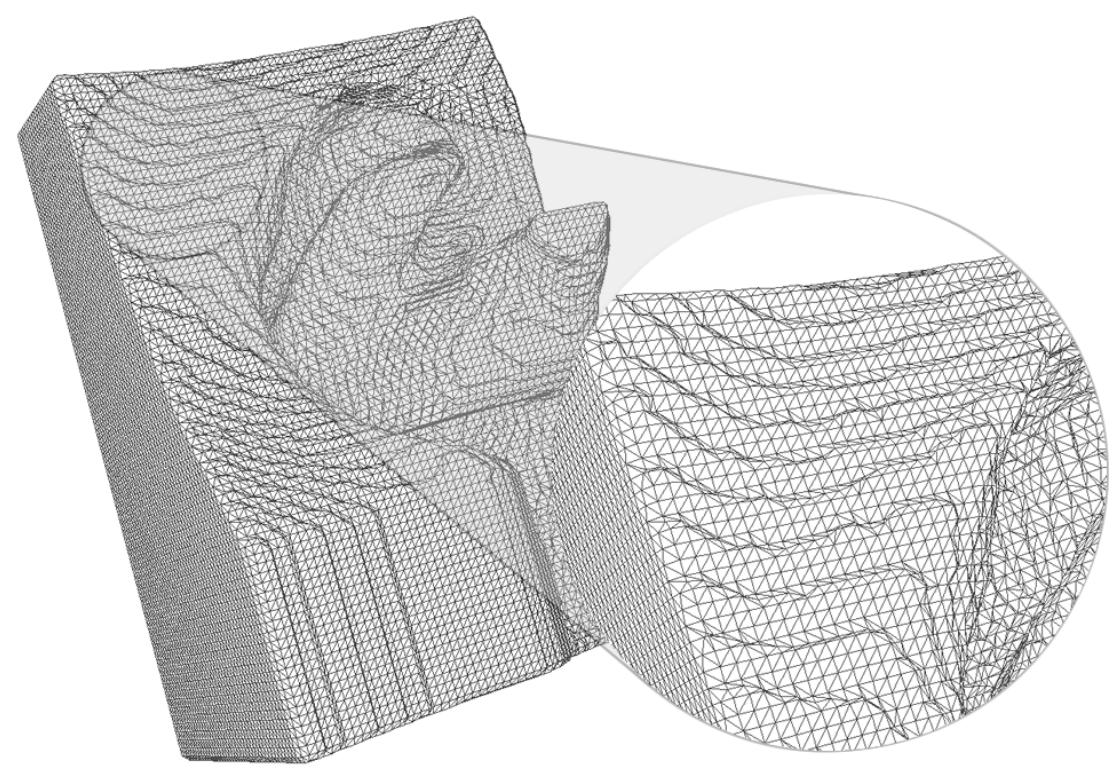

Fonte: Autor.

onde, $M$ representa a malha, $\lambda$ é um fator escalar de controle da difusão e $L$ o operador Laplaciano determinado pela equação 4.21 .

$$
L\left(v_{i}\right)=\sum_{v_{j} \subset v_{i}} w_{i j}\left(v_{i}-v_{j}\right)
$$

onde, $v_{i}$ um vértice qualquer, $v_{j} \subset v_{i}$ todos vértices $v_{j}$ diretamente conectados com $v_{i}$ e $w_{i j}$ é o peso da aresta $\overline{v_{i} v_{j}}$. O peso da aresta foi determinado uniformemente entre os vértices $\left(w_{i j}=1 / \eta_{v}\right)$ e essa forma é conhecida como Laplaciano discreto uniforme. Fundamentalmente, a posição de cada vértice é movimentada para a posição média dos vértices adjacentes.

A representação do operador discreto em espaço bidimensional $\mathbb{R}^{2}$ pode ser 
dada como na equação 4.22 .

$$
p_{i}^{(t+1)}=p_{i}^{(t)}+\lambda L\left(p_{i}^{(t)}\right)
$$

onde, $p_{i}$ é um ponto na posição $i$ de um determinado polígono e $t$ a discretização em função do tempo. Neste caso, o operador discreto uniforme assume peso 1/2 pela divisão equivalente entre as arestas. A figura 25 ilustra o comportamento do método, onde é possível notar a suavização do polígono.

Figura 25: Comportamento do Laplaciano discreto uniforme em um polígono $P$

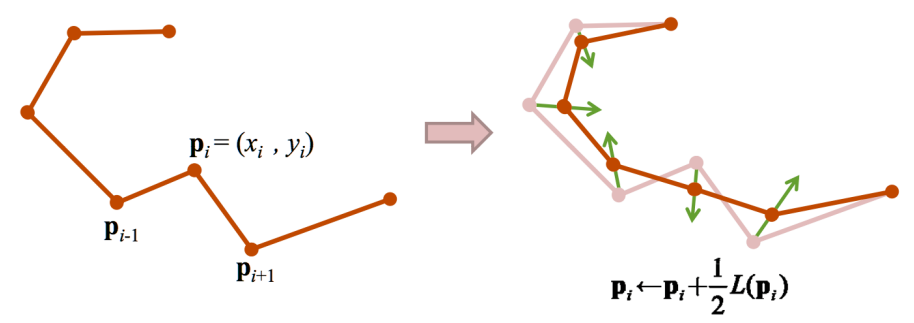

Fonte: Autor.

Na representação em espaço euclidiano n-dimensional definido em $\mathbb{R}^{3}$, o comportamento do Laplaciano discreto para um determinado ponto $p_{i}$ pode ser observado na figura 26 .

Figura 26: Representação do comportamento do operador Laplaciano em malha tridimensional

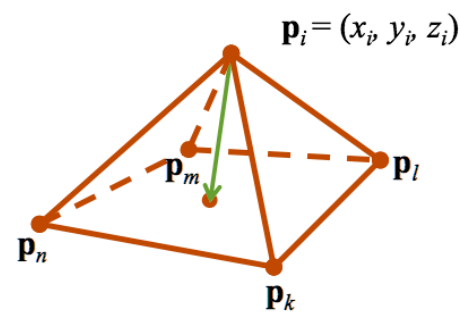

Fonte: Autor.

A suavização pelo Laplaciano discreto, dada sua propriedade de posiciona- 
mento pela média, resulta em um aspecto de triangulação homogêneo. Uma outra propriedade importante do método é a preservação das conexões dos vértices, a cada passo os vértices são movimentados, nenhum vértice é adicionado ou removido, preservando a isosuperfície.

Entretanto, como a difusão é realizada uniformemente, regiões de bordas e cantos da malha podem ser distorcidas ou encolhidas pela característica de triangulação sem critérios. A quantidade de iterações pela qual a malha é submetida é o fator ponderante à distorção.

Foi adicionado ao método duas funcionalidades visando evitar deformações em regiões importantes da orelha e aumentar a velocidade de processamento.

A primeira funcionalidade torna o método dependente de escala através do uso de pesos inversamente proporcionais à distância entre os vértices adjacentes. Este operador laplaciano ponderado é conhecido como operador de Fujiwara (FUJIWARA, 1995) e está apresentado na equação 4.23. O principal benefício desse operador é a preservação da distribuição das dimensões dos triângulos, minimizando potenciais deformações no modelo. Por ser um operador laplaciano combinado com uma característica local de cálculo de peso o operador não é linear. A cada iteração o operador é recalculado conforme os vértices se movem e a iteração chega ao final quando não há mais aproximações a serem realizadas.

$$
L_{p}(M)=\frac{1}{\sum l_{j}} \sum \frac{Q_{j}-P}{l_{j}}
$$

A segunda funcionalidade adicionada é a diminuição do passo da iteração proporcionalmente à quantidade de modificações que são realizadas na iteração. Ou seja, no início do processo de suavização, quando os triângulos são reposicionados com mais velocidade, o passo é maior, permitindo um ganho de velocidade no processo; quando o reposicionamento dos vértices dos triângulos diminui de 
frequência, o passo da iteração é também diminuído possibilitando que ajustes finos de reposicionamento sejam realizados. Este cálculo é feito sobre o desvio padrão dos reposicionamentos conforme a equação 4.24 .

$$
s_{i}=\sigma t+0,1
$$

onde, $\sigma$ t é o desvio padrão da quantidade de reposicionamento dos vértices e a constante 0,1 é o passo mínimo da iteração do método de Jacobi para solução laplaciana. A figura 27 ilustra a sua aplicação em um modelo tridimensional de um molde (item a) e seu resultado (item b).

Figura 27: Aplicação da suavização por Laplace dependente de escala.

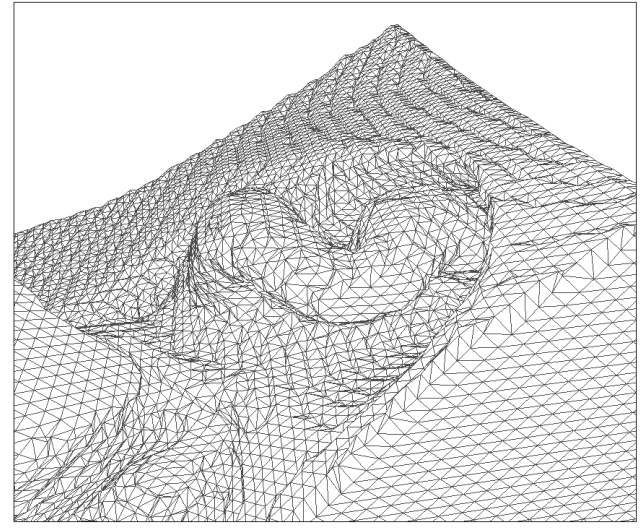

a)

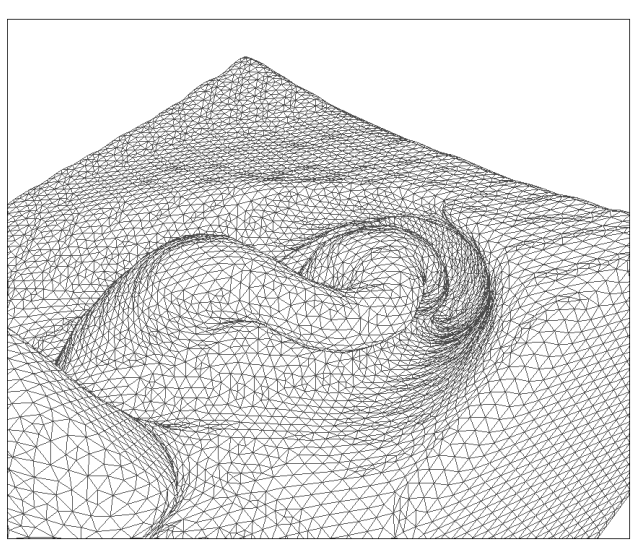

b)

a) Modelo tridimensional original.

b) Modelo após a suavização de malhas por Laplace dependente de escala.

Fonte: Autor.

O método laplaciano com operador dependente de escala apresenta estabilidade geométrica, onde a convergência é obtida pela estabilização do cálculo de pesos de acordo com comprimento das arestas. O passo de iteração muito alto poderia causar uma falha na convergência final, pois o método pode atingir mínimos locais (DESBRUN et al., 1999). A funcionalidade adicionada para diminuição do passo da iteração inversamente proporcional à frequência de reposicionamento 
suprime a eventualidade de mínimos locais, pois o passo da iteração é diminuído até o seu valor mínimo antes da convergência.

\subsection{Fabricação do Molde}

Dentre as estratégias de Manufatura Aditiva, a FFF foi escolhida para uso neste trabalho na fabricação dos moldes por apresentar maior acessibilidade e menor custo de material. Equipamentos desta tecnologia e seus materiais são facilmente encontrados no mercado nacional e com valores menores se comparado as demais tecnologias. A tabela 4 apresenta um comparativo entre as estratégias considerando o equipamento mais acessível encontrado e também uma estimativa dos custos de aquisição e de seus materiais.

Tabela 4: Tabela comparativa entre estratégias de Manufatura Aditiva.

\begin{tabular}{cclccc}
\hline Estratégia & Equipamento & Fabricante & Custo equipamento*** & Custo material* & Resolução $(\mu m)$ \\
\hline SLA & ProJet 3510 SD & 3DSystems & $\mathrm{U} \$ 69.500,00$ & $\mathrm{U} \$ 185,00$ & 25 \\
LOM & MCor Iris & MCor & $\mathrm{U} \$ 48.000,00$ & $\mathrm{U} \$ 36,00$ & 100 \\
SLS & Projet 6000 SLS & 3DSystems & $\mathrm{U} \$ 207.000,00$ & $\mathrm{U} \$ 19,60$ & 50 \\
3D InkJet & Objet24 & Stratasys & $\mathrm{U} \$ 21.450,00$ & $\mathrm{U} \$ 32,00$ & 28 \\
FFF & 3D Cloner ST & Microbras & $\mathrm{R} \$ 5.195,00$ & $\mathrm{R} \$ 7,80^{* *}$ & 50 \\
& & & & \\
\hline
\end{tabular}

Valores obtidos no período entre janeiro e março de 2015.

* Considerando a estimativa para um objeto de 100 gramas.

** Considerado o material ABS $1.75 \mathrm{~mm}$.

*** Custos Free On Board (FOB) - é designação utilizada para quando o remetente do produto é responsável pelos custos de envio e seguro até o momento de embarque para exportação.

Fonte: Autor.

\subsubsection{Material}

Atualmente é possível encontrar diversos tipos de materiais disponíveis para uso em FFF. Essa diversidade se dá pelo propósito de aplicação, variando entre materiais acrílicos transparentes, compostos mistos de madeira e termoplásticos, poliésteres com capacidade elástica, dentre outros. Dentre os materiais disponí- 
veis, os termoplásticos mais comuns são o Acrilonitrila Butadieno Estireno (ABS) e o Poliácido Láctico (PLA). Ambos são amplamente utilizados em impressão 3D e possuem características físicas semelhantes, como dureza, resistência e temperatura de fusão.

Foi optado por este trabalho o ABS como material para a fabricação dos moldes por permitir um tratamento superficial com um solvente não tóxico. Este tratamento está detalhado na seção 4.4.2.

O ABS é um copolímero sintético derivado de três monômeros: acrilonitrila, butadieno e estireno. Por ser um termoplástico, em temperatura ambiente se apresenta em estado sólido e conforme submetido a temperaturas próximas ao seu ponto de fusão (entre 200 e 250 graus Celsius) sua viscosidade aumenta gradualmente, permitindo sua moldagem e/ou manipulação.

Sua fórmula química é $\mathrm{C}_{8} \mathrm{H}_{8}, \mathrm{C}_{4} \mathrm{H}_{6}$ ou $\mathrm{C}_{3} \mathrm{H}_{3} N$, e a proporção de cada componente na composição varia conforme utilização final do produto, podendo alterar sua flexibilidade e dureza. O resultado físico deste polímero é um material termoplástico rígido ${ }^{2}$ e leve ${ }^{3}$, com estabilidade dimensional e resistência na absorção de impacto. É amplamente utilizado em produtos industrializados, como em brinquedos Lego (The Lego Group, Dinamarca) e no setor automotivo.

De acordo com a revisão sistemática apresentada por Rutkowski e Levint (1986), o ABS possui relativa toxicidade apenas em condições de combustão (acima de 500 graus), onde libera os gases Cianeto de Hidrogênio (HCN) e Monóxido de Carbono $(\mathrm{CO})$. Em seu estado sólido, o ABS não apresenta níveis toxicológicos e de acordo com o Food and Drug Administration (FDA) ${ }^{4}$ é permitido para uso em contato direto com alimentos.

\footnotetext{
${ }^{2}$ Dureza Rockwell: R105

${ }^{3}$ Densidade 1,060 a $1,080 \mathrm{~g} / \mathrm{cm}^{3}$

${ }^{4}$ Code of Federal Regulations, seção 177.1020, abril de 2014, FDA, EUA.
} 


\subsubsection{Processo de Tratamento de Superfície}

Em quase todas as estratégias de Manufatura Aditiva, a superfície dos objetos produzidos apresenta uma determinada rugosidade inerente ao processo de fabricação. Essa rugosidade é proveniente do processo de fabricação por camadas, onde a cada camada o material depositado ou sinterizado forma um "degrau", conforme ilustrado na figura 28. A altura desse desnível é variante à técnica utilizada e no trabalho em questão foi utilizada a resolução de 100 micrômetros entre camadas.

Figura 28: Desníveis inerentes ao processo de Manufatura Aditiva por camadas

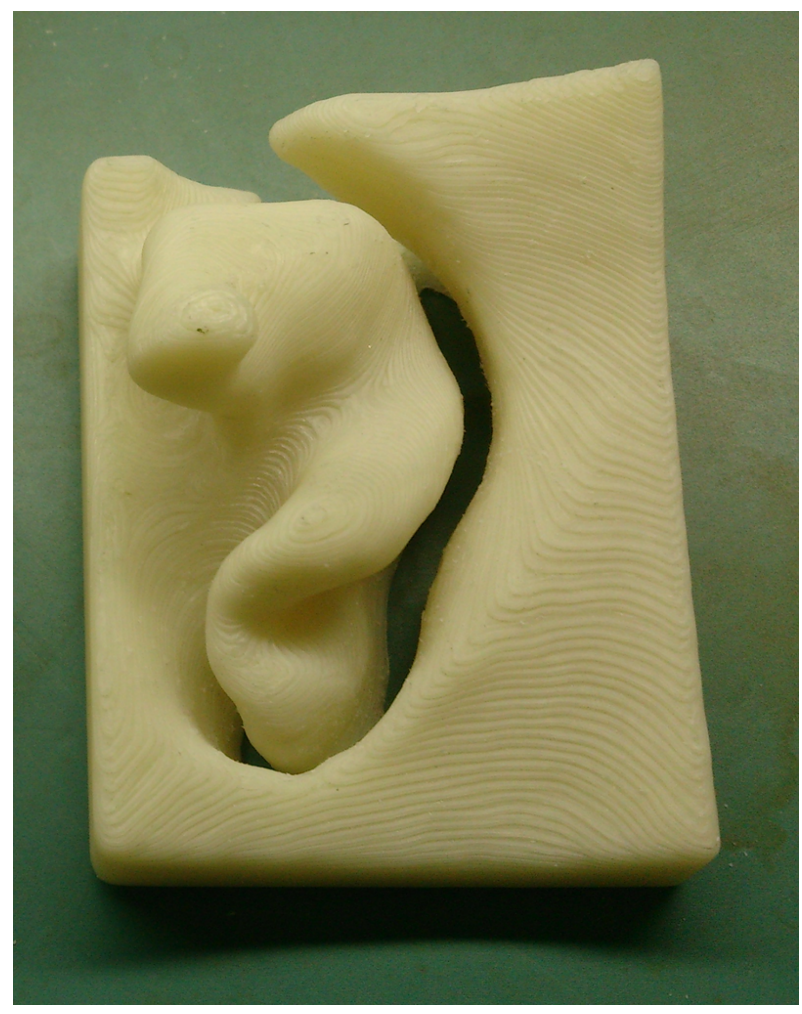

Fonte: Autor.

De forma a inibir a propagação destes desníveis para a prótese, um processo de suavização superficial é aplicado ao molde. Não foi considerada a alternativa de tratamento superficial por meios mecânicos e/ou manuais, o que poderia resultar naturalmente em falta de precisão. 
A utilização de solventes reativos oferece um método flexível para alteração das características físicas de polímeros termoplásticos para além dos seus limites existentes (MEIJER et al., 1996). Os solventes atuam nas forças intermoleculares dos polímeros, atraindo estas forças ao solvente conforme sua absorção, e assim permitindo que as moléculas se movimentem. A capacidade de movimentação das moléculas é proporcional a concentração de solvente absorvido pelo polímero, e dessa forma é possível realizar um controle sobre o processo.

As forças intermoleculares ditam o estado da matéria e a solubilidade em um solvente. Conforme a concentração e o tempo de exposição ao solvente, o polímero tem sua viscosidade aumentada, permitindo que suas moléculas se movimentem e se posicionem de acordo com algumas forças, dentre elas, a tensão superficial.

A absorção gradual do solvente a partir da superfície do polímero permite que esse posicionamento aconteça a partir da superfície em direção ao centro do objeto, resultando em uma acomodação das moléculas pela tensão superficial, e dessa forma, suavizando a superfície.

A aplicação de solventes em baixa pressão de vapor apresenta eficiência e controle no processo de suavização de superfícies de polímeros (MüLLERBUSCHBAUM et al., 2001). A maior eficiência em relação ao controle do processo se dá pela utilização do solvente em vapor, tornando a interação com polímero uniforme em toda superfície aparente.

Dessa forma, a escolha do solvente para suavização superficial do molde em ABS seguiu os critérios de toxidade e acessibilidade. A opção pelo critério toxicológico é devido a não exposição de riscos à saúde aos especialistas e pacientes envolvidos.

Os critérios toxicológicos adotados foram de acordo com o Guidance for In- 
dustry $^{5}$ do Food and Drug Administration (FDA) do Departamento de Saúde e Serviços Humanos dos EUA. A tabela 5 apresenta a classificação dos solventes de acordo com sua toxicologia, onde a classificação é apresentada de forma crescente de acordo com os riscos envolvidos.

Tabela 5: Classificação de solventes conforme sua toxicologia.

\begin{tabular}{lc}
\hline Solvente & Classificação \\
\hline Acetona $\mathrm{C}_{3} \mathrm{H}_{6} \mathrm{O}$ & 3 \\
Clorofórmio $\mathrm{CHCl}$ & 2 \\
Tetrahidrofurano $\mathrm{C}_{4} \mathrm{H}_{8} \mathrm{O}$ & 2 \\
Tolueno $\mathrm{C}_{7} \mathrm{H}_{8}$ & 2 \\
\hline
\end{tabular}

Fonte: Food and Drug Administration (FDA), EUA.

A listagem abaixo apresenta a definição das classes obtidas:

- Classe 2: inclui solventes com limitação apenas a produtos farmacêuticos devido sua toxicidade inerente.

- Classe 3: inclui solventes sem perigo a saúde humana em níveis normalmente aceitos.

Devido a classificação apresentada a Acetona $\mathrm{C}_{3} \mathrm{H}_{6} \mathrm{O}$ em concentração $100 \%$ foi adotada para o processo de tratamento do molde. Conforme eficiência e estabilidade da aplicação de solventes em baixa pressão de vapor descrito por MüllerBuschbaum et al. (2001), foi optado pela utilização do solvente em forma gasosa utilizando um dessecador hermético com diâmetro de 160mm disposto sobre uma mesa aquecedora com temperatura controlada, conforme apresentado pela figura 29.

\footnotetext{
${ }^{5}$ Guidance for Industry, segunda revisão, fevereiro de 2012, Food and Drug Administration (FDA), EUA.
} 
Figura 29: Disposição do ambiente para suavização superficial, composto por um dessecador hermético disposto sobre uma mesa aquecedora

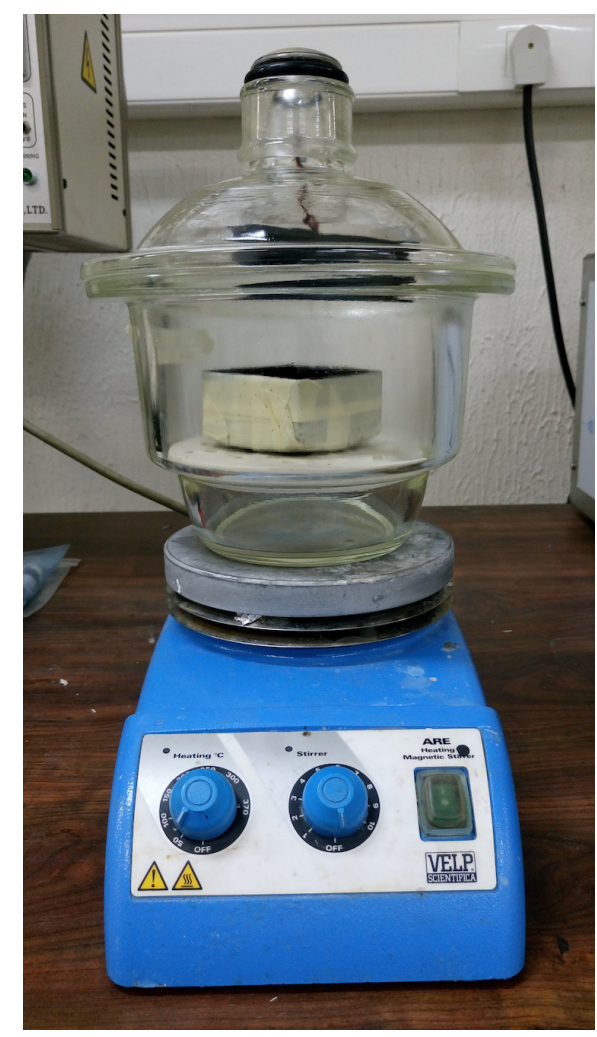

Fonte: Autor.

A Acetona possui o ponto de ebulição a $56^{\circ} \mathrm{C}$ e esta foi a temperatura utilizada na mesa aquecedora. O molde foi disposto sobre a plataforma cerâmica do próprio dessecador, evitando o contato com o solvente no estado líquido.

A proporção de solvente necessária para suavizar um molde foi determinada através de um cálculo de regressão linear sobre uma análise experimental. Para o experimento foram fabricados 21 moldes de um mesmo caso clínico, divididos em 3 grupos. Cada grupo foi experimentado com 7 diferentes quantidades de solvente. A análise teve como objetivo encontrar a menor quantidade de solvente capaz de suavizar a peça cujo o índice de rugosidade - média aritmética das alturas da superfície $\left(S_{a}\right)$ do Geometric Product Specifications (GPS) do ISO 25178 - fosse menor que $7,88 \mu \mathrm{m}$. A escolha do valor determinado para $S_{a}$ foi 
baseada em Htsuki, Akamaki e Ominaga (2013), onde foi realizado um estudo de sobre a rugosidade da pele humana e a região amostral com menor rugosidade obtida para $S_{a}$ foi 7,88 $\mu \mathrm{m}$. Foi obtida a proporção de $0,435 \mathrm{ml}$ de acetona em concentração $100 \%$ para cada $\mathrm{cm}^{2}$ de área de superfície do molde. Os testes de rugosidade para a obtenção de $S_{a}$ foram realizados por um perfilômetro ótico digital. O processo é de tratamento superficial é encerrado ao final da ebulição total da Acetona.

Após a primeira análise experimental, o cálculo de quantidade mínima de solvente por $\mathrm{cm}^{2}$ foi reavaliado em um segundo experimento, contendo 5 moldes de diferentes casos clínicos. Em todos os casos foram obtidos valores menores que $7,88 \mu m$ para $S_{a}$.

A seção de 5.5 Análise Física do capítulo 5 apresenta os resultados visuais obtidos e uma análise técnica de rugosidade.

Ao final do processo de tratamento superficial o molde está apto para receber a injeção de silicone para a elaboração da prótese. O silicone utilizado foi o A2186, Factor $\mathrm{II}^{\mathrm{tm}}$, Lakeside, EUA, cujo o tempo de cura é de 1 hora a $50^{\circ} \mathrm{C}$. 


\section{RESULTADOS}

Neste capítulo serão apresentados os resultados obtidos com a metodologia proposta aplicada a dois casos clínicos de pacientes da Faculdade de Odontologia da Universidade de São Paulo. Um terceiro caso clínico experimental também foi realizado pelo método, porém aplicado à elaboração de uma prótese facial. Inicialmente, a aplicação da técnica de segmentação foi orientada à segmentação da região auricular principalmente pela sua geometria complexa, no entanto, sua aplicação pode ser expandida para outros casos clínicos, conforme experimento com a prótese facial.

Os pacientes e/ou responsáveis assinaram um termo de consentimento para a participação experimental no projeto de pesquisa, permitindo que seus exames de tomografia computadorizada fossem utilizados.

A aplicação do procedimento foi realizada nos seguintes casos clínicos: ARF, 14 anos, sexo feminino, com perda total do pavilhão auricular direito por decorrência acidental; KSS, 6 anos, sexo masculino, com má formação congênita no pavilhão auricular esquerdo e RL, 59 anos, sexo masculino, com perda da região da face orbital e temporal do osso zigomático esquerdo, incluindo tecidos musculares adjacentes.

A tomografia computadorizada obtida do caso ARF compreende 181 imagens DICOM com resolução 512 por 512 pixels e com distância $0,8 \mathrm{~mm}$ entre camadas. O exame do caso KSS resultou em 116 imagens de mesma resolução e equidistan- 
tes por 2,0 $\mathrm{mm}$ e do caso RL é composto por 262 imagens com camadas de 1,5 mm e de mesma resolução.

Os dois primeiros casos (ARF e KSS), de prótese auricular, foram fabricados pelo procedimento proposto estão apresentados na figura 30, onde o item a) ilustra o molde do caso KSS e b) de ARF.

Figura 30: Moldes fabricados para os casos clínicos.

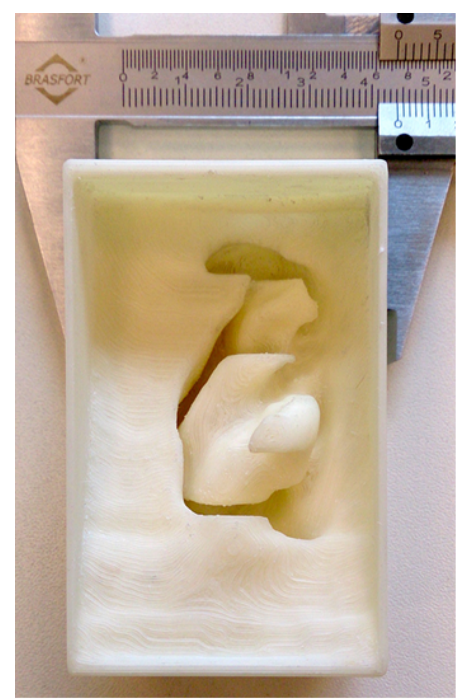

a)

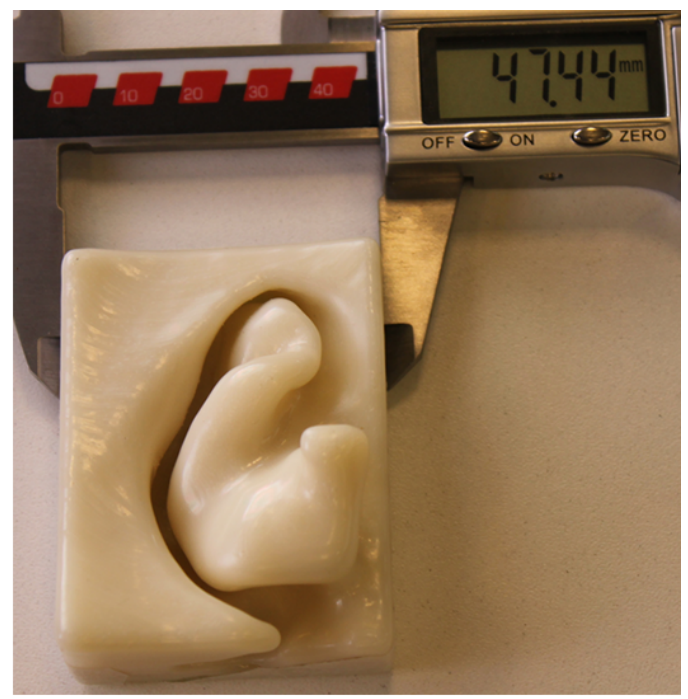

b)

a) KSS.

b) ARF.

Fonte: Autor.

O molde do terceiro caso clínico, feito de forma experimental, foi fabricado em duas partes divididas por um corte diagonal de forma a facilitar a injeção e desmoldagem, a figura 31 apresenta o molde do caso.

O método proposto possui aspectos voltados à automatização da elaboração de próteses através de técnicas computacionais, visando a não dependência de um especialista em modelagem 3D, como grande parte dos trabalhos correlatos citados, o que poderia tornar o processo ainda complexo e dependente de processos manuais. O tratamento de superfície realizado sobre o molde se diferencia dos demais trabalhos observados, permitindo que a prótese tenha um aspecto su- 
Figura 31: Molde para prótese facil do caso clínico RL

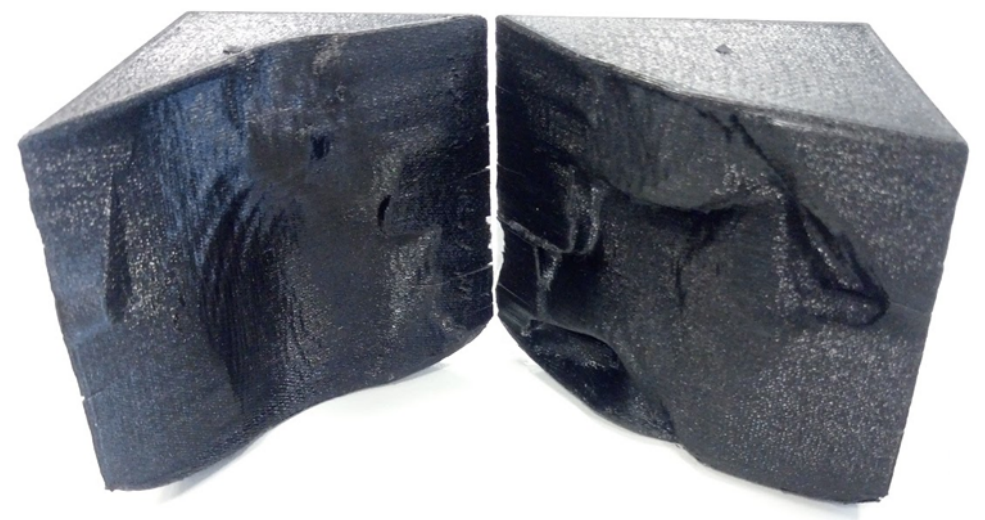

Fonte: Autor.

perficial liso. A tabela 6 apresenta uma correlação de características do presente estudo com os principais trabalhos correlatos observados.

Tabela 6: Correlação de características entre o presente trabalho e seus correlatos.

\begin{tabular}{|c|c|c|c|c|c|c|c|c|c|}
\hline & 1 & 2 & 3 & 4 & 5 & 6 & 7 & 8 & 9 \\
\hline Moldagem no paciente & $\mathrm{X}$ & $\mathrm{X}$ & & $\mathrm{X}$ & $\mathrm{X}$ & $\mathrm{X}$ & $\mathrm{X}$ & $\mathrm{X}$ & \\
\hline Muflagem & $\mathrm{X}$ & $\mathrm{X}$ & $\mathrm{X}$ & $\mathrm{X}$ & $\mathrm{X}$ & $\mathrm{X}$ & $\mathrm{X}$ & $\mathrm{X}$ & \\
\hline Reconstrução sobre TC & & & $\mathrm{X}$ & & & $\mathrm{X}$ & $\mathrm{X}$ & & $\mathrm{X}$ \\
\hline $\begin{array}{l}\text { Modelagem CAD manual } \\
\text { Tratamento de superfície }\end{array}$ & $\mathrm{X}$ & $\mathrm{X}$ & & $\mathrm{X}$ & $\mathrm{X}$ & $\mathrm{X}$ & $\mathrm{X}$ & $\mathrm{X}$ & $\mathrm{X}$ \\
\hline Reconstrução 3D automática & & & & & & & & & $\mathrm{X}$ \\
\hline Fabricação direta do molde & & & & & $\mathrm{X}$ & & & & $\mathrm{X}$ \\
\hline
\end{tabular}

1: Coward, Watson e Wilkinson (1999), 2: Mardini, Ercoli e Graser (2005), 3: Jiao et al. (2004), 4: Subburaj et al. (2007), 5: Ciocca et al. (2007), 6: Karayazgan-Saracoglu, Gunay e Atay (2009), 7: Karatas et al. (2011), 8: Watson e Hatamleh (2014), 9: Presente trabalho Fonte: Autor.

\subsection{Software}

A parte computacional teve como resultado um software de código fonte aberto $^{1}$, desenvolvido em linguagem de programação multi plataforma Java. O

\footnotetext{
${ }^{1}$ Disponível em https://github.com/emersonmoretto/snakegvf
} 
software recebe como parâmetro o conjunto de imagens DICOM, o usuário é responsável por marcar uma caixa de seleção sobre a região saudável e a partir daí o software realiza o processamento de imagens e a reconstrução tridimensional do molde de forma automática. Após o processamento, o software gera como saída um arquivo do tipo STL apto a ser materializado por impressora 3D. A figura 32 apresenta a interface principal do software, com as janelas de processamento, imagem original com a caixa de seleção do usuário e projeção 3D em tempo real do molde.

Figura 32: Interface do usuário para elaboração do molde

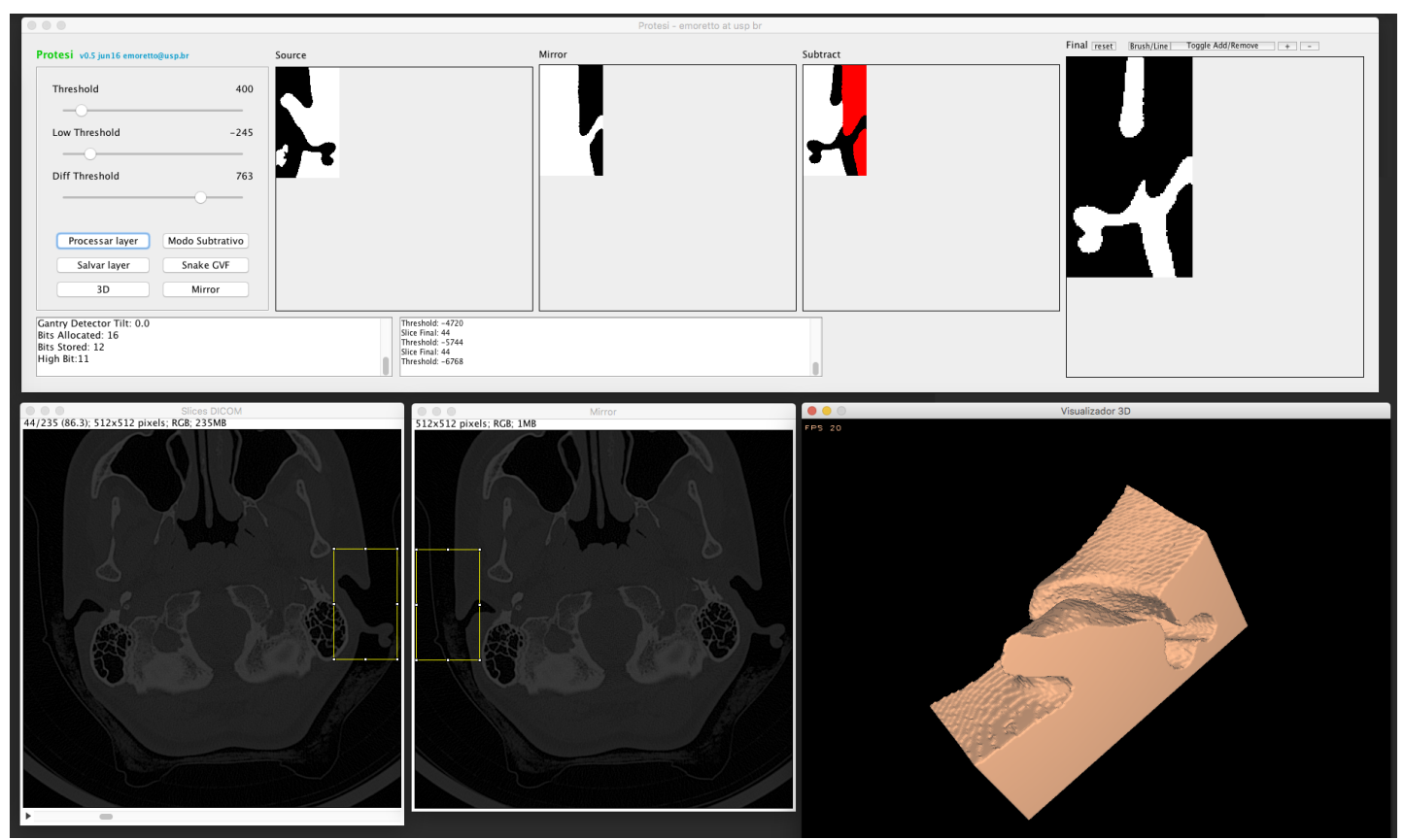

Fonte: Autor.

A segmentação por contorno ativo possui parâmetros para ajustes de comportamento do contorno. Para o trabalho em questão os valores padrões sugeridos por Prince (1997) resultaram numa segmentação correta. O software desenvolvido possui uma interface para redefinição dos parâmetros com o objetivo experimental, e a figura 33 apresenta esta interface de interação. A implementação do algoritmo foi validada com os parâmetros e imagens utilizadas pelo autor (PRINCE, 
1997) e não fora encontrada uma implementação prévia com código aberto em Java na Internet.

Figura 33: Interface do usuário para parametrização e segmentação da região de interesse

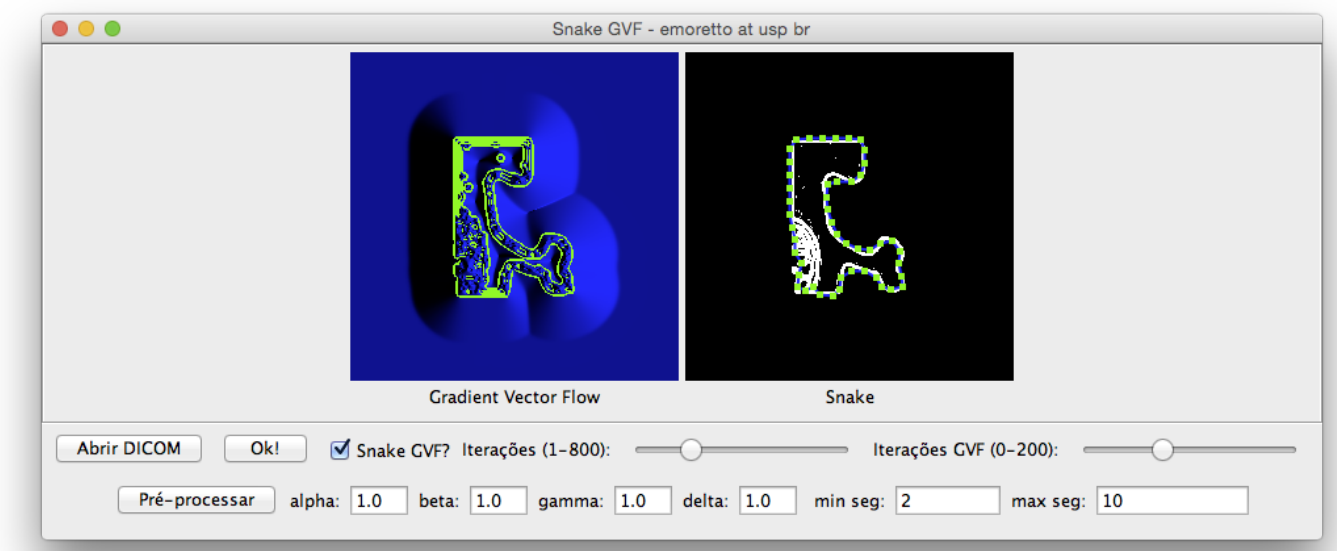

Fonte: Autor.

\subsection{Publicação}

Um artigo baseado no presente trabalho sob o título "Elaboração de próteses auriculares individualizadas por meio de manufatura auxiliada por computador" foi aceito e apresentado no Workshop de Informática Médica do XXXVI Congresso da Sociedade Brasileira de Computação (CSBC) e recebeu o prêmio de melhor trabalho completo do evento.

\subsection{Filtragem por Crescimento de Regiões Proba- bilístico}

A primeira etapa do processo computacional envolve a filtragem de ruídos e de regiões indesejadas. A técnica de Crescimento de Regiões Probabilístico para supressão de regiões que não fazem parte do pavilhão auricular foi aplicada 
e avaliada manualmente sobre um conjunto de 62 imagens de tomografia. Posteriormente, um segundo conjunto de 332 imagens foi objeto de uma avaliação automática, onde o resultado foi utilizado para a reconstrução tridimensional. Os modelos 3D obtidos foram verificados através de observação visual para avaliação da técnica. A adoção deste método de avaliação se dá pela maior facilidade na visualização do conjunto. A figura 34 apresenta três exemplos da aplicação da técnica. Os mesmos casos, sem a aplicação da remoção dos ruídos, falham na etapa seguinte de segmentação do pavilhão auricular e, portanto, a filtragem se apresenta fundamental para a correta segmentação do pavilhão auricular.

Figura 34: Aplicação do filtro de Crescimento de Regiões Probabilístico em três imagens de tomografia
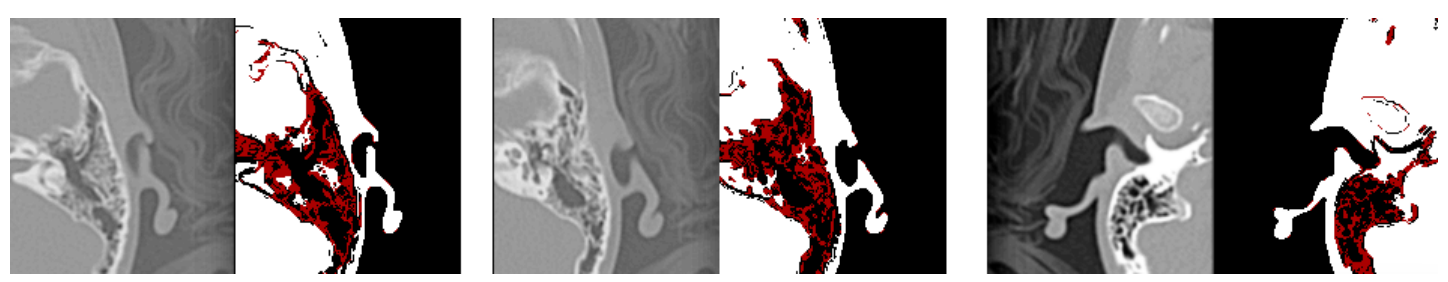

Fonte: Autor.

\subsection{Suavização de Malhas Tridimensionais}

A suavização de malhas tridimensionais pelo método laplaciano modificado para atuar dependente de escala foi utilizado com o objetivo de atenuar e/ou eliminar os desníveis causados pela distância entre as camadas das imagens DICOM. O operador adicionado ao método laplaciano discreto (detalhado na seção 4.3) busca limitar distorções no modelo tridimensional. De forma a avaliar este operador foi realizado o cálculo da Distância Hausdorff (CIGNONI; ROCCHINI; SCOPIGNO, 1998) que visa medir o quão distante dois subconjuntos de pontos no espaço de métrica estão um do outro. A escolha da Distância de Hausdorff se dá pelo seu amplo uso na computação gráfica para comparação de malhas tridi- 
mensionais e seu cálculo foi feito através do software aberto MeshLab (CIGNONI; CORSINI; RANZUGLIA, 2008). O cálculo de distância foi realizado utilizando o modelo tridimensional original não suavizado em relação aos modelos suavizados por Laplace discreto e por Laplace dependente de escala.

A tabela 7 apresenta os valores obtidos pela análise e através dela é possível observar uma diferença máxima de até 3,09 $\mathrm{mm}$ em um determinado ponto, o que pode ser considerado significativo se tratando de uma prótese auricular cujo o aspecto visual é um critério importante.

Tabela 7: Valores da Distância Hausdorff entre as técnicas de suavização

\begin{tabular}{ccc}
\hline Técnica & Máxima diferença & Valor eficaz (root mean square) \\
\hline Laplace discreto & 3,092838 & 0,424668 \\
Laplace dependente de escala & 1,34392 & 0,1319698 \\
\hline
\end{tabular}

Fonte: Autor.

A figura 35 apresenta a comparação do resultado obtido pela suavização aplicada ao molde tridimensional de $\mathrm{ARF}$, onde a) apresenta o modelo tridimensional original, b) suavização por laplaciano discreto e c) suavização por laplaciano dependente de escala.

É possível observar que técnica por Laplace discreto resulta em uma suavização não uniforme com regiões pontiagudas, que devido a ausência de ponderação em seu operador resulta em mínimos locais. Como não há um critério equilibrado para a movimentação dos vértices adjacentes alguns vértices acabam por se posicionarem muito próximos um dos outros. Esses vértices praticamente sobrepostos não são mais reposicionados pelo cálculo que considera apenas a média do posicionamento de seus vértices vizinhos, e dessa forma, sua próxima posição prevalece no mesmo ponto. Consequentemente, o vértice em questão permanece estático diferentemente dos seus adjacentes que continuam sendo reposicionados, resultando em uma região pontiaguda. A figura 36 destaca um desses pontos e é 
Figura 35: Suavização superficial do modelo 3D.

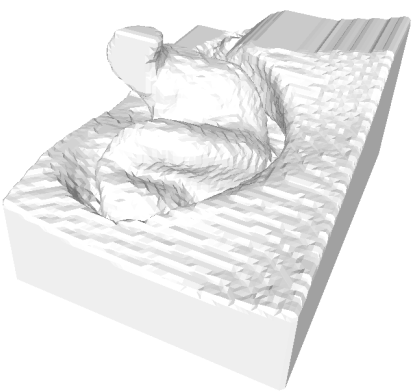

a)

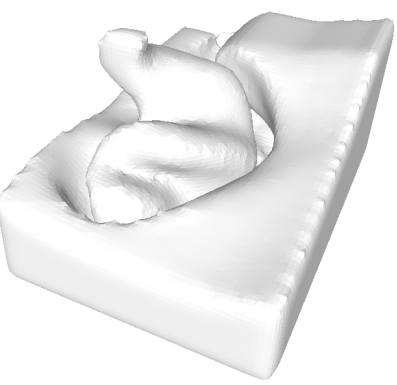

b)

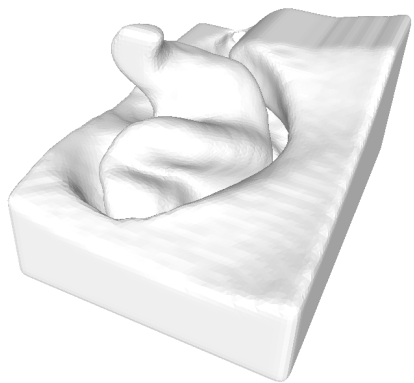

c)

a) Malha de triângulos obtida.

b) Malha de triângulos suavizada.

c) Modelo 3D obtido.

d) Modelo 3D suavizado.

Fonte: Autor.

possível observar uma concentração de vértices no ápice da região.

Figura 36: Destaque para as regiões pontiagudas resultantes do método laplaciano discreto

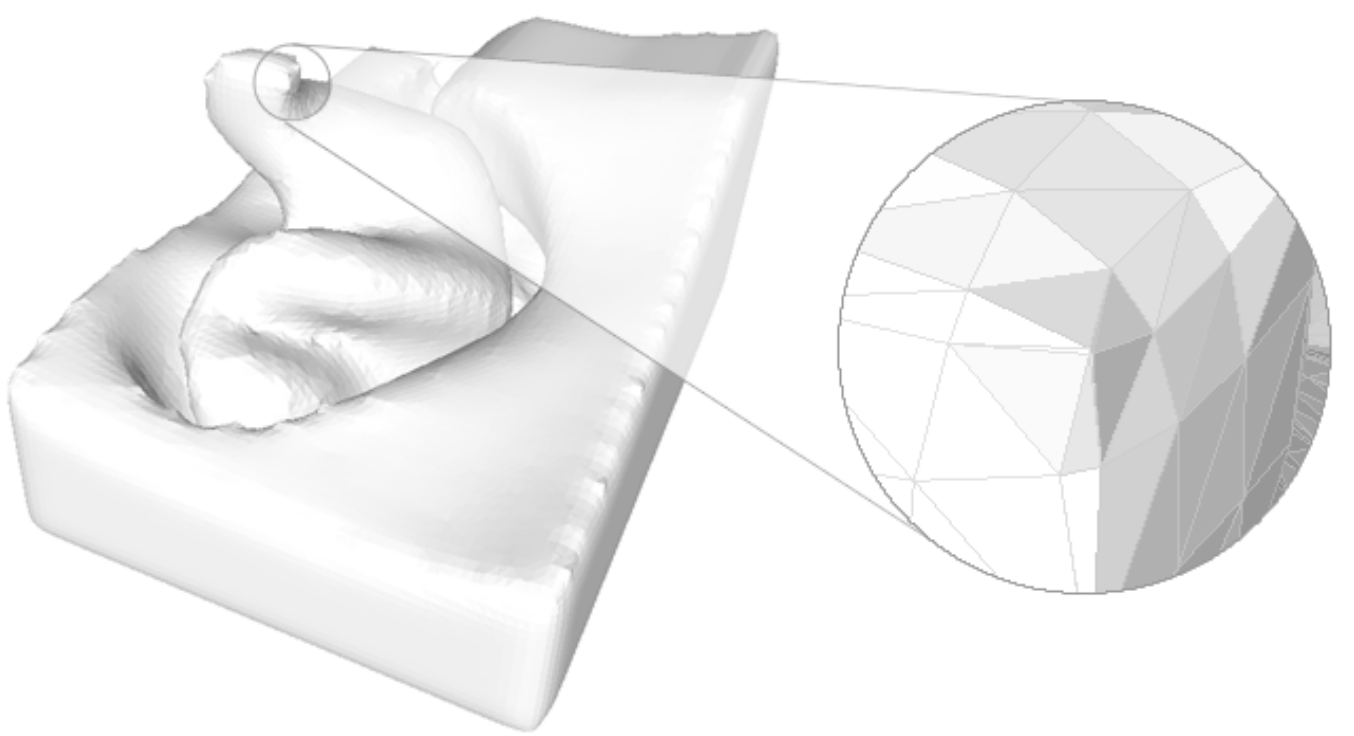

Fonte: Autor.

A figura 37 apresenta uma sobreposição dos modelos tridimensionais em co- 
res anaglíficas, onde é possível observar a distorção entre o modelo original em vermelho e os modelos suavizados em azul por Laplace discreto e Laplace dependente de escala, respectivamente em a) e b). Fica evidenciado que a técnica por Laplace discreto distorce a malha, reduzindo seu tamanho, justamente pela falta de critérios para reposicionamento dos vértices.

Figura 37: Sobreposição dos modelos suavizados pelos dois métodos (em azul) com o modelo original (em vermelho).

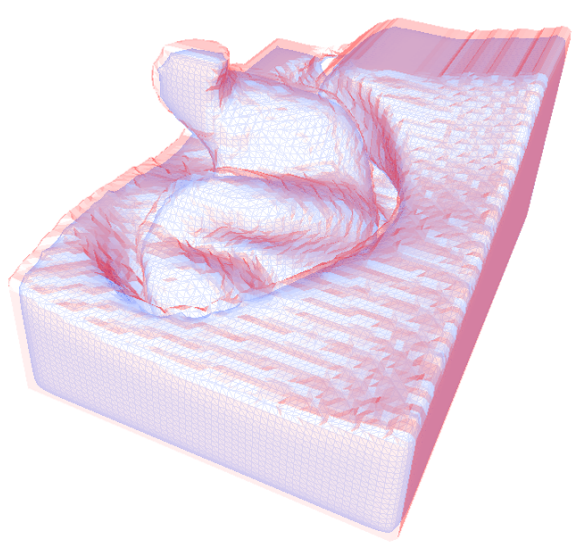

a)

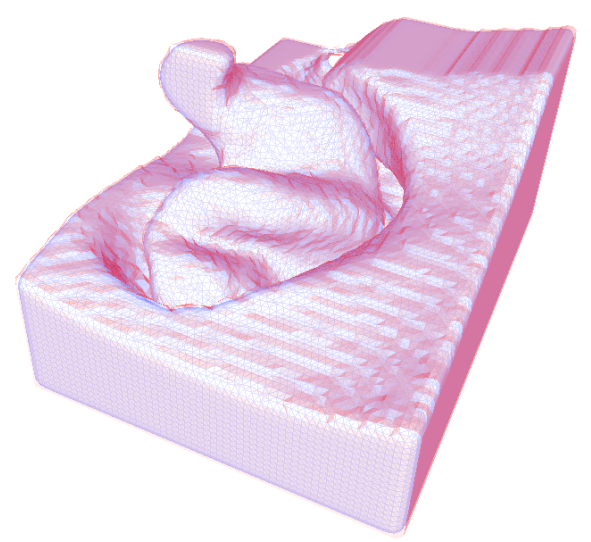

b)

a) Laplace discreto.

b) Laplace dependente de escala.

Fonte: Autor.

\subsection{Análise Física}

O molde produzido pelo processo de FFF através de uma impressora 3D de baixo custo, com resoluções $100 \mu \mathrm{m}$ nos três eixos, apresentou determinada rugosidade superficial inerente à estratégia de fabricação por camadas. A figura 38 apresenta o molde produzido para o caso clínico ARF com destaque para a superfície com desníveis.

O processo de suavização de superfície através de solvente foi empregado nos 
Figura 38: Destaque para os desníveis causados pelo processo de fabricação FFF

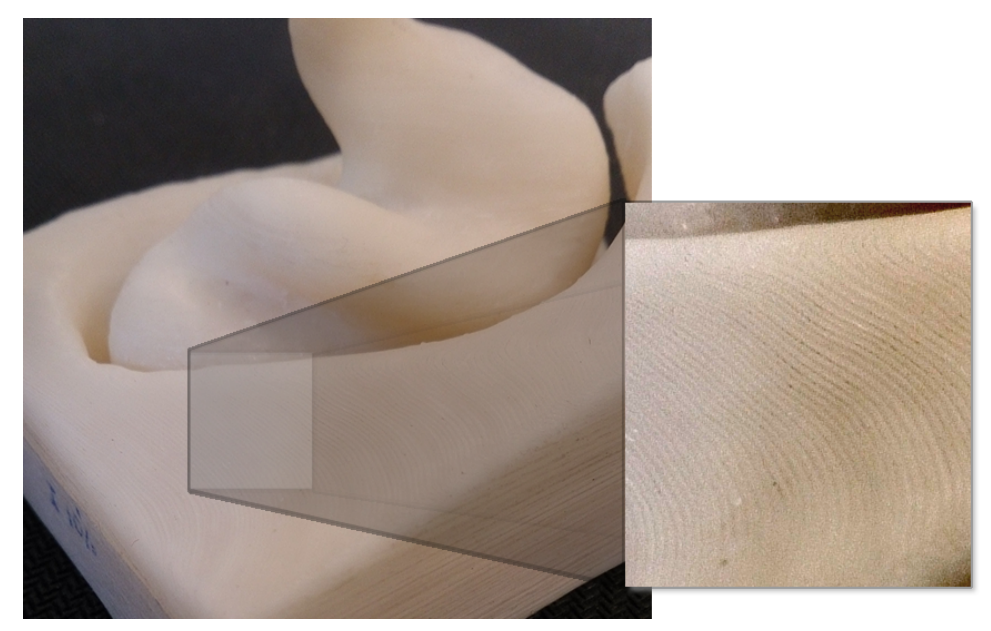

Fonte: Autor.

moldes, de forma a atenuar estes desníveis. Os moldes apresentaram 9.299, 7.134 e $12.210 \mathrm{~mm}^{2}$ para ARF, KSS e RL respectivamente e foram utilizados 40,45 ml, 31,03 $m l$ e 53,11 $m l$ de Acetona para a dissolução, respectivamente. O processo foi realizado conforme seção 4.4.2, utilizando uma mesa aquecedora a 56 graus Celsius até que o solvente se evaporasse por completo, processo que levou 21 minutos para ARF, 18 para KSS e 29 para RL. O polímero ABS absorve o solvente em forma de vapor pela sua superfície, resultando em um aspecto cristalino durante o processo, conforme ilustrado na figura 39.

As imagens da figura 40 apresentam ampliações de 32 vezes sobre duas regiões do molde. É possível notar um aspecto mais liso se comparado ao molde antes da suavização.

\subsubsection{Análise de Perfil Superficial}

Uma análise técnica de rugosidade foi realizada no Laboratório de Fenômenos de Superfície (LFS), da Engenharia Mecânica da Escola Politécnica da USP com o objetivo de discretizar a superfície obtida. Foi utilizado o perfilômetro ótico digital CCI MP-HS (Taylor Hobson, Leicester, Inglaterra). 
Figura 39: Foto ampliação durante o processo de suavização superficial, polímero apresenta aspecto cristalino pela absorção de solvente.

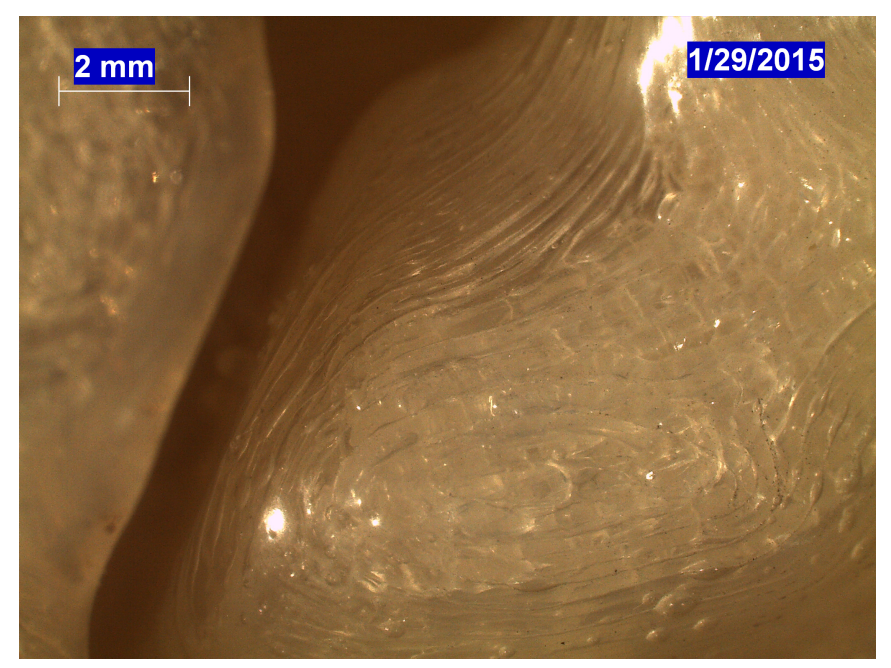

Fonte: Autor.

Figura 40: Ampliação de 32 vezes sobre detalhe da superfície obtida.
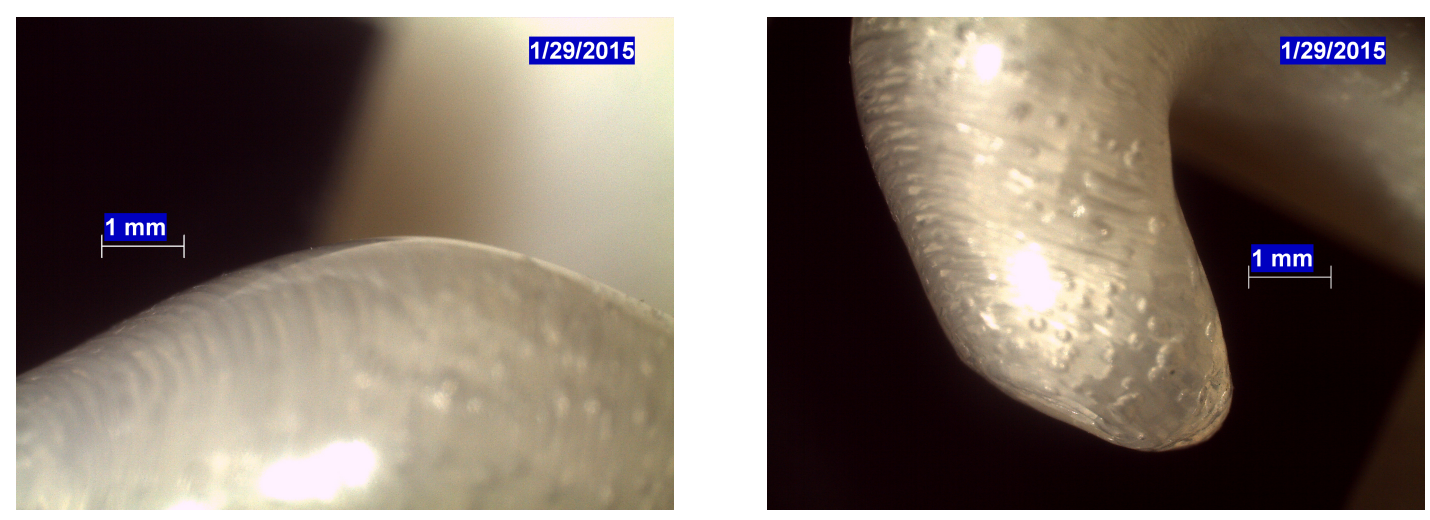

Fonte: Autor.

A figura 41 apresenta a projeção tridimensional da superfície do molde antes do tratamento para suavização. É possível notar na projeção as camadas provenientes do processo de manufatura, resultando em desníveis em escala micrométrica, distantes aproximadamente por $100 \mu \mathrm{m}$ (resolução da impressão 3D).

A mesma análise técnica foi realizada sobre um molde após o tratamento de suavização superficial. As figuras 42 e 43 apresentam o resultado da suavização. 
Figura 41: Vista lateral da projeção tridimensional do perfil de rugosidade antes do tratamento de superfície

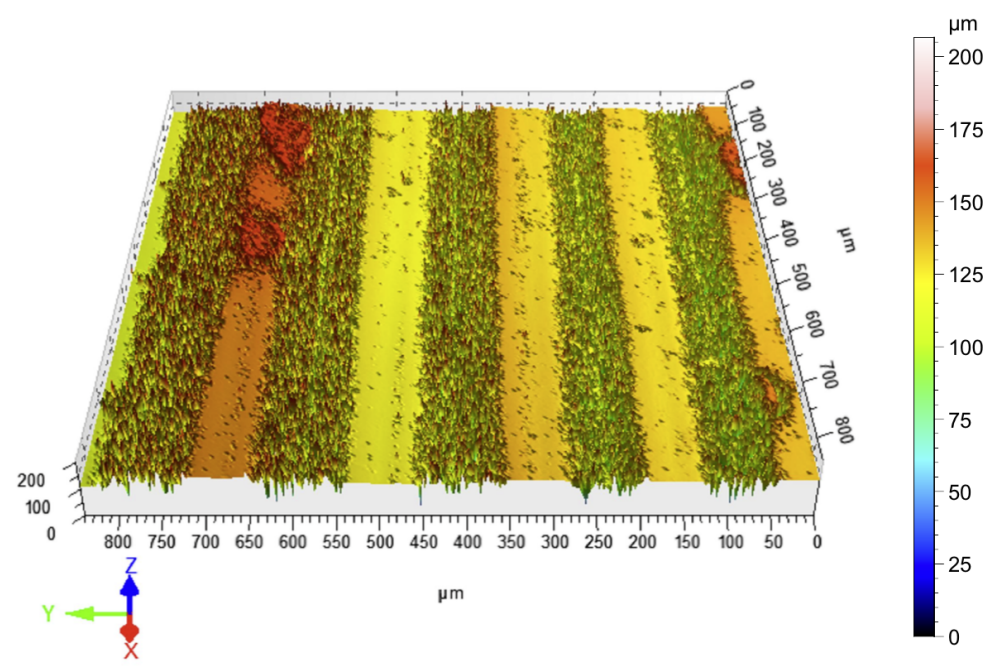

Fonte: Autor.

Figura 42: Vista lateral da projeção tridimensional do perfil de rugosidade obtido

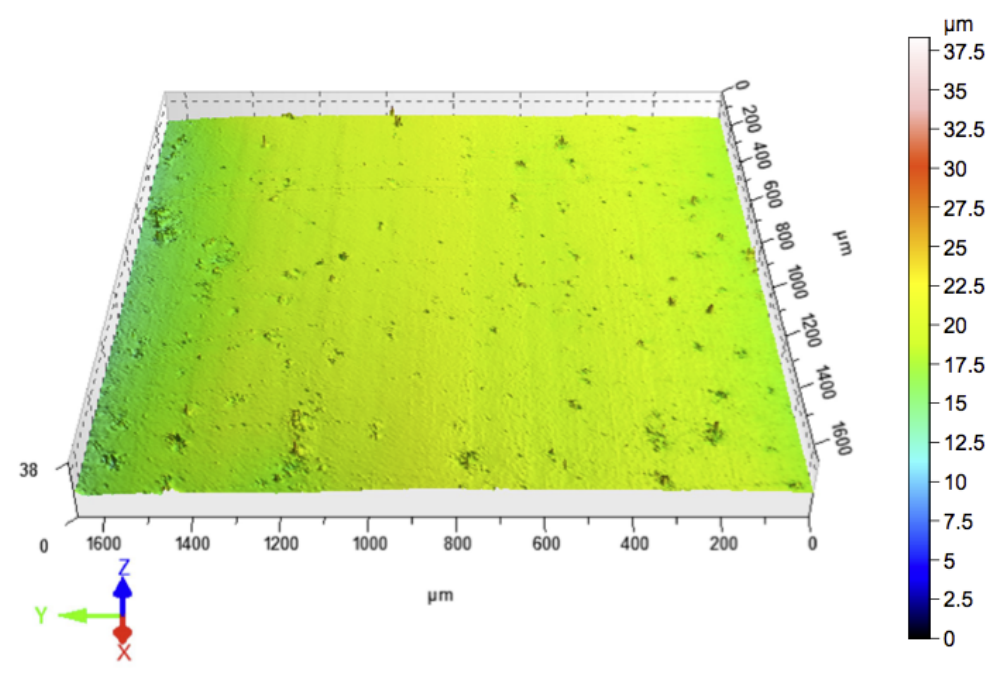

Fonte: Autor.

Htsuki, Akamaki e Ominaga (2013) apresentam um estudo sobre a rugosidade da pele humana, a qual foi discretizada em função do desvio da média aritmética 
Figura 43: Vista superior da projeção tridimensional do perfil de rugosidade obtido

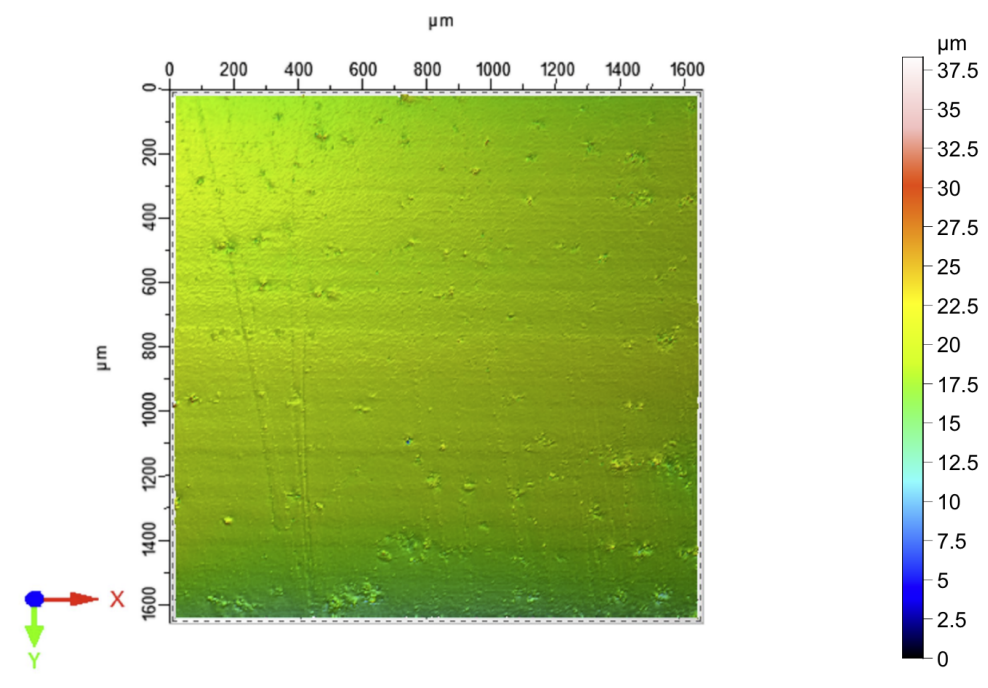

Fonte: Autor.

da altura de cada ponto observado, $R_{a}$, calculado através da equação 5.1.

$$
R_{a}=\frac{1}{L} \int_{0}^{L}|Z(x)| d x
$$

A análise feita por Htsuki, Akamaki e Ominaga (2013) calculou $R_{a}$ para 8 amostras de pele humana sem a descrição de região a qual pertence. Os valores obtidos foram entre $7,88 \mu m$ e $16,36 \mu m$ e estão apresentados na tabela 8 .

Tabela 8: Valores de rugosidade de amostras de pele.

\begin{tabular}{cc}
\hline Amostra & Rugosidade $(\mu m)$ \\
\hline A & 12,5 \\
B & 7,88 \\
C & 13,28 \\
D & 14,24 \\
E & 16,36 \\
F & 13,64 \\
G & 9,18 \\
H & 10,66 \\
\hline
\end{tabular}

Fonte: Htsuki, Akamaki e Ominaga (2013). 
O padrão ISO 25178-2² especifica os termos e a padronização de medidas para texturas de superfície. Na especificação, o parâmetro $S_{a}$ representa igualmente o parâmetro $R_{a}$ apresentado por Htsuki, Akamaki e Ominaga (2013). A análise técnica realizada no LFS da Poli/USP utilizou-se da especificação ISO e seus resultados estão apresentados na figura 44, onde o item a) é o resultado obtido para o molde sem tratamento e o item b) sobre o molde tratado.

Figura 44: Parâmetros ISO 25178-2 obtidos sobre os moldes.

\begin{tabular}{|c|c|c|}
\hline \multicolumn{2}{|l|}{ ISO 25178 } \\
\multicolumn{2}{|l|}{ Parâmetros de altura } \\
\hline Sq & 24.48 & $\mu \mathrm{m}$ \\
\hline Ssk & -0.8386 & \\
\hline Sku & 3.919 & \\
\hline Sp & 85.00 & $\mu \mathrm{m}$ \\
\hline Sv & 121.7 & $\mu \mathrm{m}$ \\
\hline Sz & 206.7 & $\mu \mathrm{m}$ \\
\hline Sa & 18.40 & $\mu \mathrm{m}$ \\
\hline
\end{tabular}

a)

\begin{tabular}{|c|c|c|}
\hline \multicolumn{2}{|l|}{ ISO 25178 } \\
\multicolumn{2}{|l|}{ Parâmetros de altura } \\
\hline Sq & 1.149 & $\mu \mathrm{m}$ \\
\hline Ssk & -1.659 & \\
\hline Sku & 8.150 & \\
\hline Sp & 19.77 & $\mu \mathrm{m}$ \\
\hline Sv & 18.55 & $\mu \mathrm{m}$ \\
\hline Sz & 38.32 & $\mu \mathrm{m}$ \\
\hline Sa & 0.7962 & $\mu \mathrm{m}$ \\
\hline
\end{tabular}

b)

a) Molde não tratado.

b) Molde tratado.

Fonte: Autor.

A comparação dos resultados obtidos da discretização da superfície dos moldes em relação aos apresentados por Htsuki, Akamaki e Ominaga (2013) oferece um indicativo substancial de que a superfície obtida após o tratamento $\left(S_{a} \cong 0,79\right)$ se apresentou com menor rugosidade em relação a pele humana $\left(S_{a} \cong 7,88\right)$.

\subsection{Elaboração da Prótese Auricular}

Através da injeção de silicone pigmentado no molde se obtém a forma da prótese auricular para implante no paciente. Foram utilizados silicones Factor II (Factor II Inc., EUA) e Silicone para Prótese 4034 (Ortho Pauher, Brasil)

\footnotetext{
${ }^{2}$ ISO 25178-2/2012 disponível em https://www.iso.org/obp/ui/\#!iso:std:42785:en
} 
e para ambos os produtos as próteses foram obtidas com sucesso. O molde é propositalmente fabricado em 2 partes para facilitar a desmoldagem, a divisão das partes é feita igualmente por uma secção horizontal. A figura 45 retrata o processo de desmoldagem da prótese.

Figura 45: Silicone pigmentado injetado no molde

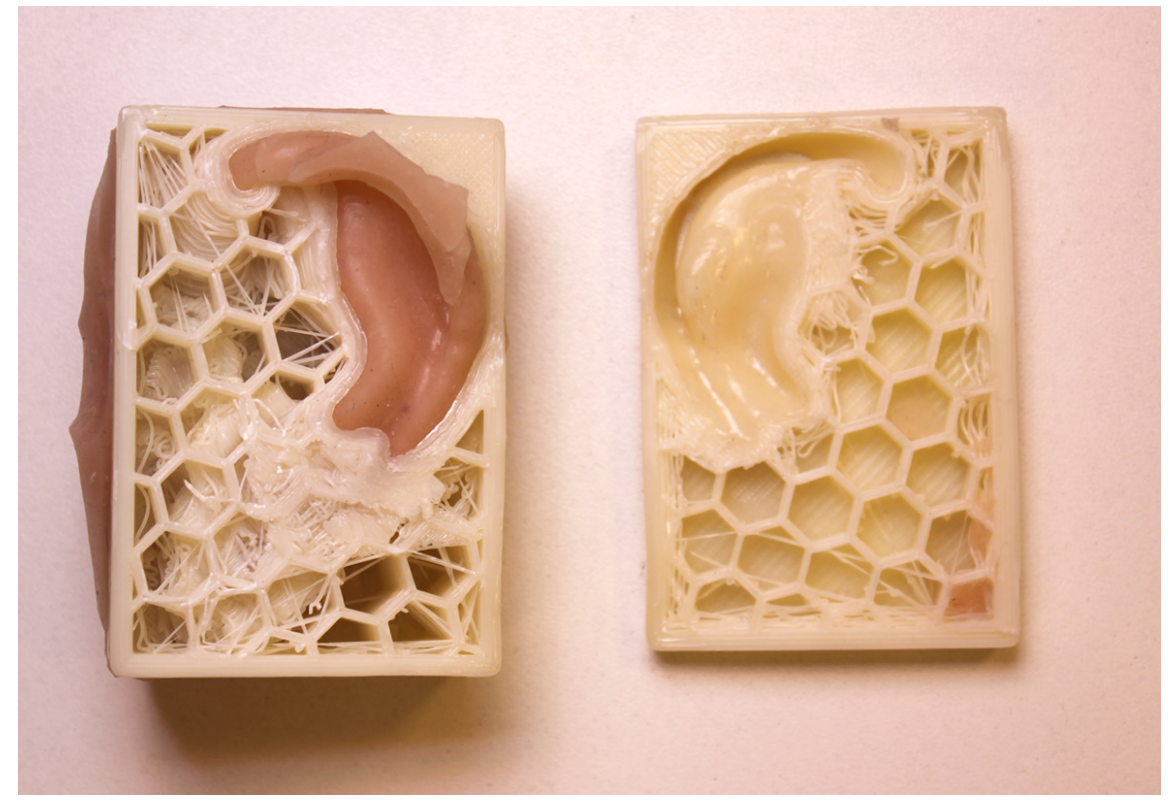

Fonte: Autor.

A prótese então é obtida após a desmoldagem, as figuras 46 e 47 apresentam o resultado do processo para o caso clínico ARF e as figuras 48 e 49 para os caso KSS e RL respectivamente, todas sem caracterização de cor e remoção de partes remanescentes.

Uma análise das medidas anatômicas da orelha oferece meios para validação da propagação das características da orelha do paciente para a prótese. As figuras 50 e 51 fazem um comparativo da distância entre da região da concha cava com a região externa da hélice em dois pontos, respectivamente. Foi utilizado o software Osirix (Pixmeo, Genebra, Suíça) para a extração das medidas.

A comparação das medidas anatômicas da orelha em relação a prótese obtida 
Figura 46: Prótese obtida para o caso clínico ARF

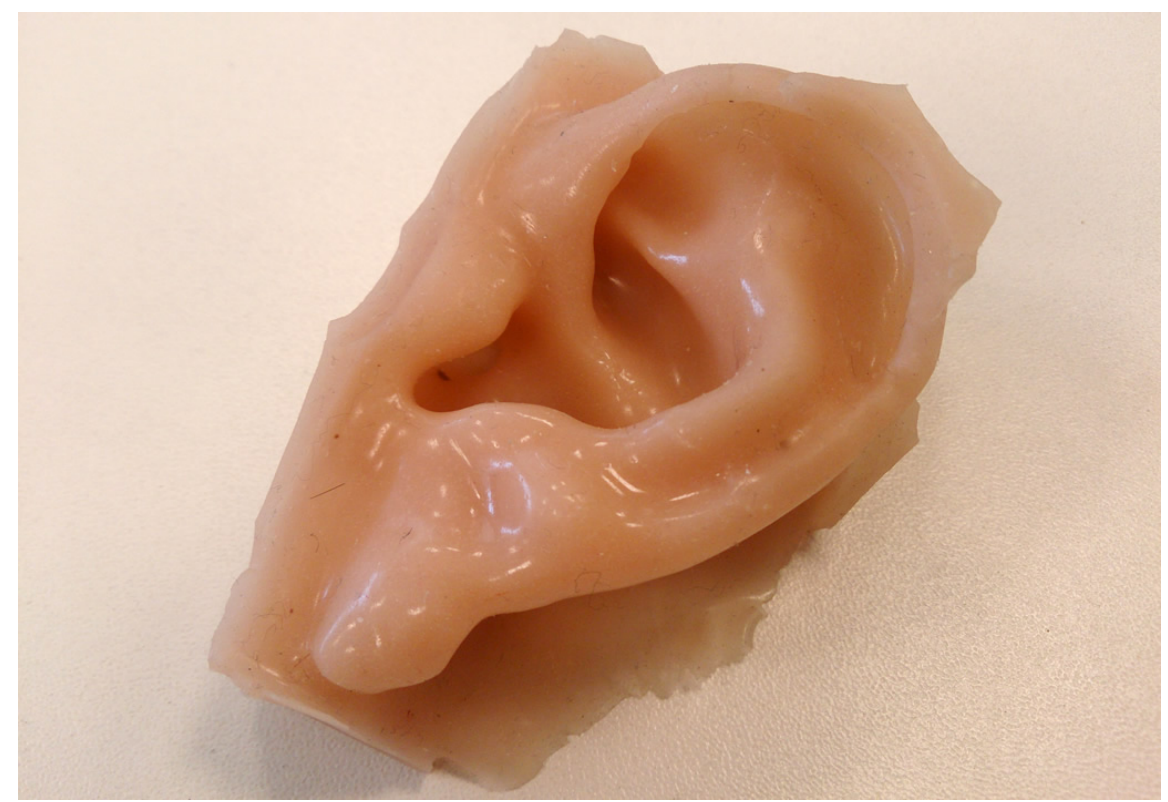

Fonte: Autor.

Figura 47: Prótese obtida para o caso clínico ARF
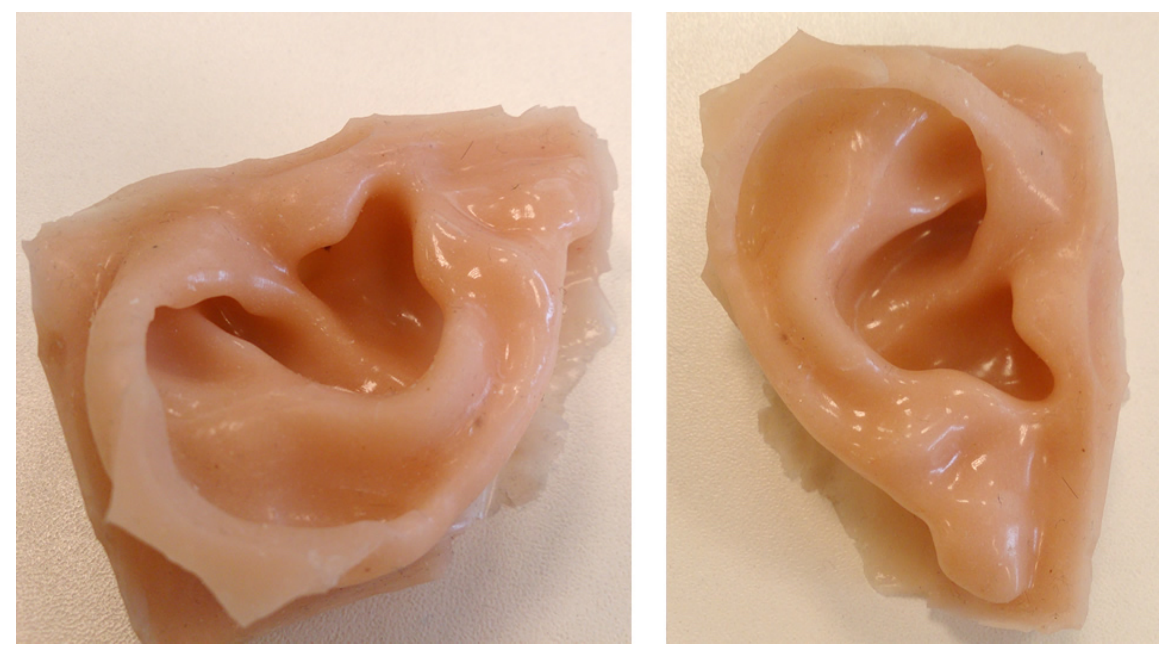

Fonte: Autor.

do caso ARF está apresentada na tabela 9. As medidas seguiram os padrões morfológicos auriculares, conforme Subburaj et al. (2007).

A diferença média das medidas observadas foi de $2,2 \%$, o que representa uma similaridade muito próxima a orelha real, com 97,8\% de semelhança. A mesma 
Figura 48: Prótese obtida para o caso clínico KSS

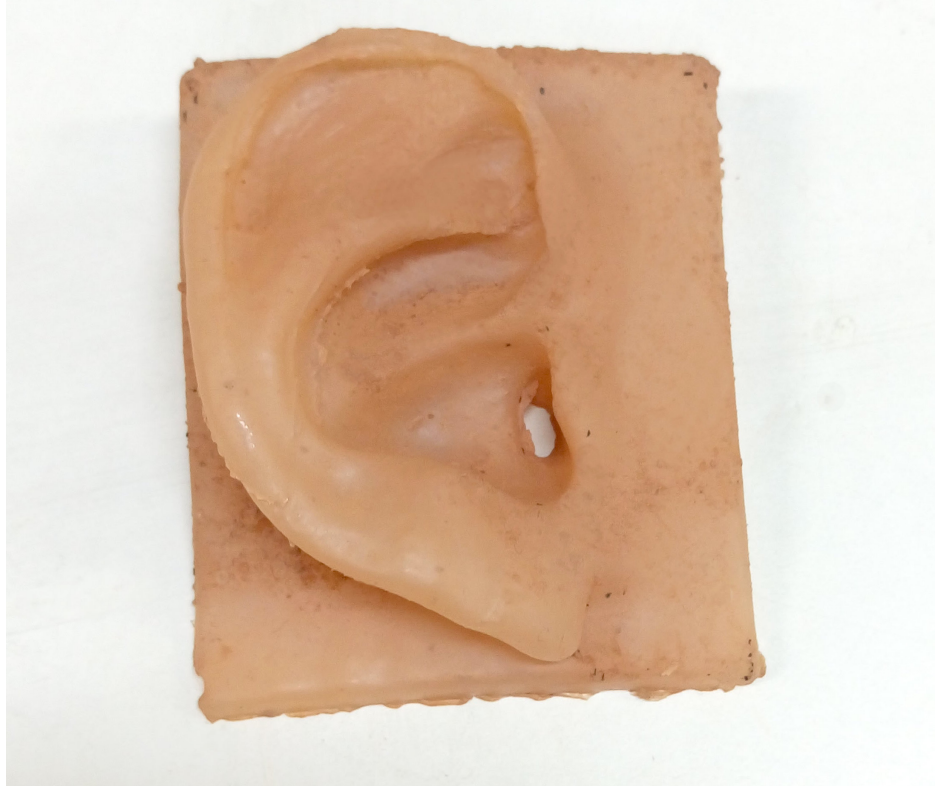

Fonte: Autor.

Tabela 9: Medidas e diferenças dos padrões morfológicos auriculares entre a orelha saudável do paciente e a prótese obtida

\begin{tabular}{cccc}
\hline Região & TC $(\mathrm{mm})$ & Prótese $(\mathrm{mm})$ & Diferença(\%) \\
\hline Altura total & 63,05 & 63,85 & 1,25 \\
Largura total & 23,50 & 23,90 & 1,67 \\
Tragus a anti-hélice & 21,50 & 22,32 & 3,66 \\
Tragus a hélice & 28,90 & 29,22 & 1,10 \\
Largura do lóbulo & 13,80 & 13,96 & 1,15 \\
Altura do lóbulo & 21,70 & 21,72 & 0,09 \\
Projeção auricular & 15,70 & 16,95 & 7,96 \\
Inclinação auricular & 6,60 & 6,55 & $-0,76$ \\
\hline
\end{tabular}

Fonte: Autor.

comparação foi realizada para o caso KSS e foi obtido um percentual de $96,9 \%$ de similaridade. O caso clínico RL compreende uma região parcial do lado esquerdo da face e, portanto, sem referência de padrões morfológicos para extração das medidas. Particularmente neste caso, a comparação de dimensões se limitou a altura e largura da prótese em relação a região de interesse, resultando em uma 
Figura 49: Prótese obtida para o caso clínico RL

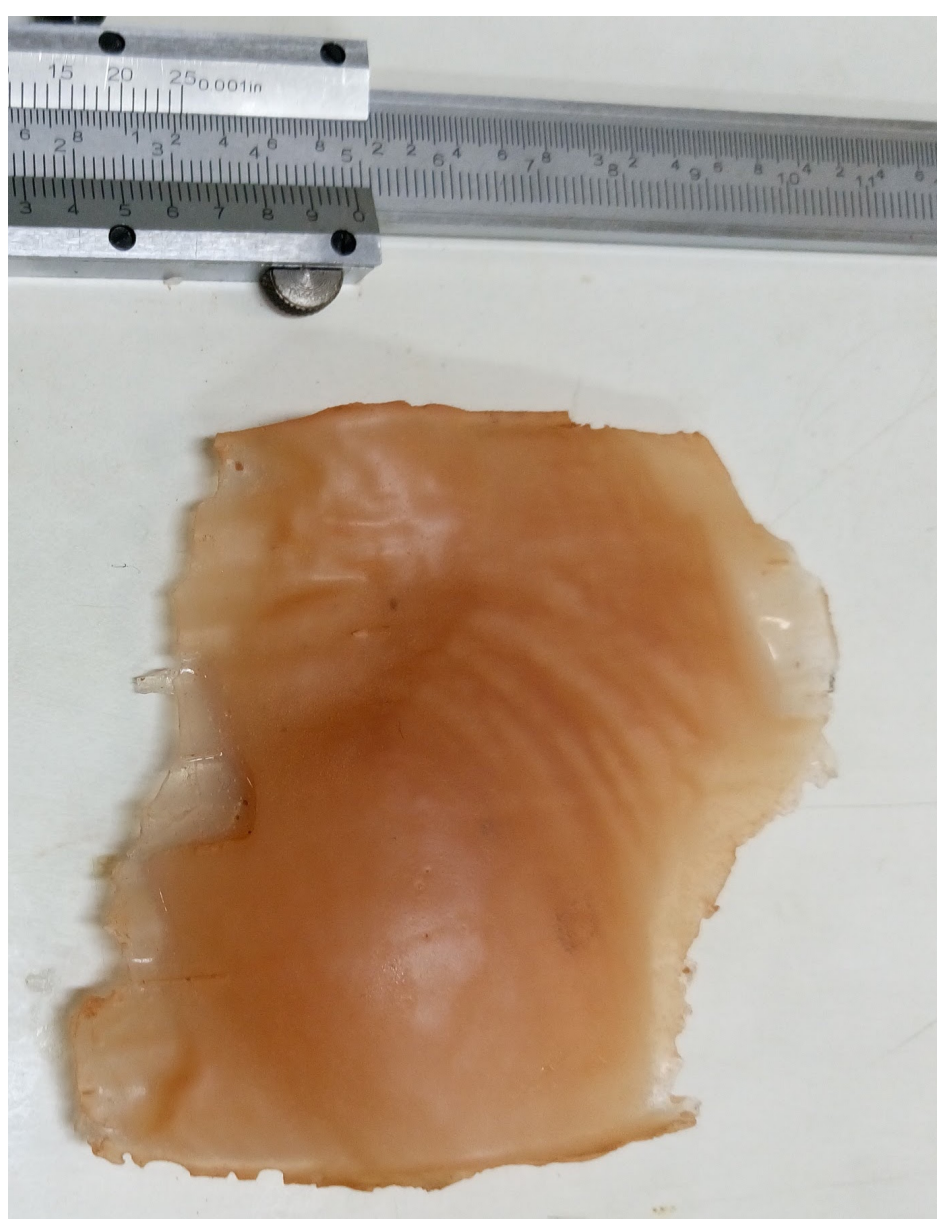

Fonte: Autor.

similaridade de $99,1 \%$ na largura e $97,34 \%$ na altura.

As próteses dos casos ARF e KSS levaram 4 horas e 11 minutos e 3 horas e 26 minutos respectivamente para serem produzidas a uma velocidade de impressão de $60 \mathrm{~mm} / \mathrm{s}$. O tempo para suavização de superfície foi de 21 minutos para ARF e 18 minutos para o molde do caso KSS. Somando ao tempo de cura do silicone, que varia entre cada fabricante, o tempo de processamento total de uma prótese pelo método proposto é de aproximadamente 6 horas. 
Figura 50: Comparação métrica entre a prótese obtida e a reconstrução volumétrica, primeiro ponto.

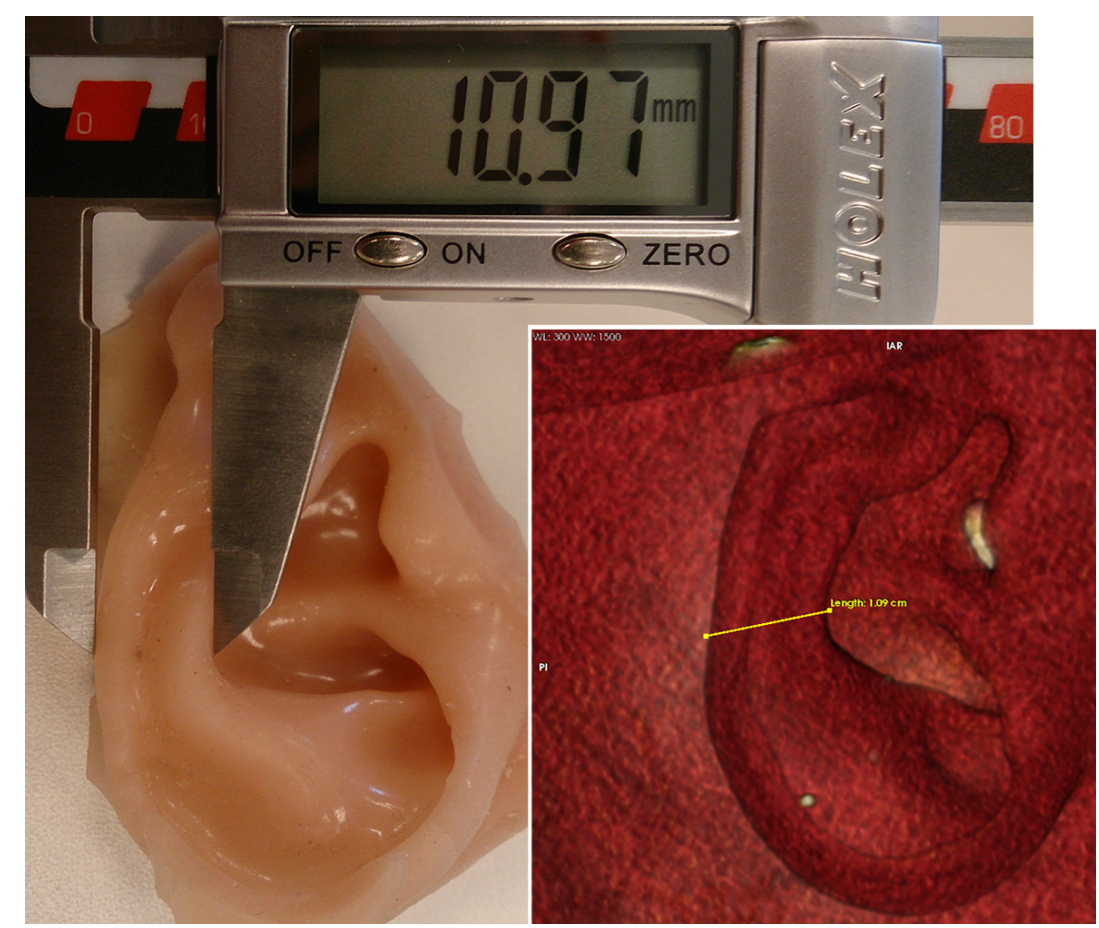

Fonte: Autor.

\subsection{Questionário}

Complementar a análise geométrica da anatomia da orelha, a prótese obtida e o presente método foram objetos de um questionário visando obter um parecer de especialistas sob os critérios de viabilidade do método, tempo de elaboração e qualidade sob o aspecto visual. O questionário, apresentado no anexo B, foi aplicado no período entre junho e julho de 2016, envolvendo 9 profissionais da área e seu resultado é apresentado a seguir.

A primeira questão visa obter o grau de envolvimento dos participantes em relação a elaboração de próteses:

1) Grau de envolvimento com elaboração de próteses bucomaxilofaciais:

66,7\% Responsável no departamento/clínica pela elaboração de próteses 
Figura 51: Comparação métrica entre a prótese obtida e a reconstrução volumétrica, segundo ponto.

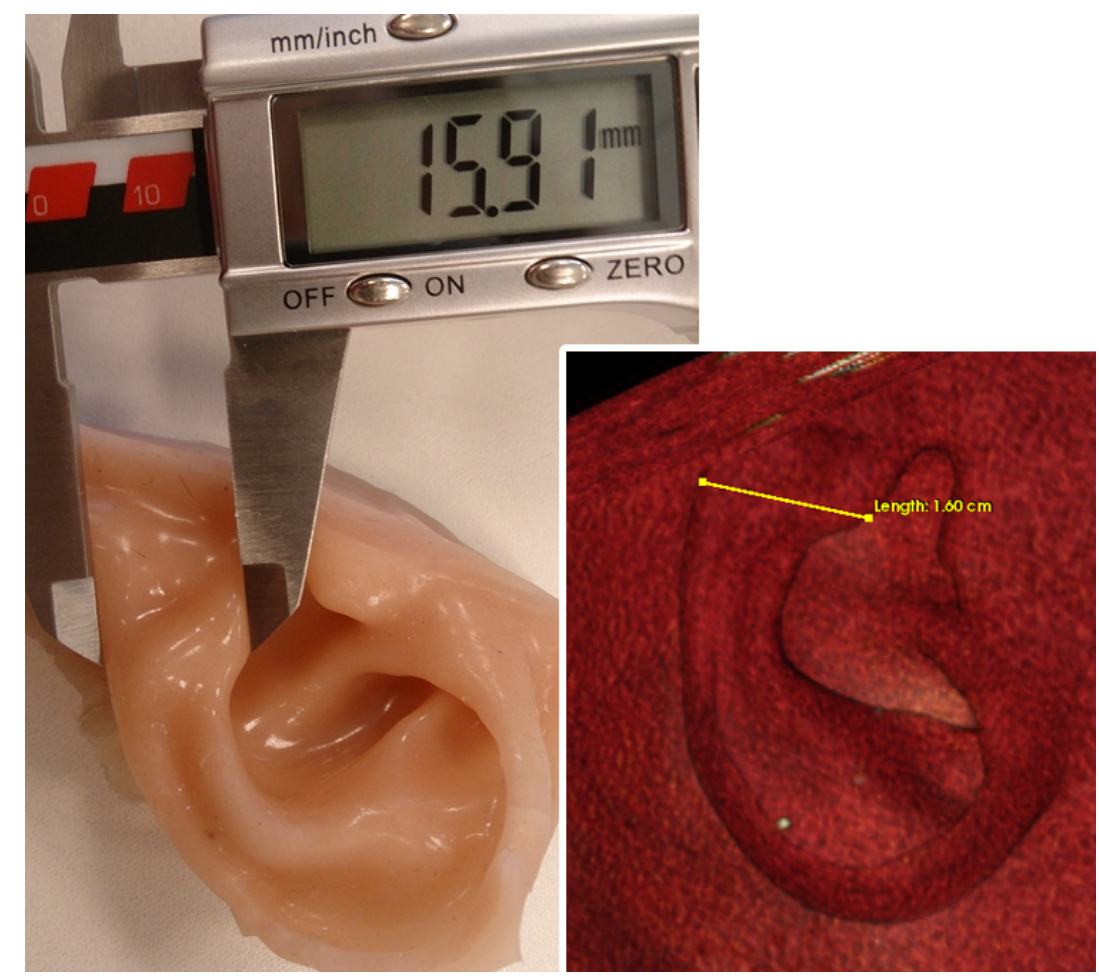

Fonte: Autor.

33,3\% Diretamente envolvido com elaboração de próteses

0\% Indiretamente envolvido com elaboração de próteses

0\% Não envolvido com elaboração de próteses

As perguntas a seguir (2, 3 e 4$)$ se referem ao método convencional de elaboração de próteses.

2) Marque os itens que você considera complexos e/ou desafiadores do processo de elaboração de próteses (múltipla escolha):

77,8\% Moldagem da orelha sã do paciente

77,8\% Escultura manual do formato da prótese

55,6\% Consultas com paciente para ajustes do formato da prótese 
$55,6 \%$ Muflagem

33,3\% Caracterização da cor

3) Qual o tempo médio que o seu departamento/clínica leva para elaborar uma prótese auricular?

$0 \%$ Entre 1 e 4 dias

$0 \%$ Entre 4 e 8 dias

0\% Entre 8 e 12 dias

$88,9 \%$ Acima de 12 dias

$11,1 \%$ Não sei informar

4) Você acredita que a geometria obtida da prótese pelo método convencional é idêntica se comparada a orelha sã espelhada?

0\% Muito satisfatório

$66,7 \%$ Satisfatório

$22,2 \%$ Pouco satisfatório

$11,1 \%$ Insatisfatório

As perguntas a seguir (5,6 e 7) se referem ao método proposto.

5) Você acredita que a geometria obtida da prótese pelo método proposto é idêntica se comparada a orelha sã espelhada?

$88,9 \%$ Muito satisfatório

$11,1 \%$ Satisfatório

0\% Pouco satisfatório

0\% Insatisfatório 
6) Você acredita que possa reduzir o tempo de elaboração de próteses auriculares se comparado ao método convencional?

$88,9 \% \operatorname{Sim}$

$0 \%$ Não

$11,1 \%$ Talvez

7) Você acredita que possa reduzir a complexidade da elaboração de próteses por parte do protesiólogo, se comparado ao método convencional?

$77,8 \% \operatorname{Sim}$

$0 \%$ Não

$22,2 \%$ Talvez

O questionário envolveu apenas profissionais diretamente ou responsáveis pela elaboração de próteses em seus respectivos departamentos. Os participantes foram apresentados e/ou utilizaram o método proposto por este trabalho. Não foi coletada nenhuma informação que possa identificar os voluntários que participaram da pesquisa. 


\section{CONCLUSÕES}

O processo proposto apresentou um procedimento de elaboração de próteses alternativo ao convencional com potencial de expansão para demais próteses bucomaxilofaciais. As próteses obtidas pelo processo apresentaram grande similaridade (aproximadamente 97\%) em relação a orelha saudável do paciente, utilizando menos recurso manual, a baixo custo e com indicativo de elaboração em menor tempo.

A necessidade de um exame de TC para a obtenção do modelo tridimensional do molde é uma desvantagem do procedimento apresentado pois expõe o paciente a uma dose de radiação onde eventualmente não seria necessário. Entretanto, em determinados casos clínicos principalmente decorrentes de dano causados por acidentes, o exame de tomografia geralmente é exigido para de análise do canal auditivo e/ou eventual fratura óssea.

O resultado do questionário envolvendo profissionais da área destacou alguns aspectos do método, como a semelhança da prótese em relação à orelha saudável do paciente, onde foi obtida uma uniformidade de opiniões em satisfatório ou muito satisfatório para a prótese obtida pelo método proposto. O Consenso também foi observado para as questões que envolviam a redução de tempo e de complexidade de elaboração da prótese, com 88,9\% e 77,8\% de aceitação respectivamente. Em relação ao método convencional foi possível observar, de acordo com os especialistas, que o tempo médio de elaboração de uma prótese leva ao 
menos 12 dias, com 88,9\% das respostas.

A elaboração de uma prótese auricular pelo procedimento proposto possui um grande potencial de ser realizado em menor tempo em relação ao método convencional utilizado pelo Departamento de Cirurgia, Prótese e Traumatologia Maxilofaciais da Faculdade de Odontologia da USP, pois um molde pode ser fabricado em até 5 horas a partir do exame de TC.

O uso de impressão 3D e técnicas computacionais na área médica vem sendo explorado amplamente nos últimos anos e deve ser um processo inerente a inovação na área, reduzindo custos e principalmente oferecendo um melhor tratamento ao paciente. 


\section{REFERÊNCIAS}

BANKMAN, I. Handbook of medical image processing and analysis. $2^{\mathrm{a}}$. ed. Burlington, MA, EUA: Academic Press, 2008.

BOAS, F. E.; FLEISCHMANN, D. CT artifacts: causes and reduction techniques. Imaging in Medicine, v. 4, p. 229-240, 2012. ISSN 1755-5191.

CARVAlHO, J. M. et al. Reabilitação protética craniomaxilofacial. $1^{\mathrm{a}}$. ed. São Paulo, SP, Brasil: Editora Santos, 2013. ISBN 9788572889704.

CHAN, T. F.; VESE, L. a. Active contours without edges. IEEE Transactions on Image Processing, v. 10, n. 2, p. 266-277, 2001. ISSN 10577149.

CIGNONI, P.; CORSINI, M.; RANZUGLIA, G. Meshlab: an open-source 3d mesh processing system. ERCIM News, n. 73, p. 45-46, April 2008.

CIGNONI, P.; ROCCHINI, C.; SCOPIGNO, R. Metro: Measuring Error on Simplfied Surfaces. Compututer Graphics Forum, v. 17, n. 2, p. 167-174, 1998. ISSN 0167-7055.

CIOCCA, L. et al. CAD/CAM ear model and virtual construction of the mold. Journal of Prosthetic Dentistry, v. 98, p. 339-343, 2007. ISSN 00223913.

CIOCCA, L.; SCOTTI, R. CAD-CAM generated ear cast by means of a laser scanner and rapid prototyping machine. Journal of Prosthetic Dentistry, v. 92, p. 591-595, 2004. ISSN 00223913.

COHEN, L. D. On active contour models and balloons. Computer Vision and Image Understanding Journal., v. 53, p. 211-218, 1991. ISSN 1049-9660.

COHEN, L. D.; COHEN, I. Finite-element methods for active contour models and balloons for 2-d and 3-d images. IEEE Transactions on Pattern Analysis and Machine Intelligence, v. 15, n. 11, p. 1131-1147, 1993.

COWARD, T. J.; WATSON, R. M.; WILKINSON, I. C. Fabrication of a wax ear by rapid-process modeling using stereolithography. The International Journal of Prosthodontics, v. 12, p. 20-27, 1999. ISSN 0893-2174.

DESBRUN, M. et al. Implicit fairing of irregular meshes using diffusion and curvature flow. ACM Press/Addison-Wesley, New York, NY, USA, p. 317-324, 1999 .

FUJIWARA, K. Eigenvalues of laplacians on a closed Riemannian manifold and its nets. American Mathematical Society, Proceedings..., v. 123, n. 8, p. 2585, aug 1995. ISSN 00029939. 
GIL, D. et al. Statistical strategy for anisotropic adventitia modelling in ivus. IEEE Transactions on Medical Imaging, IEEE, v. 25, n. 6, p. 768-778, 2006.

GOLDMAN, L. W. Principles of CT and CT technology. Journal of Nuclear Medicine Technology, v. 35, n. 3, p. 115-128, sep 2007. ISSN 0091-4916.

GONZALEZ, R. C.; WOODS, R. E. Digital image processing. 3a . ed. Upper Saddle River, NJ, EUA: Prentice-Hall, 2006. ISBN 013168728X.

HTSUKI, R. O.; AKAMAKI, T. S.; OMINAGA, S. T. Analysis of Skin Surface Roughness by Visual Assessment and Surface Measurement. v. 20, n. 2, p. 94-101, 2013.

C.W. Hull, S.T. Spence, D.J. Albert, D.R. Smalley, R.A. Harlow, P. Stinebaugh, H.L. Tarnoff, H.D. Nguyen, C.W. Lewis, T.J. Vorgitch et al. Method and apparatus for production of high resolution three-dimensional objects by stereolithography. 1993. US Patent 5,184,307.

Charles W. Hull. Apparatus for production of three-dimensional objects by stereolithography. 1984. US Patent 5,184,307.

JIAO, T. et al. Design and fabrication of auricular prostheses by CAD/CAM system. The International Journal of Prosthodontics, 2004.

KARATAS, M. O. et al. Manufacturing implant supported auricular prostheses by rapid prototyping techniques. European Journal of Dentistry, v. 5, n. 4, p. 472-7, ago. 2011. ISSN 1305-7464.

KARAYAZGAN-SARACOGLU, B.; GUNAY, Y.; ATAY, A. Fabrication of an auricular prosthesis using computed tomography and rapid prototyping technique. Journal of Craniofacial Surgery, v. 20, n. 4, p. 1169-1172, 2009. ISSN 1049-2275.

KASS, M.; WITKIN, A.; TERZOPOULOS, D. Snakes: Active contour models. International Journal of Computer Vision, v. 1, p. 321-331, 1988. ISSN 09205691.

KICHENASSAMY, S. et al. Gradient flows and geometric active contour models. IEEE International Conference on Computer Vision, Proceedings..., 1995.

LANTADA, A. D.; MORGADO, P. L. Rapid prototyping for biomedical engineering: current capabilities and challenges. Annual Review of Biomedical Engineering, v. 14, p. 73-96, 2012. ISSN 1523-9829.

LIACOURAS, P. et al. Designing and manufacturing an auricular prosthesis using computed tomography, 3-dimensional photographic imaging, and additive manufacturing: a clinical report. Journal of Prosthetic Dentistry, v. 105, n. 2, p. 78-82, fev. 2011. ISSN 1097-6841.

LORENSEN, W. E.; CLINE, H. E. Marching cubes: A high resolution 3D surface construction algorithm. ACM SIGGRAPH Computer Graphics, v. 21, n. 4, p. 163-169, 1987. ISSN 00978930. 
MARDINI, M. A.; ERCOLI, C.; GRASER, G. N. A technique to produce a mirror-image wax pattern of an ear using rapid prototyping technology. Journal of Prosthetic Dentistry, n. August, p. 195-198, 2005.

MEIJER, H. E. H. et al. Processing of Thermoplastic Polymers using Reactive Solvents. Journal of High Performance Polymers, v. 8, p. 133-167, 1996.

MüLLER-BUSCHBAUM, P. et al. Solvent-induced surface morphology of thin polymer films. v. 34, p. 1369-1375, 2001. ISSN 00249297.

MURPHY, S. V.; ATALA, A. 3d bioprinting of tissues and organs. Nature Biotechnology, Nature Publishing Group, v. 32, n. 8, p. 773-785, 2014.

PERONA, P.; MALIK, J. Scale-space and edge detection using anisotropic diffusion. IEEE Transactions on Pattern Analysis and Machine Intelligence, v. 12, p. 629-639, 1990.

PRINCE, J. Gradient vector flow: a new external force for snakes. IEEE Computer Society Conference on Computer Vision and Pattern Recognition, Proceedings..., v. 2, n. 1, p. 66-71, 1997. ISSN 10636919.

PRINZ, F. B. et al. Rapid prototyping in europe and japan. Center for Advanced Technology, v. 102, 1997.

RAUT, V. N.; RUIKAR, S. D. Image quality improvement in computed tomography using anisotropic diffusion. In: IEEE International Conference on Emerging Trends in Computing, Communication and Nanotechnology (ICECCN), Conference... Tuticorin, India: [s.n.], 2013. p. 601-605. ISBN 978-1-4673-5036-5.

RAVURI, R. et al. Auricular prosthesis-a case report. Journal of Clinical and Diagnostic Research, v. 8, n. 1, p. 294-6, jan. 2014. ISSN 2249-782X.

RENGIER, F. et al. 3d printing based on imaging data: review of medical applications. International Journal of Computer Assisted Radiology and Surgery, Springer, v. 5, n. 4, p. 335-341, 2010.

RUTKOWSKI, J. V.; LEVINT, B. C. Acrylonitrile-butadiene-styrene copolymers (ABS): Pyrolysis and combustion products and their toxicity. Fire and Materials, v. 10, n. February, p. 93-105, 1986. ISSN 1099-1018.

SILVA, I. M. D. C. C. et al. Bone density: comparative evaluation of Hounsfield units in multislice and cone-beam computed tomography. Brazilian Oral Research, v. 26, n. 6, p. 550-6, 2012. ISSN 1807-3107.

SUBBURAJ, K. et al. Rapid development of auricular prosthesis using CAD and rapid prototyping technologies. International Journal of Oral and Maxillofacial Surgery, v. 36, n. 10, p. 938-43, out. 2007. ISSN 0901-5027. 
TANNER, P. B.; MOBLEY, S. R. External auricular and facial prosthetics: a collaborative effort of the reconstructive surgeon and anaplastologist. Facial Plastic Surgery Clinics of North America, v. 14, n. 2, p. 137-45, vi-vii, maio 2006. ISSN 1064-7406.

TURGUT, G. et al. Use of rapid prototyping in prosthetic auricular restoration. Journal of Craniofacial Surgery, v. 20, n. 2, p. 321-325, 2009. ISSN 1049-2275.

VELDKAMP, W. Quantitative comparison of iterative reconstruction for CT with FBP: can we use standard deviation of Hounsfield Units as an image quality measure? Radiological Society of North America, 2011.

WATSON, J.; HATAMLEH, M. M. Complete integration of technology for improved reproduction of auricular prostheses. Journal of Prosthetic Dentistry, v. 111, n. 5, p. 430-6, maio 2014. ISSN 1097-6841.

WIENS, J. P. et al. Maxillofacial prosthetics: A preliminary analysis of resource based relative value scale. The Journal of Prosthetic Dentistry, v. 72, n. 2, p. 159-163, ago. 1994. ISSN 00223913.

XU, C.; PRINCE, J. Snakes, shapes, and gradient vector flow. IEEE Transactions on Image Processing, v. 7, n. 3, p. 359-369, Mar 1998. ISSN 1057-7149.

YEZZI, a. et al. A geometric snake model for segmentation of medical imagery. IEEE Transactions on Medical Imaging, v. 16, n. 2, p. 199-209, 1997. ISSN 0278-0062. 


\section{APÊNDICE A - PARECER DO COMITÊ DE ÉTICA EM PESQUISA}

Número do Parecer: 864.391

Data da Relatoria:24/09/2014

Recomendações:

Apenas como sugestão, para caracterizar pesquisa, seria interessante adotar alguns indicadores a serem avaliados (ex: características anatômicas peculiares, adaptação, conforto, etc). Sugere-se a obtenção de Carta de Autorização do paciente caso haja possibilidade de quebra de sigilo na divulgação do caso.

Conclusões ou Pendências e Lista de Inadequações:

É um trabalho necessário, já que mostrará a reprodução 3D como auxiliar da reconstrução auricular, o que pode ser empregado para outras reconstruções da anatomia humana.

Comentários e Considerações sobre a Pesquisa:

Não tem carater de pesquisa: é um caso clínico de 1 único paciente a ser documentado.

Situação do Parecer: Retirado

Necessita Apreciação da CONEP: Não 


\section{APÊNDICE B - QUESTIONÁRIO PARA ESPECIALISTAS}

Este formulário visa fazer um levantamento de opiniões de especialistas em próteses bucomaxilofaciais sobre próteses auriculares desenvolvidas através de Impressão 3D e técnicas computacionais.

Nenhuma informação qualitativa será divulgada, nem mesmo quaisquer informações capazes de identificar os voluntários que responderam a este formulário.

Informações qualitativas obtidas por este formulário fornecerão uma análise sobre a viabilidade e o potencial de um método que envolve novas técnicas e que visa melhorar o tratamento aos pacientes.

1) Grau de envolvimento com elaboração de próteses bucomaxilofaciais:

O Responsável no departamento/clínica pela elaboração de próteses

Diretamente envolvido com elaboração de próteses

Indiretamente envolvido com elaboração de próteses

Não envolvido com elaboração de próteses

As perguntas a seguir se referem ao método convencional de elaboração de próteses. Considera-se o método convencional a técnica utilizada atualmente nas Disciplinas de Prótese Bucomaxilofacial que envolvem processos de moldagem, escultura, muflagem, dentre outros. Técnicas que envolvam processos computacionais, manufatura aditiva, computação gráfica não devem ser consideradas 
neste caso.

2) Marque os itens que você considera complexos e/ou desafiadores do processo de elaboração de próteses

$\square \quad$ Moldagem da orelha sã do paciente

$\square \quad$ Escultura manual do formato da prótese

$\square \quad$ Consultas com paciente para ajustes do formato da prótese

$\square \quad$ Muflagem

$\square \quad$ Caracterização da cor

3) Qual o tempo médio que o seu departamento/clínica leva para elaborar uma prótese auricular?

Entre 1 e 4 dias

Entre 4 e 8 dias

Entre 8 e 12 dias

Acima de 12 dias

4) Você acredita que a geometria obtida da prótese pelo método convencional é idêntica se comparada a orelha sã espelhada?

O Muito satisfatório

Satisfatório

Pouco satisfatório

Insatisfatório

As perguntas a seguir se referem ao método proposto no qual você recebeu um descritivo e uma prótese auricular para análise. O método proposto envolve a elaboração de próteses auriculares utilizando Impressão 3D e técnicas 
computacionais e se apresenta atualmente como uma pesquisa científica.

5) Você acredita que a geometria obtida da prótese pelo método proposto é idêntica se comparada a orelha sã espelhada?
O Muito satisfatório
Satisfatório
O Pouco satisfatório
Insatisfatório

6) Você acredita que possa reduzir o tempo de elaboração de próteses auriculares se comparado ao método convencional?
$\bigcirc \quad \operatorname{Sim}$
○ Não
O Talvez

7) Você acredita que possa reduzir a complexidade da elaboração de próteses por parte do protesiólogo, se comparado ao método convencional?
○ Sim
○ Não
O Talvez

8) Campo livre para seu parecer, comentários e sugestões: 